\title{
A coral-eating barnacle, revisited (Cirripedia, Pyrgomatidae)
}

\author{
Arnold Ross \& William A. Newman \\ Scripps Institution of Oceanography, La Jolla, California 92093-0202, USA*
}
Keywords: Cirripedia, Pyrgomatidae, Hoekia, coral-eating barnacles, new species, parasitism, functional morphology

\begin{abstract}
The coral-eating barnacle Hoekia monticulariae (Gray, 1831), the only internal parasite among the Thoracica described to this day, is characterized by an irregularly-shaped shell nestled cryptically between the polyps of the hermatypic coral Hydnophora Fischer, 1807, which occurs throughout most of the Indo-West Pacific. Because of its protean form, cirripedologists have failed to appreciate the diversity of taxa related to Hoekia, a presumed monotypic genus. We describe seven new species divided between Hoekia and three new genera, Eohoekia, Parahoekia, and Ahoekia for which the Tribe Hoekiini is proposed. As in other pyrgomatids, calcareous overgrowth by the coral is inhibited around the edge of the wall and aperture. But in Hoekiini a pseudopolyp, upon which the barnacle feeds with modified trophi, covers the wall and aperture. Furthermore, rather than articulating with a calcareous basis, the wall is suspended in coral tissue. Its hypertrophied lateral margin (= basal margin), in contact with the host's tissue, is the site where metabolic activities are inferred to take place. In Hoekia and Ahoekia, the wall develops simple or connecting tubes that lead to openings in the margin, which serve as circulatory pathways. A hypertrophied margin and elaborated circulatory system suggests that the Hoekiini may not be wholly dependent on feeding directly on host tissue and/or coelenteronic material, but may also be absorptive parasites. Although other pyrgomatids, in the tribes Pyrgopsellini nov. and Pyrgomatini nov., exercise some control over their hosts by an apertural frill and through discontinuities between the shell and basis, they are still planktotrophic.
\end{abstract}

\section{Résumé}

Le Cirripède mangeur de Corail Hoekia monticulariae (Gray, 1831) - jusqu'à présent unique endoparasite décrit parmi les
Thoracica - est caractérisé par une coquille de forme irrégulière nichée de manière cryptique entre les polypes du Corail hermatypique Hydnophora Fischer, 1807, à distribution dans la majeure partie de l'Océan Indien et du Pacifique de l'Ouest. A cause de l'aspect protéiforme des animaux, les cirripédologues n'ont pas correctement apprécié leur diversité, Hoekia étant considéré comme genre monotypique. Sont décrites ici 7 nouvelles espèces reparties entre Hoekia et 3 nouveaux genres (Eohoekia, Parahoekia et Ahoekia), la tribu Hoekiini étant proposée pour ce complexe. Comme c'est le cas dans d'autres Pyrgomatides, l'encroûtement par le Corail est inhibé le long du bord de la paroi et au niveau de l'aperture. Mais, dans les Hoekiini, paroi et aperture sont recouverts par un pseudopolype au dépens duquel le Cirripède se nourrit à l'aide de trophi modifiés. De plus, leur paroi est suspendue dans le tissu du Corail - et non articulée à une base calcaire; le bord latéral (basal) hypertrophié de cette paroi est l'endroit au niveau duquel on suppose que des activités métaboliques se déroulent. Chez Hoekia et Ahoekia on trouve dans la paroi des tubes simples ou communiquants, qui aboutissent à des orifices dans le bord, fonctionnant comme voies circulatoires. Bord hypertrophié et système circulatoire élaboré suggèrent qu'il est possible que les Hoekiini ne soient pas uniquement des consommateurs directs de tissu de l'hôte ou/et de matériel du coelenteron, et qu'ils pourraient être aussi des parasites absorbtifs. Pour ce qui est d'autres Pyrgomatides (membres des tribus Pyrgopsellini nov. et Pyrgomatini nov.), ils restent planctotrophes, bien qu'exerçant un certain contrôle sur leur hôtes par une collerette aperturale et par des discontinuités entre la coquille et la base.

\section{Introduction}

Hoekia monticulariae (Gray, 1831) is not only the most unique coral-inhabiting barnacle in the Pyrgo-

* A contribution of the Scripps Institution of Oceanography, new series. 
Table I. Species of Hoekiini, host coral and locality.

\begin{tabular}{|c|c|c|}
\hline Hoekiini & Host coral & Locality \\
\hline \multicolumn{3}{|l|}{ Eohoekia n. gen. } \\
\hline chaos n. sp. & Hydnophora sp. & Gulf of Aqaba \\
\hline nyx n. sp. & H. exesa (Pallas, 1766) & Gulf of Suez \\
\hline \multicolumn{3}{|l|}{ Parahoekia n. gen. } \\
\hline aster n. sp. & H. microconos (Lamarck, 1816) & New Caledonia \\
\hline \multicolumn{3}{|l|}{ Hoekia Ross \& Newman } \\
\hline fornix n. sp. & H. exesa & Obilatu Isl., Moluccas \\
\hline monticulariae (Gray) & H. exesa & Singapore \\
\hline mortenseni $\mathbf{n} . \mathbf{s p}$. & $H$. exesa & Mauritius \\
\hline \multicolumn{3}{|l|}{ Ahoekia n. gen. } \\
\hline tanabensis n. sp. & H.? exesa ${ }^{1}, H$. bonsai Veron, 1990 & Tanabe Bay, Japan \\
\hline chuangi n. sp. & H. rigida (Dana, 1846) & Bay of Batavia, Java \\
\hline
\end{tabular}

1 The host coral as listed on the label accompanying the type specimens was $H$. exesa. Present evidence indicates that $H y d n o p h o r a$ is represented in Japanese waters by $H$. bonsai Veron, 1990 as well as $H$. exesa, but we have only been able to confirm that the $A$. tanabensis we examined occurred on the former (see text for further discussion).

matidae, it is the only known wholly parasitic balanomorph barnacle. Because of its peculiar shell, Darwin (1854: 373) initially "... did not believe that it was a cirripede." He had only the shell and therefore did not realize that the animal within had aberrant cirri and fed directly on host tissue with its trophi (Ross \& Newman, 1969: 255). In our earlier study we concentrated on the aberrant cirri and biting trophi of preserved specimens, and failed to pay sufficient attention to the hard parts. We have since discovered that the shells of distant populations have different organization plans, and therefore Hoekia includes a number of taxa for which we now propose three new genera and seven new species of coral-eating barnacles.

Since our earlier studies (Ross \& Newman, 1969, 1973) there has been considerable interest in pyrgomatid functional morphology and symbiosis (Moyse, 1971; Newman \& Ladd, 1974; Anderson, 1978, 1992; Anderson \& Southward, 1987; Cook et al., 1991). The implication in many of these studies is that pyrgomatids are able to manipulate their hosts, on one hand limiting deposition of coral sclerosepta on certain areas of the shell surface through chemical interactions, and on the other metabolically stimulating the growth of coral coenenchyme that forms all or a portion of the barnacles' diet (Ross \& Newman, 1969: 255).
Two statements by Darwin (1854: 373) prompted a restudy of $H$. monticulariae. The first involves why "... the outer lamina of the shell in this one species does not nearly reach the circumference of the walls ..." And the second, why "Internally ... the walls are ... perforated by many quite irregular, small orifices ..." that "... admit threads of corium into certain irregular pores which penetrate the shell." Our answers, presented below, explain not only the functional aspects of these structures but also reveal a previously unknown diversity of genera and species.

A list of taxa, host corals and localities is provided in Table I. Diagnoses for all of the species are based wholly on characters of the wall, an approach necessitated by the rarity of complete specimens, especially those preserved in alcohol. Also, the characteristics of the wall laminae utilized are limited to those readily seen under simple magnification. Characteristics of the genera and species are distinguished in the diagnostic key to the Hoekiini and the accompanying illustrations of principal anatomical features (Figs. 1-3). This general information and the accompanying systematics section, of interest mainly to specialists, is followed by a discussion of the functional morphology and host relationships of these specialized parasitic barnacles. 

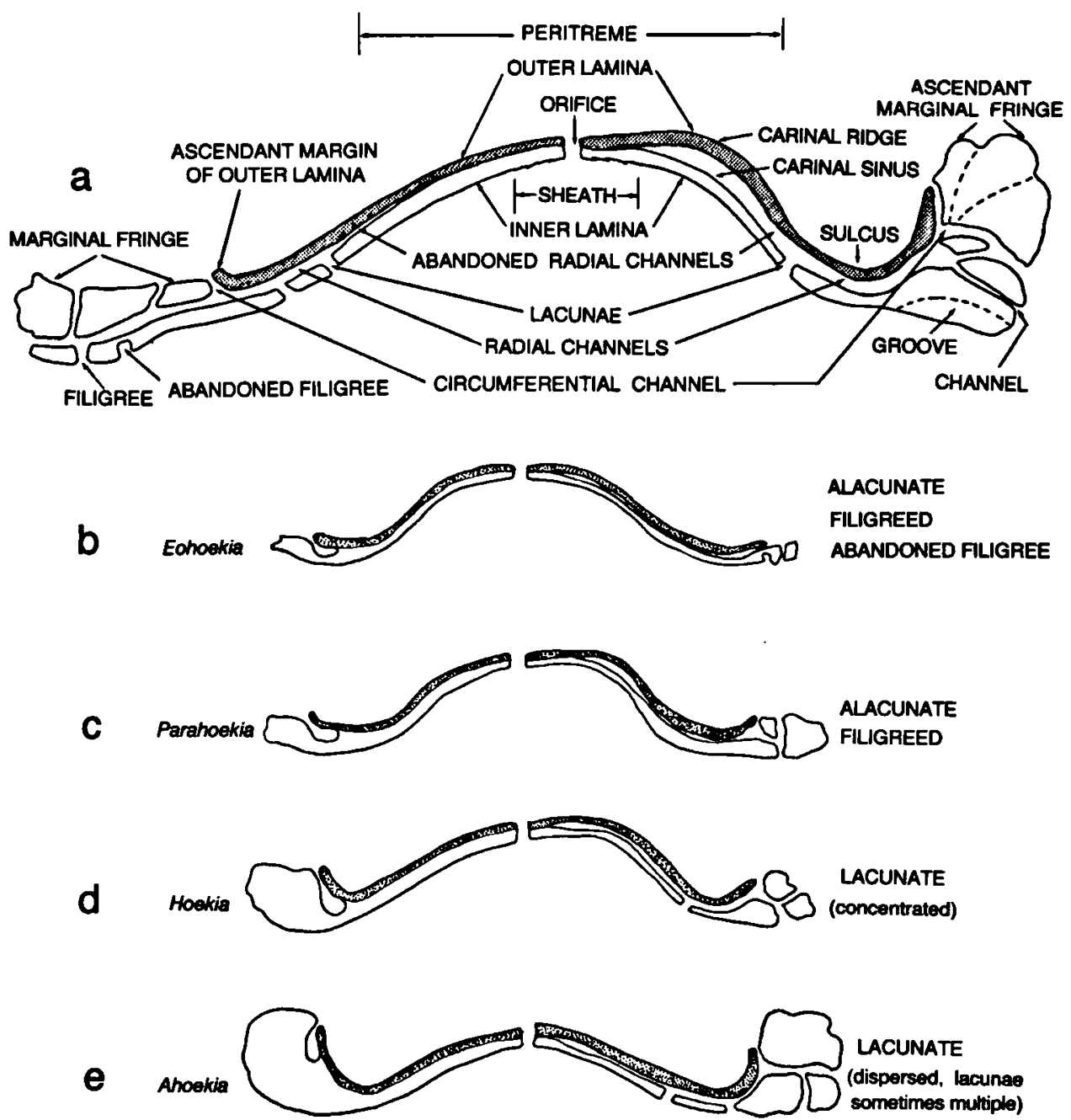

Fig. 1. Principal anatomical features of the wall in Hoekiini: a, Schematic cross-section of the wall of a generalized, mature, coral-eating barnacle viewed from the right side. The outer lamina (stippled) consists of an elevated central portion (peritreme) separated by a sulcus from a slightly to highly reflexed or ascendant outer margin (left and right ends, respectively). The inner lamina (unstippled) forms a marginal fringe which is subdivided by radial grooves and channels inferred to serve, or to have served as circulatory passages. These join each other occasionally along their lengths, and at the circumferential channel beneath the distal margin of the outer lamina. The inner and outer laminae are separated by the predecessors of these radial grooves and channels. Those between the marginal fringe and the circumferential channel in alacunate forms, and between both and the lacunae in lacunate forms, are functional (see Eohoekia/Parahoekia and Hoekia/Ahoekia, respectively). Alternatively, the functionless portion of a radial channel, that central to the circumferential channel in alacunate forms or the lacunae in lacunate forms, is either filled or simply abandoned. The most obvious abandoned radial channel is that forming the carinal sinus. Ascendant marginal fringes can exceed the height of the peritreme. The highly vascularized marginal and upper surfaces of the marginal fringe are in intimate contact with tissue of the host coral (see Fig. 3). b-e, Schematic cross-sections of the shell wall of Eohoekia, Parahoekia, Hoekia, and Ahoekia, respectively, viewed from the right side. The outer and inner laminae are stippled and unstippled, respectively, and grooves and channels of the marginal fringe of the rostral end (left) are omitted. For the key to these genera and the distinctions between wall types depicted here, see p. 134 and text, respectively. 


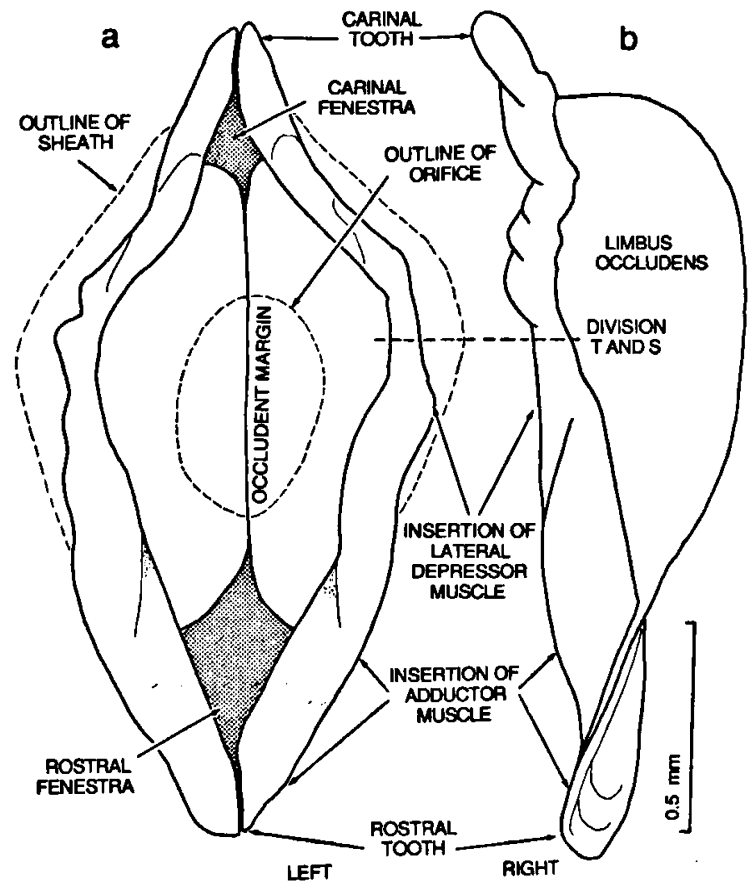

Fig. 2. Principal anatomical features of the opercular plates in Hoekia monticulariae: a, plan view in situ, with the outlines of the underlying sheath and orifice of the wall identified by the lightly dashed lines; $b$, side view of the right plate also viewed from within. The heavier dashed line labelled "Division $T$ and $S$ " indicates the approximate division between the fused scutal and tergal portions of the plates. When the plates are closed (a), the arches over the scutal and rostral portions of each plate, the limbus occludens (b), meet to occlude the orifice of the wall as well as the aperture to the mantle cavity. The two stippled areas represent openings between the plates when closed, the rostral and carinal fenestrae. As indicated, the insertion of the lateral depressor is relatively discrete, and that for the tergal depressors is limited to the region of the carinal tooth. See also Figs. 9a, b.

\section{Materials and methods}

The material available was either dried, or less commonly, preserved in alcohol. A few of the specimens were examined during our previous studies, but most were acquired over the intervening 25 years. A relatively well preserved sample of $H y d-$ nophora exesa (Pallas), containing $H$. monticulariae from Singapore, was especially useful in clarifying the relationships of the barnacle to its host as well as its anatomy. Procedures for the preparation of soft parts are detailed in Newman \& Ross (1971: 17). We found a small hand-held grinder with either an abrasive or diamond impregnated dental wheel useful in cutting through the coral skeleton in order to remove the whole shell and basis intact. Once the shell was removed, this small block was cut again to reveal the relationship of the wall to the basis. We found that the easiest way to trace pathways or openings on the inner wall to the marginal fringe was by inserting an eyelash into the opening, and observing where it exited. All of the specimens were examined with transmitted light, or "candled", which proved especially helpful in elucidating the development of the pathways within the wall.

Specimens chosen for scanning electron microscopy were cleaned in a $5.25 \%$ solution of sodium hypochlorite, rinsed several times in tap water and air dried. These were mounted on aluminium stubs with double-sided tape, sputter-coated with silver, and viewed in a Cambridge $\mathbf{S} 360$ operating at $10 \mathrm{kV}$.

Maximum parsimony analyses, including $50 \%$ majority rule consensus trees, and bootstrapping with the Branch and Bound search algorithm in the software package PAUP (version 3.1.1) were developed on a Macintosh Quadra 840 running System 7.

\section{Abbreviations of depositories}

MNHN Muséum National d'Histoire Naturelle, Paris

NNM Nationaal Natuurhistorisch Museum, Leiden

SIO Scripps Institution of Oceanography, La Jolla, Ca.

USNM National Museum of Natural History, Washington DC (formerly United States National Museum)

ZM Zoologisk Museum, Copenhagen

ZMA Zoölogisch Museum, Amsterdam

\section{Systematics}

Suborder Balanomorpha Pilsbry, 1916

Family Pyrgomatidae Gray, 1825

Subfamily Pyrgomatinae Gray, 1825

Remarks. - For a list of genera included in this subfamily, see Newman \& Ross (1976: 39), Galkin (1986: 1290), and Anderson (1992: 335). The generic name Utinomia proposed by Galkin (1986: 1290) is preoccupied by Utinomia Tomlinson (1963: 264), an acrothoracican barnacle. As a replacement name we propose Galkinia, with Pyrgoma indicum Annandale, 1924 as the type species, by original designation.

Within the Pyrgomatinae there are three major taxa, distinguished on shell characters and mode of feeding, which are readily separable from one another. For each of these lineages we propose tribal names: Pyrgomatini, Pyrgopsellini, and Hoekiini, as defined below. 


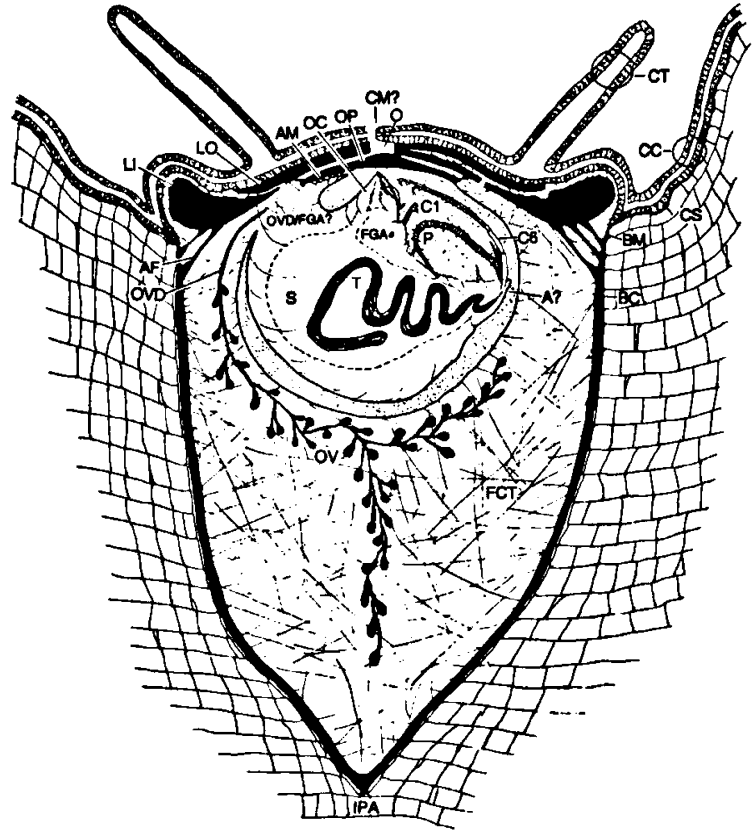

Fig. 3. Schematic optical cross-section of a lacunate coral-eating barnacle viewed from the right side, with a shell (black) approximately $1 \mathrm{~cm}$ in diameter. Note that the outline of the host coral, Hydnophora spp. (CC, CT), superficially resembles a simple polyp, but whether it is provided with a mouth (CM?) could not be determined in the material available. The barnacle's inflated prosoma and reduced thorax reside in the confines of a closefitting mantle cavity (stippled) and the relatively voluminous space formed by growth of the cup-shaped basis is largely filled with fibrous connective tissue (FCT). The oral cone with the contained mouth parts (OC), when extended up through the orifice $(0)$ of the shell, with the contained mouth parts, can cut and rasp coral tissue, and the distended stomach (S) is commonly filled with nematocysts. The shell (black) consists of the wall tethered by attachment fibers (AF) to the calcareous portion of the basis $(B C)$. The margin of the wall is separated from the coral by the membranous portion of the basis (BM). Thus, the wall is suspended in the surrounding tissue of the host (CC) by the hypertrophied inner lamina (LI). Furthermore, circulatory channels pass through the wall (see Fig. 1a) from the tissues within to the relatively isolated outer surfaces of the hypertrophied inner lamina, presumably in connection with an absorptive function.

$\mathbf{A}$ ?, anus (presence not confirmed by gross inspection); $\mathbf{A F}$, attachment fibers; AM, adductor muscle; $\mathrm{BC}$, calcareous portion of basis; BM, membranous portion of basis; $\mathrm{CC}$, coral coenenchyme (soft tissue); CM?, coral mouth (presence not confirmed by gross inspection); CS, calcareous coral skeleton; CT, coral tentacle; $\mathbf{C 1}$, right cirrus I; $\mathbf{C 6}$, right cirrus VI; FCT, fibrous connective tissue; FGA, female genital aperture at base of $\mathrm{Cl}$; IPA, initial point of attachment; LI, lamina inner; LO, lamina outer; $\mathrm{O}$, orifice; $\mathrm{OC}$, oral cone; $\mathrm{OP}$, operculum; $\mathrm{OV}$,
Tribe Pyrgomatini Gray, 1825 nom. transl.

Definition. - Shell wholly calcareous, wall of 4 plates or concrescent, regular in outline; orifice large; lacking carinal ridge; wall interlocking with calcareous basis; cirri and trophi normal, employed in planktotrophic feeding; living in stony corals.

The included genera are: Pyrgoma Leach, 1817 (type genus), Creusia Leach, 1817, Nobia Sowerby, 1839, Cantellius Ross \& Newman, 1973, Hiroa Ross \& Newman, 1973, Galkinia Ross \& Newman, herein, Paranobia Galkin, 1986, Darwiniella Anderson, 1992, Wanella Anderson, 1992, Arossella Anderson, 1992, and Trevathana Anderson, 1992.

Tribe Pyrgopsellini n. tribe

Definition. - Shell only partly calcareous, walls always concrescent, regular in outline; orifice large; lacking carinal ridge; wall attached to wholly membranous basis; cirri and trophi normal, employed in planktotrophic feeding; living in sponges.

Type genus: Pyrgopsella Zullo, 1967 (substitute name for Pyrgopsis Gruvel, 1907, not Rochebrune, 1884).

Remarks. - Only Pyrgopsella is included in this tribe. In $P$. stellula Rosell, 1975, the opercular plates are separate, the scutum transversely elongated, and the triangular tergum lacks a spur (Rosell, 1975: 212), features that ally it with Wanella Anderson, 1992 and Savignium Leach, 1825, both of which are in the Pyrgomatini. Pyrgopsella apparently represents an early radiation that has adapted to living in calcareous sponges, which have growth characteristics not greatly unlike corals.

\section{Tribe Hoekiini n. tribe}

Definition. - Shell calcareous, wall concrescent, irregular in outline; orifice remarkably small; with

ovary; OVD, oviduct; OVD/FGA?, connection of OVD to FGA not observed; $P$, penis; $S$, stomach; $T$, right testis and seminal receptacle. 
carinal ridge; inferior portion of basis calcareous, superior membranous; lateral margin of wall in contact with tissue of host, not with basis; cirri aberrant; trophi modified for feeding on host tissue; living only in species of the stony coral Hydnophora Fischer, 1807.

Type genus: Hoekia Ross \& Newman, 1973.

Remarks. - We propose this new tribe to include Hoekia and the three new genera below. All of the species possess shells with variable outlines, i.e., no two individuals of the same species have a consistent shell outline comparable to those found in other Pyrgomatidae, and balanomorphs in general (Spivey, 1988: 279). Although there appear to be consistent differences in the soft parts, of which we have seen only those in three of the eight species, there appears to be considerable variation in the shell characters employed in the following key, and therefore it remains tentative.

\section{Key to the genera and species in the tribe Hoekiini}

1. Inner surface with numerous lacunae connected directly to circumferential channel; shell with thick, complex marginal

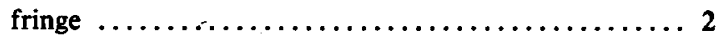

- Inner surface occasionally with few foramina occurring in marginal fringe, and a few blind "lacunae" on inner wall not connected directly to circumferential channel .....6 6

2. Distal margin of outer lamina slightly ascendant, lower than peritreme..$\ldots \ldots \ldots \ldots$ Hoekia ............ 3

- Distal margin of outer lamina strongly ascendant, higher than peritreme .......... Ahoekia n. gen. ....... 5

3. Orifice apical, round; carinal ridge lower than orifice ... $\ldots \ldots \ldots \ldots \ldots \ldots \ldots \ldots \ldots \ldots$. fornix $\mathbf{n} . \mathbf{s p}$.

- Orifice subapical, ovate; carinal ridge higher than orifice . 4

4. Shell white, peritreme generally patelliform; carinal ridge low, broad, commonly obscure ................ ................... monticulariae (Gray, 1831)

- Shell pink to rose, peritreme subcircular, carinal ridge high, narrow, distinct .............. mortenseni $\mathrm{n}$. sp.

5. Shell red, peritreme large, carinal ridge low and broad; border of marginal fringe forming open network concomitant with pronounced gap between outer lamina ....... ....................... tanabensis n. sp.

- Shell white, peritreme small, carinal ridge low and narrow; border of marginal fringe forming closed network concomitant with indistinct gap between outer lamina ......... $\ldots \ldots \ldots \ldots \ldots \ldots \ldots \ldots \ldots \ldots \ldots \ldots \ldots \ldots \ldots \ldots \ldots$. chuangi n. sp.

6. Outer lamina lobate, not reflexed or ascendant; marginal fringe narrow, not ascendant; carinal and rostral ridge prominent ........... Parahoekia aster n. gen., n. sp.

- Outer lamina ovate, reflexed; marginal fringe wide, reflexed; carinal ridge obscure, rostral ridge lacking ..... ............ Eohoekia n. gen. .......... 7

7. Marginal fringe distally anastomosing or filigreed; foramina in fringe develop by coalescence of proximal elements; lacunae absent on inner wall ........ Eohoekia chaos n. sp.

- Marginal fringe distally serrate, not filigreed; foramina in fringe absent; lacunae rarely present on inner wall ...... Eohoekia nyx n. sp.

Eohoekia n. gen.

Definition. - Shell thin, delicate in appearance; carinal ridge obscure, rostral ridge lacking; distal margin of outer lamina flat to slightly reflexed; marginal fringe thin, simple, strongly reflexed, as high as or higher than orifice; foramina present in marginal fringe, rarely on inner wall of shell and then not connected to circumferential channel.

Type species: Eohoekia chaos n. sp.

Etymology. - Derived from the Greek prefix eos-, dawn or early, and-Hoekia, relative to the following genera, especially Hoekia.

Eohoekia chaos n. sp.

(Figs. 4, 18b)

Material. - Twelve dried specimens from Hydnophora sp., Elat, Gulf of Aqaba, Red Sea, Israel, L. Fishelson coll., 1971, approx. $29^{\circ} 33^{\prime} \mathrm{N}, 34^{\circ} 57^{\prime} \mathrm{E}$. Holotype: USNM no. 259978 , 2 paratypes, same, no. 259979; 1 paratype, Nationaal Natuurhistorisch Museum, Leiden, no. C-2537; 1 paratype, Tel Aviv University, Israel, no. AR 27533; 1 paratype, Zoölogisch Museum Amsterdam, no. ZMA Cirr. 201515; 6 paratypes, Scripps Institution of Oceanography, no. C-5983.

Diagnosis. - Shell low; marginal fringe thin, simple, exceedingly broad, higher than outer lamina, commonly higher than orifice; distal elements of fringe separate, arborescent or filigreed; elements of fringe coalesce forming open foramina distal to outer lamina.

Description. - Shell white, translucent, thin, delicate in appearance; orifice ovate, subapical on 


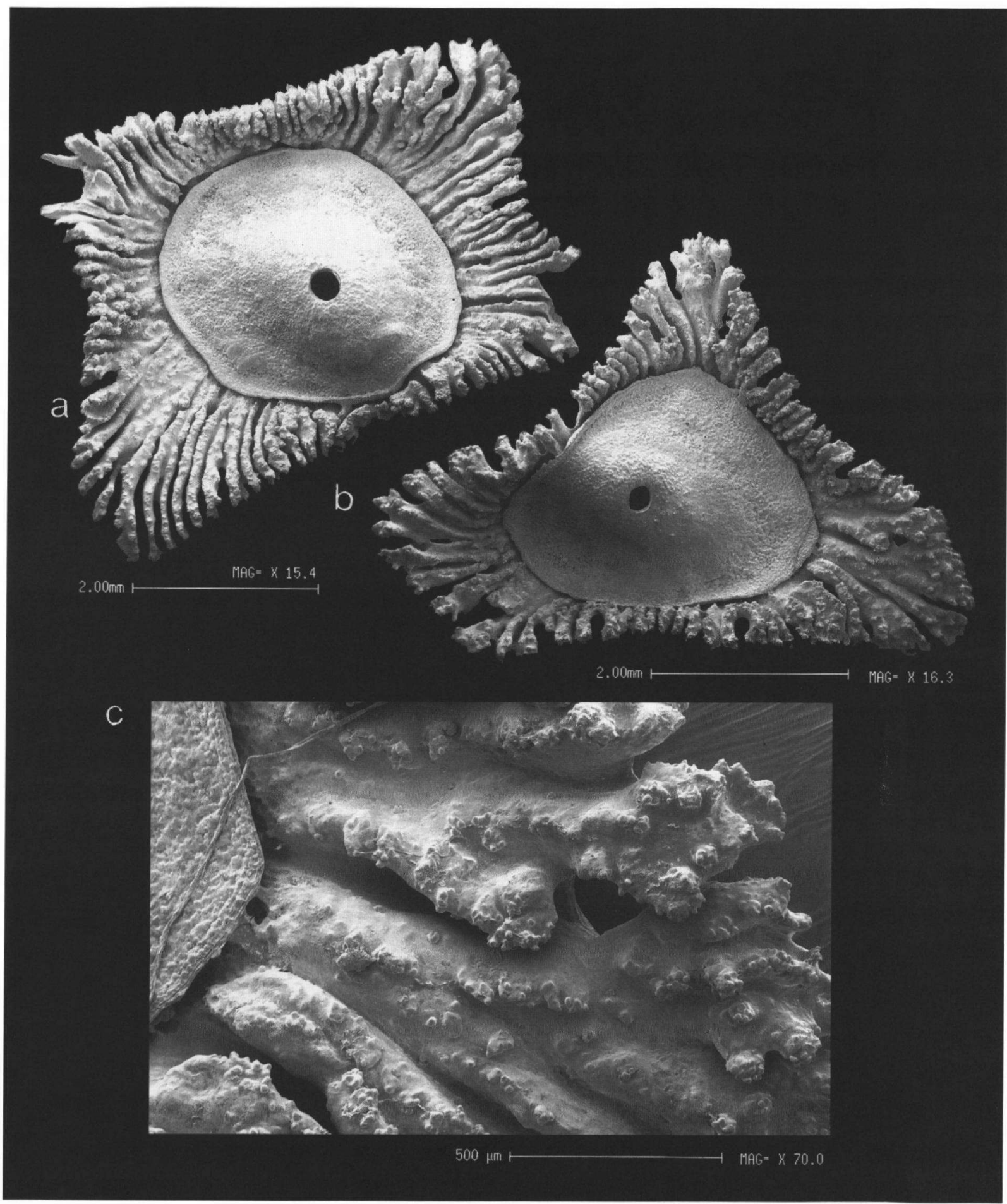

Fig. 4. Eohoekia chaos n. sp.: a, apical view of holotype, USNM no. 259978, carinal end at lower right; b, apical view of paratype, USNM no. 259979, carinal end at left, showing open filigree of fringe and some closed and some incipient foramina; $c$, portion of fringe at right in $b$, showing elements forming a foramen and the partially closed radial channel leading to the circumferential channel. 


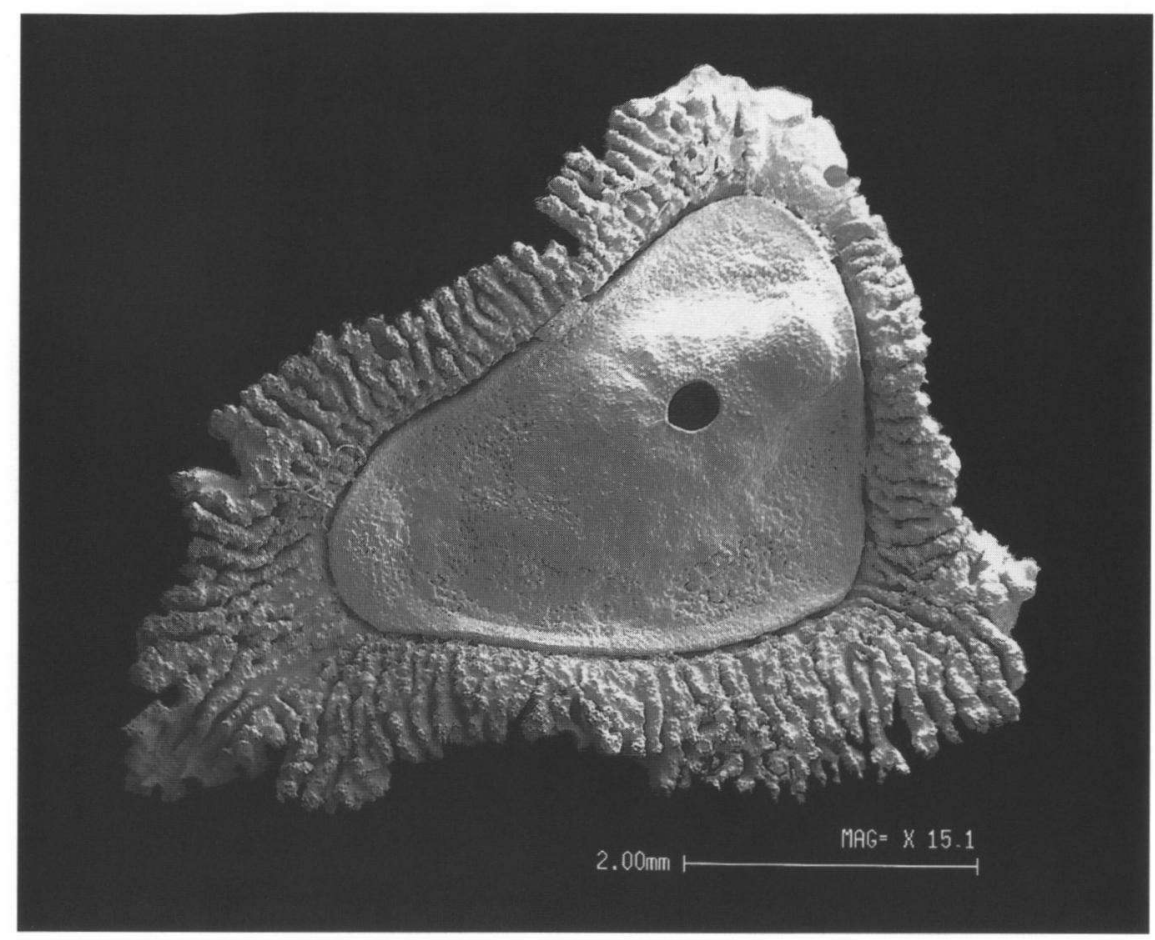

Fig. 5. Eohoekia nyx n. sp., apical view of holotype, USNM no. 259980, carinal end at right.

rostral slope; shell surface verrucose to pustulose without discernible growth ridges; marginal fringe slightly to greatly reflexed; fringe supradecompounded to anastomosing (Fig. 4b); sheath about one-half height of wall, glossy; internal surface slightly roughened; lacunae lacking on inner wall.

Opercular plates thin, translucent, approximately 3 times longer than high; growth ridges thin, beaded; long axis strongly arcuate in section; rostral tooth of scutum slightly elevated and greatly produced, inflexed and distally spatulate; tooth of right plate slightly broader than that of left; teeth about twice as wide and long as tergal end; tergal end distally spatulate.

Etymology. - Derived from the Greek chaos, an allusion to utter formlessness, or state of things in which chance is supreme.

\section{Eohoekia nyx n. sp.}

(Figs. 5, 16)

Material. - Four dried specimens and several fragments from Hydnophora exesa (Pallas); El-Tur, Egypt, Gulf of Suez, Red
Sea; Y. Achituv leg., 20 June 1967 , approx. $28^{\circ} 14^{\prime} \mathrm{N}, 33^{\circ} 38^{\prime} \mathrm{E}$. Holotype: USNM no. 259980; 1 paratype, same, no. 259981; 1 paratype, Nationaal Natuurhistorisch Museum, Leiden, no. C-2538; 1 paratype, Tel Aviv University, Israel, no. AR 27534; 1 paratype, Zoölogisch Museum Amsterdam, no. ZMA Cirr. 201516.

Diagnosis. - Shell low; marginal fringe moderately thick, narrow, distally serrate, higher than outer lamina, commonly higher than orifice; distal elements of fringe confluent, or developing foramina that fill secondarily.

Description. - Shell white, opaque to semitranslucent, thick, somewhat delicate in appearance; carinal ridge prominent in juveniles, obscure in adults; orifice ovate, subapical on rostral slope; shell surface granulate to pustulose; growth ridges discernible along periphery of outer lamina; fringe margin weakly branching, not strongly digitiform or filigreed (Fig. 5); sheath about one-half height of wall, glossy; internal surface roughened, chalky; blind or secondarily filled lacunae present at or near periphery of inner lamina.

Opercular plates thick, opaque, approximately 
4.5 times longer than high; growth ridges thin, beaded; long axis strongly arcuate in section; rostral tooth well elevated and greatly produced, inflexed, terminally spatulate, slightly wider and longer than tergal crest; crest thinner and about $1 / 2$ length of rostral tooth, terminally spatulate.

Remarks. - Our attempt to restore the dried specimens in a weak solution of tri-sodium phosphate was unsuccessful. We did note that the opercular plates, attached by the opercular membrane to the sheath, had the adductor muscle bundle attached to the medial edge of the rostral tooth. The adductor extends from the middle of the fused plate almost to the tips of the rostral tooth. Although there were portions of the scutal lateral depressors, their length could not be determined.

Etymology. - Derived from Greek mythology, nyx, night, the offspring of Chaos.

\section{Parahoekia n. gen.}

Definition. - Shell moderately thick, somewhat delicate in appearance; surface ornamented with carinal, rostral, and subsidiary lateral ridges; distal margin of outer lamina irregular, narrow, flat, not reflexed; sulcus lacking between margin and peritreme; orifice higher than surrounding surface; marginal fringe moderately thick, flat, foraminate; lacunae absent on inner wall of shell.

Type species: Parahoekia aster n. sp.

Etymology. - Derived from the Greek prefix para-, beside or close by, and -Hoekia, to denote their relationship.

\section{Parahoekia aster n. sp.}

(Figs. 6, 7)

Material. - One dried specimen from Hydnophora microconos (Lamarck, 1816); Passe Dumbea, outside barrier reef, New Caledonia, 20-35 m, 21/22 June 1976; approx. $22^{\circ} 10^{\prime} \mathrm{S}$, $166^{\circ} 30^{\prime}$ E. Holotype: Nationaal Natuurhistorisch Museum, Leiden, no. C-2539. Paratype: one preserved specimen from $\boldsymbol{H}$. microconos; Kouare Reef, New Caledonia, $1 \mathrm{~m}$, Georges Bargibant coll., 18 May $1994,22^{\circ} 46.30^{\prime} \mathrm{S}, 166^{\circ} 47.40^{\prime} \mathrm{E}$, Muséum National d'Histoire Naturelle, Paris, no. CI-2352.

Diagnosis. - Shell high; peritreme prominent; marginal fringe moderately thick, slightly filigreed, narrow, not reflexed or ascendant, lower than outer lamina and orifice.

Description. - Shell moderately thick, white to translucent; short carinal ridge as high as or higher than orifice; rostral ridge lower than orifice; orifice ovate, subapical on rostral slope; distal portion of outer lamina flat, not reflexed or ascendant (Fig. 6b); short low ridges intercalated between carinal and rostral ridges; growth ridges beaded, poorly developed; marginal fringe exceedingly narrow, wider at extremities; fringe bifurcates and coalesces to form foramina in extremities; sheath glossy, about $1 / 2$ height of inner lamina; wide band below sheath translucent and roughened; lower portion milky white, similarly roughened.

Opercular plates twice as wide as high, thin, translucent; long axis arcuate in section; growth ridges slightly beaded; bilaterally symmetrical and equal in size; scutal rostral tooth greatly produced, comprising about $1 / 3$ length of plate, slender, but twice as wide as tergal end; tip of tooth inflexed; tergal end acicular, about $1 / 4$ length of plate.

Crest of labrum deeply notched, devoid of setae and teeth; oral surface clothed with downward projecting ctenoid scales (Fig. 7a). Palps fused basally to lateral margins of labrum; clothed with long, simple setae. Mandible with leading edge straight; divisible into three parts; superior 1/4 devoid of teeth, but armed with a few short, slender setae; inferior 3/4 divisible into two parts, upper armed with wide-spaced, strong, stout, simple or bicuspid teeth; inferior angle armed with closespaced multicuspid teeth and short, slender setae along inferior margin; cutting edge of whole appendage clothed with ctenoid scales. Maxilla I with moderately short, uniform, simple, equally spaced spines; lateral surface of appendage clothed with ctenoid scales. Maxilla II bilobed; upper lobe reduced to knob-like protuberance with either a few 


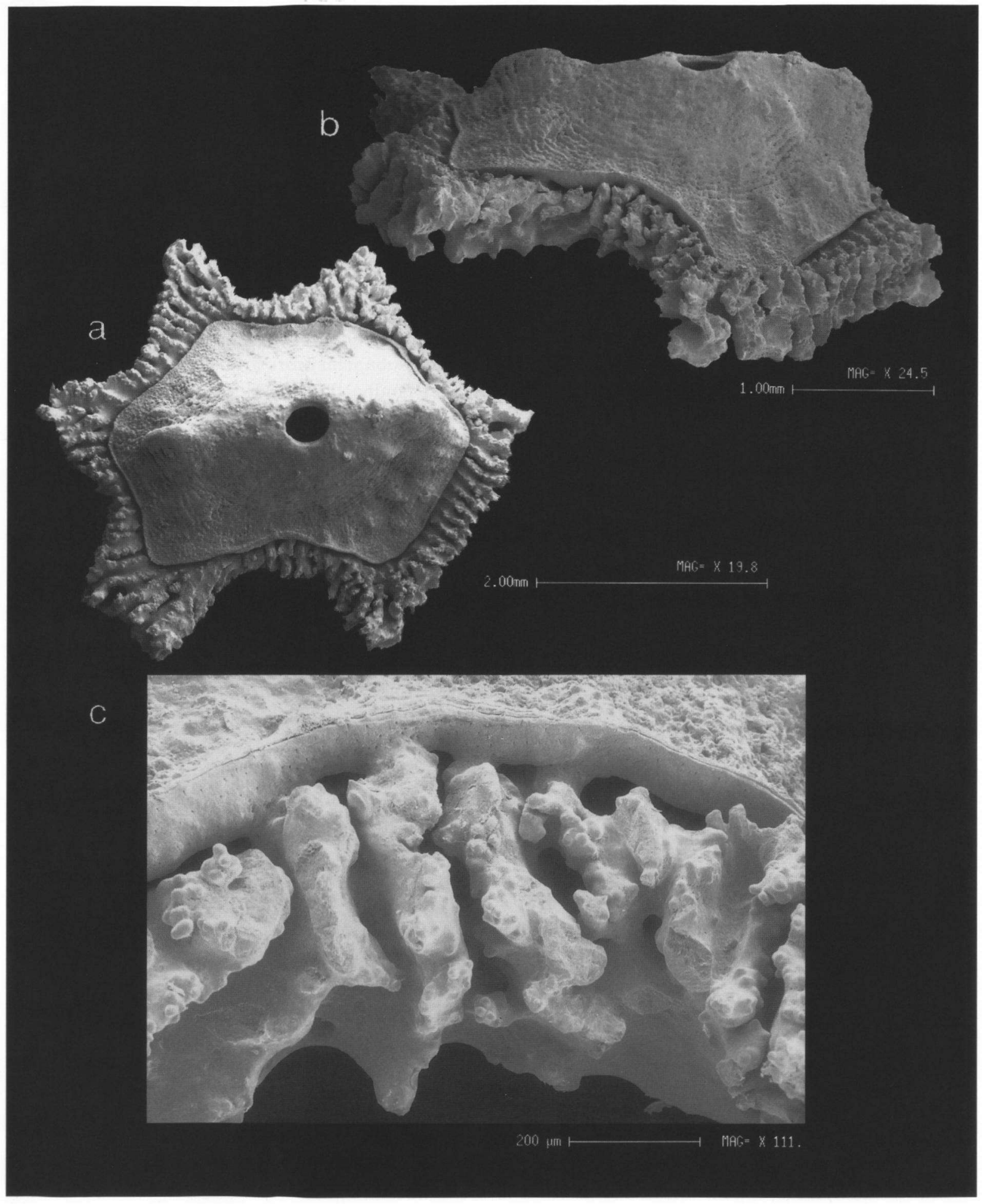

Fig. 6. Parahoekia aster n. sp.: a, apical view of holotype, NNM no. C-2539, carinal end at right; b, lateral view of same showing carinal, rostral, and subsidiary lateral ridges; $c$, enlarged view of fringe from below, illustrating convolute channels leading to circumferential channel; minute pits in border of outer lamina are passages for setae that traverse the shell. 


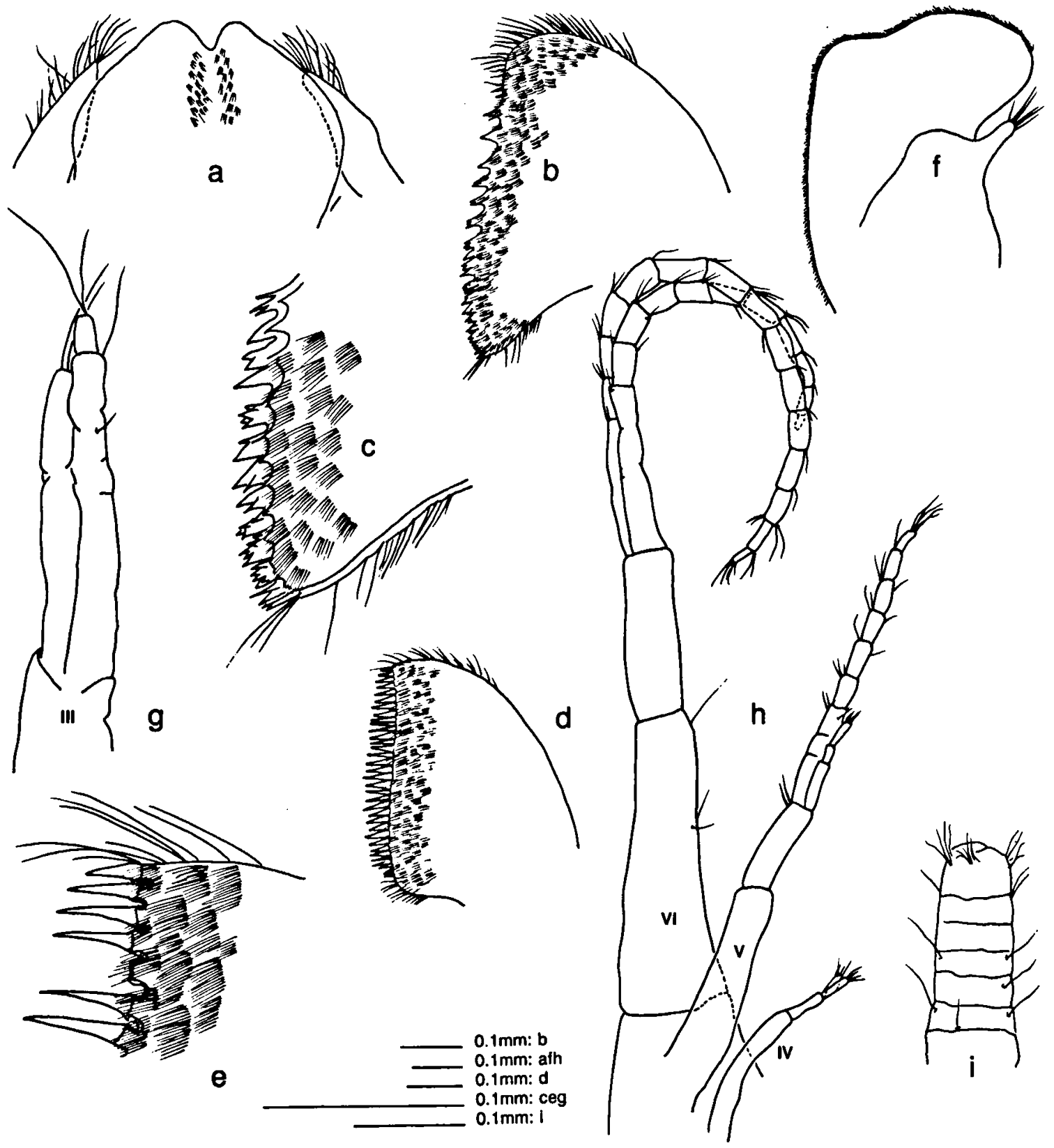

Fig. 7. Parahoekia aster n. sp., mouthparts and appendages: a, labrum and palps; b, mandible; c, enlarged view of inferior angle of mandible; d, maxilla I; e, enlarged view of apical portion of maxilla I; f, median languette and reduced right maxilla II; $g$, cirrus III; $h$, cirri IV-VI; $i$, distal end of penis.

or several short, slender, apical setae. Median languette exceedingly large, laterally compressed; peripheral margin with minute, slender, simple setae; anterior edge straight; superior edge sulcate; posterior of appendage strongly protuberant (Fig. 7f).
Cirri I-V distinctly aberrant; coxopodite of protopodite of cirrus I broad, about 20 times larger than basipodite; segments of rami distinct, armed with a few long, simple setae. Distinct hiatus between cirrus I and II; cirrus II biramous, segments indistinguishable; terminal setae short, slender. 
Cirrus IV biramous; rami equal in length, and equal in length to basipodite of protopodite; about $3 / 4$ length of coxopodite of cirrus V. Cirrus V shorter than protopodite of cirrus VI; outer ramus shorter than first 3 segments of inner ramus; inner ramus with short, simple setae at each articulation along greater curvature. Cirrus VI with rami shorter than protopodite; outer ramus shorter than inner, with 13 segments, inner with 15 segments; intermediate segments with one pair of apical setae on lesser curvature; at articulation on greater curvature 2 long and 1 shorter, single setae. Intromittent organ annulated, more than twice length of- cirrus VI. Basidorsal point low, slender, apically acuminate.

Remarks. - The shell of the preserved paratype, which agrees in all particulars with the holotype, was chipped when removed from the host coral. The outer lamina has a crystalline calcareous covering, apparently laid down by the coral, that masks the growth lines. The subsidiary radial, but not the carinal and rostral ridges are poorly defined owing to this overgrowth.

Etymology. - Derived from the Latin aster, a star, in reference to the appearance of the outline of the shell.

Hoekia Ross \& Newman, 1973

Definition. - Shell relatively thin, delicate in appearance; carinal crest narrow, prominent; orifice apical or subapical; peritreme small to large; distal margin of outer lamina ascendent, low; marginal fringe moderately thick, complex, ascendant deliquescence lower than orifice; lacunae of inner wall separate, ovate to circular in outline, slightly irregularly arranged, connecting directly to circumferential channel.

Type species: Pyrgoma monticulariae Gray, 1831, by original designation (Ross \& Newman, 1973: 162).

Remarks. - We proposed Hoekia to honor the late Dr. P.P.C. Hoek, a contemporary of Charles Darwin, in recognition of his monumental studies on the Cirripedia collected by expeditions of H.M.S. "Challenger" and the Dutch Man-of-War "Siboga". For a recent expose of his early career, and correspondence with Darwin and others, which led to his work on the cirripeds of the "Challenger" and "Siboga" expeditions, see Pieters \& Winthagen (1990), who do not mention his incomparable studies on the cirripeds collected by the "Siboga".

Hoekia fornix n. sp.

(Fig. 8)

Material. - One dried specimen lacking opercular plates from Hydnophora exesa, on reef of Poeloe Toesa east of Obilatu Isl., Moluccas, Indonesia; approx. $1^{\circ} 47.5^{\prime} \mathrm{S}, 126^{\circ} 59.5^{\prime} \mathrm{E}$, Snellius Exped. sta. 253a, 23-27 April 1930. Holotype: Nationaal Natuurhistorisch Museum, Leiden, no. C-2540.

Diagnosis. - Shell suffused with pink; peritreme large; orifice apical, circular; carinal ridge narrow, lower than orifice.

Description. - Shell thin, delicate, somewhat translucent; peritreme highly domed, conical, growth ridges indistinct; orifice apical, circular; carinal ridge narrow, lower than orifice; distal edge of outer lamina slightly thickened, slightly ascendent, with distinct gap between it and fringe (Fig. 8a); marginal fringe higher than outer lamina, narrow but wider at extremities; sheath less than $1 / 2$ height of wall, hyaline, glossy; inner wall opaque, roughened; lacunae circular to elongate-oval, of various sizes.

Remarks. - The shell surface is encrusted by calcareous growths which may or may not have been the result of coral overgrowth (Fig. $8 b$ ).

Etymology. - From the Latin, fornix, arched or vaulted, in reference to the pronounced dome shape of the peritreme.

Hoekia monticulariae (Gray, 1831)

(Figs. 9, 10, 15, 17, 18a, 19)

Pyrgoma (Daracia) monticulariae Gray, 1831: 6; Darwin, 1854: 372, pl. 12 fig. 5A-E; Kolosvàry, 1947: 427; Ross \& Newman, 


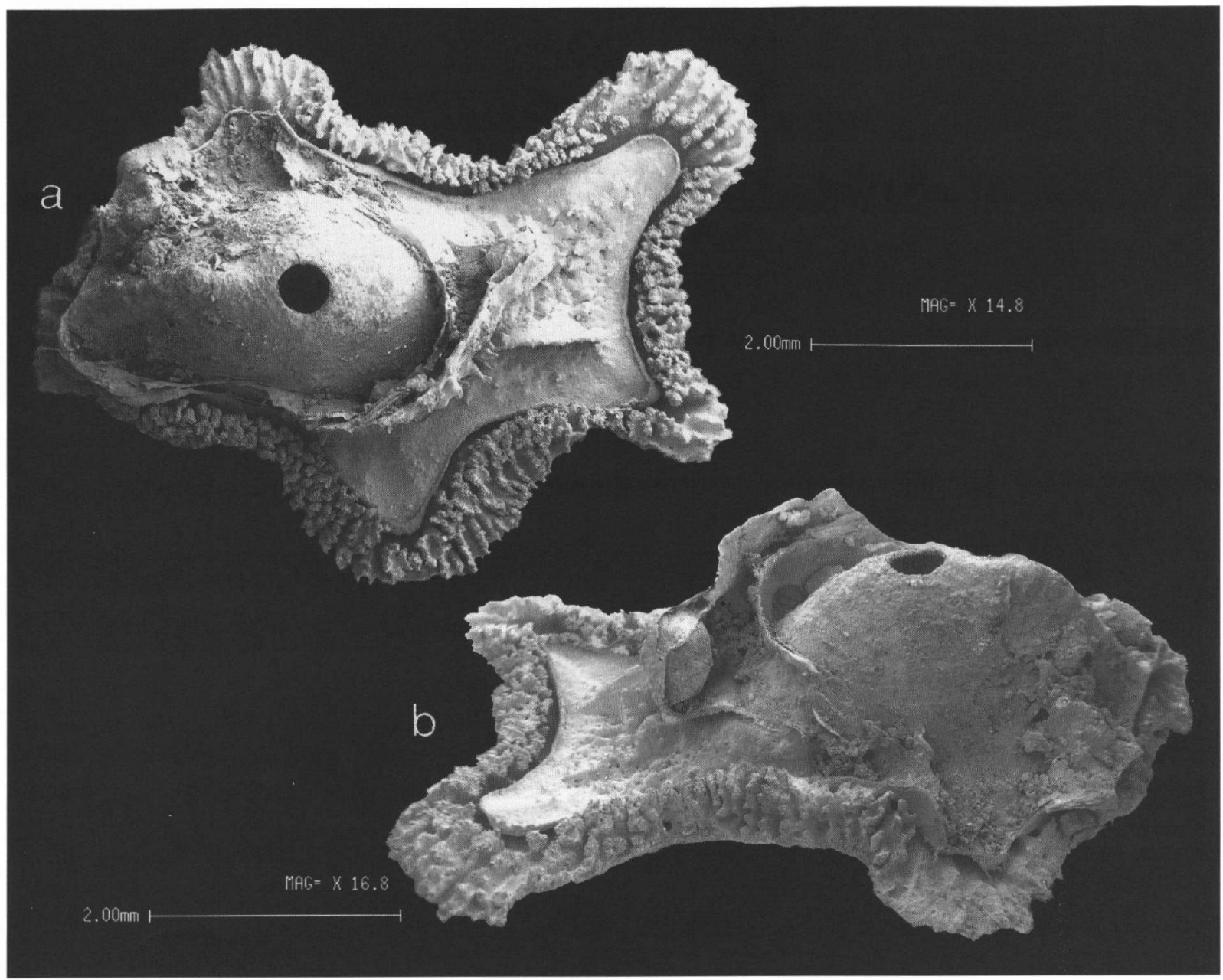

Fig. 8. Hoekia fornix n. sp.: a, apical view of holotype, NNM no. C-2540, carinal end at left; b, oblique view of same, carinal end at right; the slightly ascendant marginal fringe is distinctly separated from the outer lamina. Also note disorganized calcareous overgrowth on shell.

1969, in part, fig. 1A only; Ross \& Newman, 1973: 162, in part, fig. 18 right, fig. 19 top.

Material. - One dried specimen lacking opercular plates from Hydnophora exesa, Singapore, John Hendley Barnhart coll., approx. $1^{\circ} 20^{\prime} \mathrm{N}, 103^{\circ} 50^{\prime} \mathrm{E}$, American Museum of Natural History, coral no. 1883. Twelve specimens from Hydnophora exesa, Singapore; S.H. Chuang coll., 3 Dec. 1975. Ten topotypes, Scripps Institution of Oceanography, no. C-8375; 1 topotype, Zoölogisch Museum Amsterdam, no. ZMA Cirr. 201517; 1 topotype, Nationaal Natuurhistorisch Museum, Leiden, no. C-2541.

Diagnosis. - Shell white, peritreme patelliform, large; carinal ridge broad, higher than orifice.

Description. - Shell semitranslucent, moderately thin, delicate in appearance; peritreme well elevated in small but lower in large specimens; carinal ridge prominent in large specimens, less pronounced in small; ridge not extending to margin of outer lamina; orifice ovate, subapical on rostral slope; growth ridges faint, beaded, widely spaced on peritreme, but proximate along distal portion of outer lamina; distal edge of outer lamina thin, slightly ascendant; marginal fringe same as or slightly higher than outer lamina, narrow in small specimens, wider in large, widest at extremities in large specimens; interior surface dull, translucent, smooth, becoming wrinkled near margin; sheath $1 / 2$ or more height of wall, glossy; lacunae of different sizes, ovate, elon- 


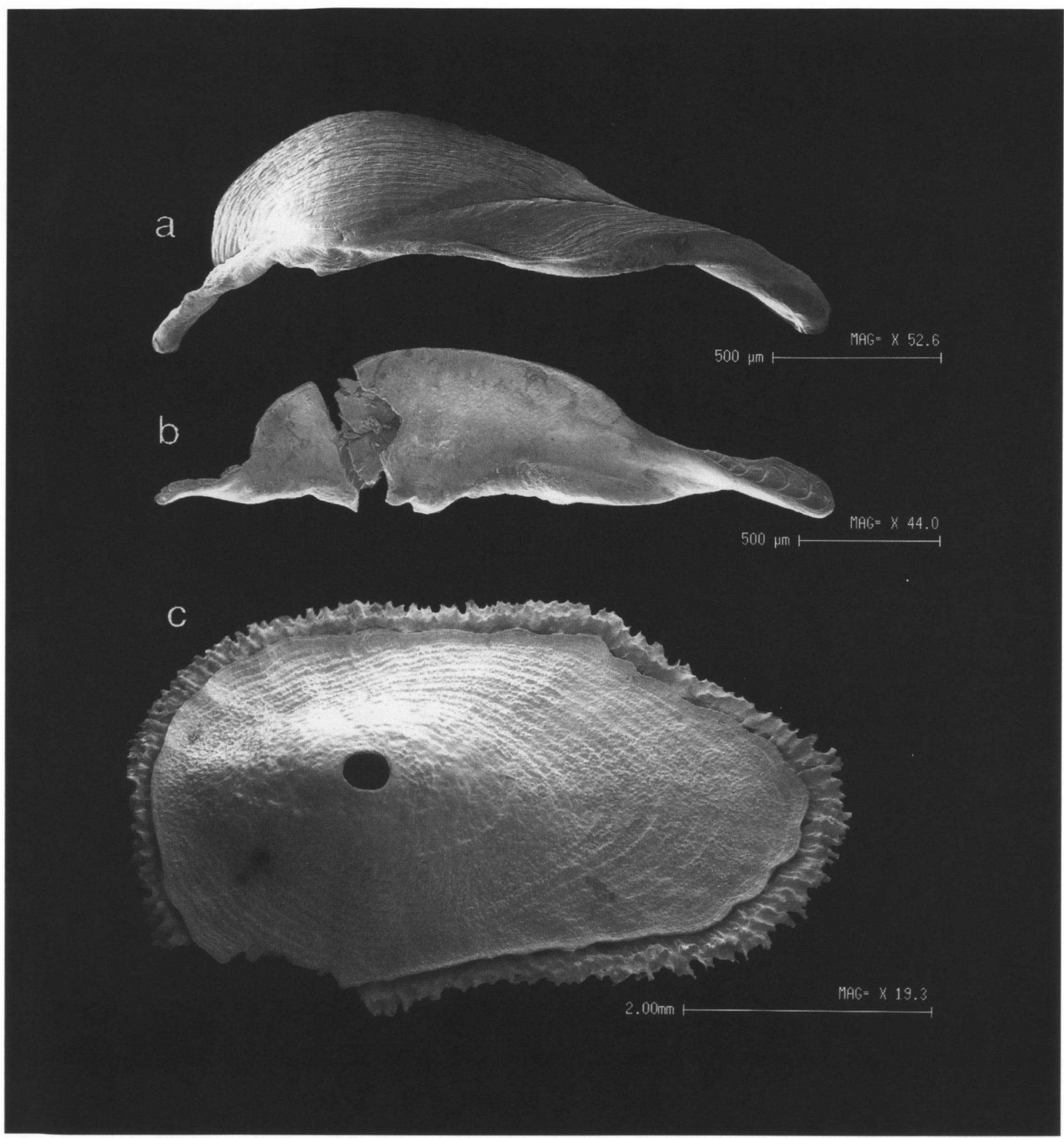

Fig. 9. Hoekia monticulariae (Gray, 1831): a, external surface of left opercular plate, limbus occludens (= occludent edge) at top (padlike flange along basal margin to the left of center is the attachment surface for lateral depressor muscle); $b$, internal surface of broken right opercular plate; $c$, apical view of young specimen with marginal fringe not fully developed; note essentially ovate shape, low carinal ridge at left, and granular to slightly beaded growth ridges. Topotypes, SIO no. C-8375. 


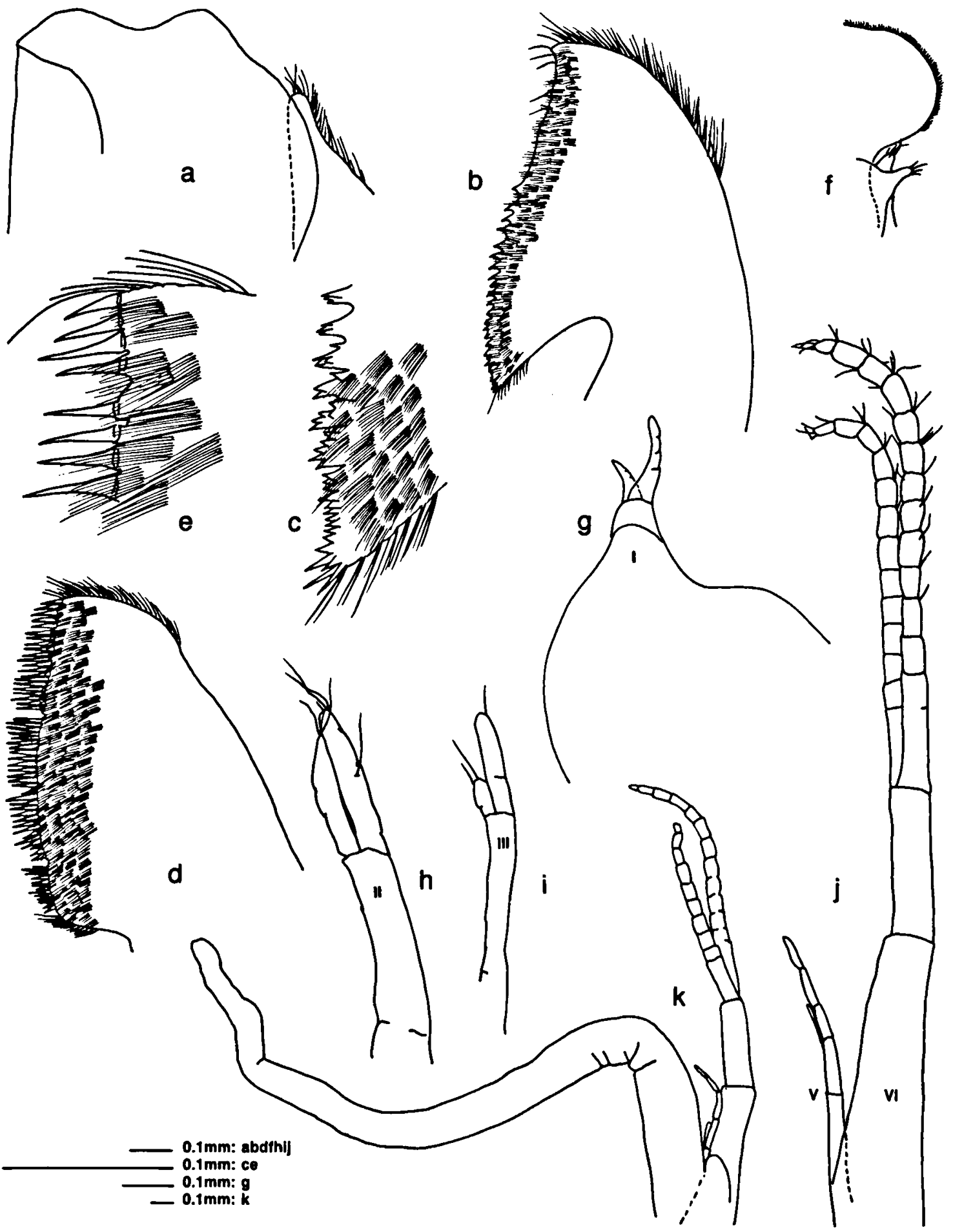

Fig. 10. Hoekia monticulariae (Gray, 1831), mouthparts and appendages: a, labrum and left palp; b, mandible; c, enlarged view of inferior angle of mandible; $d$, maxilla I; e, enlarged view of apical portion of maxilla $I ; f$, posterior portion of median languette and reduced maxillae II; g, cirrus I; h, cirrus II; i, cirrus III; $j$, cirri V and VI; $k$, cirri V, VI, and penis. 
gate or irregularly shaped, irregularly arranged but essentially in a circle.

Opercular valves thin, translucent; strongly arcuate to U-shaped in section; growth ridges slightly beaded; plates bilaterally asymmetrical, right plate longer and not as arcuate as left; rostral depressor tooth of scutal portion elevated; tooth about $1 / 4$ length of plate; tergal crest about $1 / 3$ width of rostral tooth, and about 1/5 length of plate (Fig. 9a, b).

Crest of labrum slightly sulcate, devoid of setae and teeth; anterior surface lacking ctenoid scales (Fig. 10a). Palps fused basally to lateral margins of labrum, lower than labral crest, clothed with long simple setae. Cutting edge of mandible almost straight, divisible into three parts; superior half devoid of teeth, but armed with a few slender setae; inferior half divisible into two parts, upper armed with strong, stout teeth with subsidiary cusps; inferior angle armed with more simple teeth and long, stout setae along inferior margin; leading edge of whole appendage clothed with long ctenae. Maxilla I with long, uniform, simple, equally spaced spines; lateral surface of appendage clothed with ctenae. Median languette of same size as adjoining trophi; peripheral margin with minute, slender, simple setae; posterior part of appendage protuberant (Fig. 10f). Maxilla II fused basally to languette; bilobed, with a few moderately long apical setae.

Coxopodite of protopodite of cirrus I broad, about 25 times larger than basipodite; segments of rami fused, malformed. Cirri II and III aberrant, medially situated and parallel with but partly hidden by coxopodite of cirrus I. Cirrus IV vestigial. Cirrus V reduced, distinctly biramous, rami unequal; medial to, and of same height as coxopodite of protopodite of cirrus VI. Cirrus VI not malformed, rami nearly equal in length, exopodite with 14 segments, endopodite with 13; greater curvature with a few short simple setae at articulations, lesser curvature essentially devoid of setae. Intromittent organ distinctly annulated, long, slightly more than twice length of cirrus VI; sparsely clothed with a few short, irregularly scattered setae. Basidorsal point large, evenly rounded.

Remarks. - All previous records for the occurrence of $H$. monticulariae except for the type locality are questionable (see under $A$. tanabensis).

Unconfirmed records: Annandale (1924: 67) identified $H$. monticulariae solely on the configuration of a basis in $H$. exesa, from the coast of Arracan, and another from an undisclosed locality in the Indian Ocean.

Hoekia mortenseni n. sp.

(Figs. 11, 12)

Pyrgoma monticulariae; Ross \& Newman, 1969, in part, figs. 1B, 2A-C only.

Hoekia monticulariae; Ross \& Newman, 1973, in part, fig. 18, left, only.

Material. - Three preserved specimens from Hydnophora exe$s a$, Th. Mortensen Java-South Africa Expedition, sta. 44, between Gunner's Quoin Isl. and Flat Isl., north of Mauritius, 46 m, Sigsbee trawl, tugboat "Maurice", 15 Oct. 1929; approx. $19^{\circ} 54^{\prime} \mathrm{S}, 57^{\circ} 37^{\prime} \mathrm{E}$. Holotype: Zoologisk Museum, Copenhagen, no. CRU 701; 2 paratypes, same, no. CRU 702. Two dried specimens lacking opercular plates, paratypes, Pointe au Sable (south of Port Louis), Mauritius, outer reef slope, $22 \mathrm{~m}$, July 1971, approx. $20^{\circ} 18^{\prime} \mathrm{S}, 57^{\circ} 31^{\prime} \mathrm{E}$, Gerard Faure coll., Muséum National d'Histoire Naturelle, Paris, no. CI-2354 and 2355.

Diagnosis. - Shell pink to rose; peritreme subcircular, small; carinal ridge narrow, higher than orifice.

Description. - Shell thin, partly translucent; peritreme low, conic (Fig. 11b); orifice subapical on rostral slope; carinal ridge prominent; growth ridges closely spaced, pustulose or beaded; distal margin of outer lamina thin, ascendant; marginal fringe narrow, low, slightly higher than outer lamina, only slightly wider on extremities; sheath less than 1/2 height of wall, glossy; area below sheath rough to slightly pustulose, translucent with radiating alternate light and dark rays emanating from near sheath; lacunae approximately same size, small, ovate.

Crest of labrum sulcate, lacking teeth (Fig. 12a); anterior (outer) surface densely clothed with ctenae. Palps slender; lower than crest of labrum; fused basally to lateral margins of labrum; sparsely setose, setae simple. Mandible with cutting edge straight; superior margin covered with single row of 


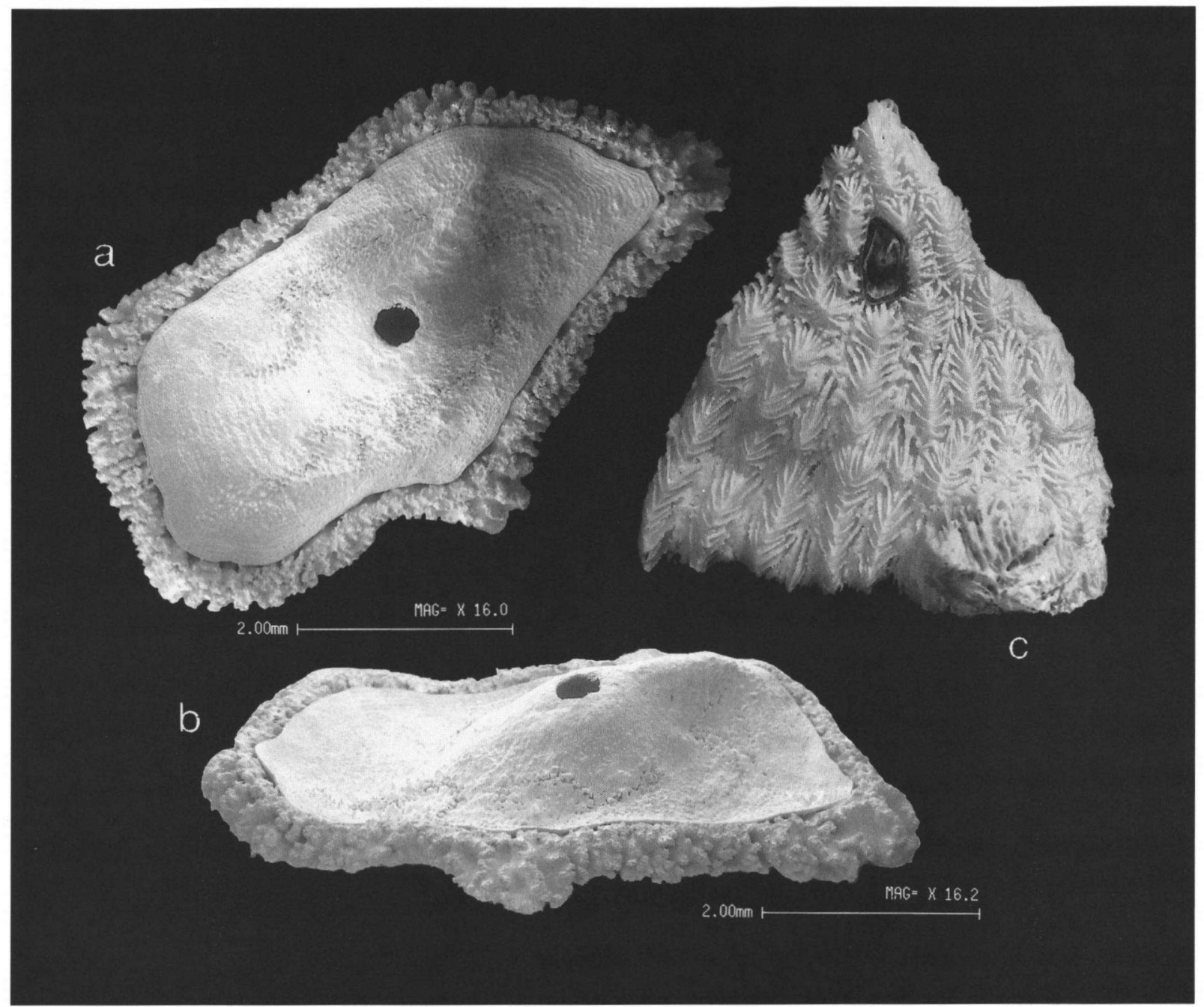

Fig. 11. Hoekia mortenseni n. sp.: a, apical view of holotype, ZM no. CRU 701, carinal end at top; b, oblique view of same; c, apical view of same, in situ on Hydnophora exesa, carinal end at top, $\times 1.85$ (image reversed).

closely spaced, simple, short setae; edge divisible into three parts; superior half devoid of teeth or setae; inferior half armed with short, multicuspid teeth; inferior angle similarly armed with multicuspid but shorter teeth; inferior margin with row of simple, stout setae. Maxilla I with straight cutting edge, armed with simple, thin, uniformly spaced spines diminishing in length basally; inner lateral face covered with ctenae. Median languette approximately of same size as adjoining trophi; periphery clothed with minute, slender, simple bristles; anterior edge slightly sulcate; posterior portion strongly protuberant (Fig. 12f). Maxilla II greatly reduced, fused basally to languette; apically clothed with short, simple setae.

Coxopodite of protopodite of Cirrus I broad, about 20 times larger than basipodite; segments of rami fused, malformed. Cirri II-IV malformed. Cirrus V questionably biramous, segments indistinguishable. Cirrus VI with rami essentially equal in length; exopodite with 13 segments, endopodite with 10; greater curvature with short simple setae at articulation, lesser curvature essentially devoid of setae. Intromittent organ annulated; sparsely covered with irregularly scattered simple setae. Basidorsal point large, evenly rounded. 


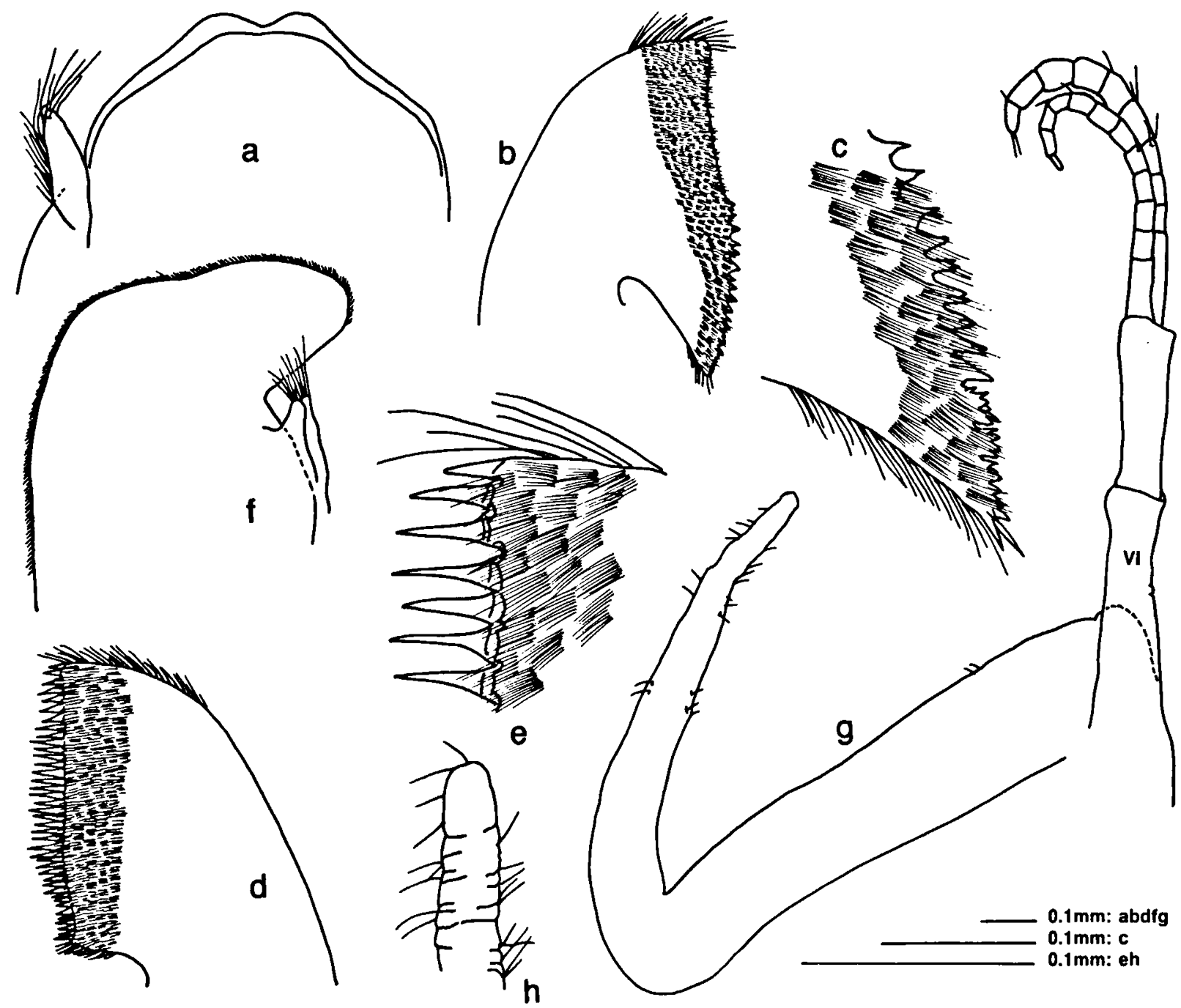

Fig. 12. Hoekia mortenseni n. sp., mouthparts and appendages: a, labrum and palp; b, mandible; c, enlarged view of inferior angle of mandible; $d$, maxilla I; e, enlarged view of apical portion of maxilla I; $f$, median languette and reduced maxillae II; $g$, cirrus VI and penis; $h$, distal end of penis.

Etymology. - We can find no more fitting tribute than to name this species for that intrepid explorer and renowned zoologist, the late Dr. Th. Mortensen of Denmark, who collected the present specimens.

\section{Ahoekia n. gen.}

Definition. - Shell thick, massive in appearance; peritreme small to minute; orifice subapical; carinal ridge low, broad; distal margin of outer lamina ascendent, high; marginal fringe thick, complexly deliquescent, as high as or higher than orifice; lacunae of inner wall separate to confluent, ovate to elongate, irregularly arranged on inner wall, commonly laterally concentrated; lacunae connected directly to circumferential channel.

Type species: Ahoekia tanabensis n. sp.

Etymology. - Derived from the Greek, an-, a negative prefix meaning not, and -Hoekia. 
Ahoekia tanabensis n. sp.

(Fig. 13)

Pyrgoma monticulariae; Hiro, 1935: 18, fig. 11; Hiro, 1938: 405.

Material. - Four dried specimens lacking opercular plates from Hydnophora? exesa, Tanabe Bay, Honshu Isl., Japan, H. Utinomi leg., approx. $33^{\circ} 43^{\prime} \mathrm{N}, 135^{\circ} 22^{\prime} \mathrm{E}$. Holotype: USNM no. 259982; 1 paratype, same, no. 259983; 2 paratypes, Scripps Institution of Oceanography, no. C-7980; 5 paratypes, Seto Marine Biological Laboratory, no. 383, date and collector unknown, on $H$. bonsai.

Diagnosis. - Shell rose to pink violaceous, opaque; peritreme relatively small; carinal ridge low, broad; periphery of marginal fringe openly perforate, with pronounced gap between it and outer lamina.

Description. - Shell dull, opaque, massive; orifice ovate, subapical on rostral slope; ratio of rostrocarinal diameter to orifice approximately $25: 1$; carinal ridge broad, short; distal edge of outer lamina ascendent, high; marginal fringe narrow to wide, greatest width at extremities; outer lamina and marginal fringe separated by distinct gap; ancillary openings in periphery of marginal fringe lead to lacunae on inner wall; internal surface roughened or wrinkled; sheath less than 1/2 height of wall, glossy; lacunae irregularly arranged, irregularly shaped, of different sizes.

Remarks. - The four dried shells from Tanabe Bay, Japan were originally identified and labelled as Pyrgoma monticulariae by the late Huzio Utinomi (= Fujio Hiro; see Newman, 1981). Hiro (1935: fig. 11) illustrated two different specimens purportedly of this species from Tanabe Bay. He omitted mentioning lacunae on the internal wall, although he illustrated them in the right but not left specimen. However, the external view of the opercular plate he illustrated is distinctly different from that figured by Darwin (1854: pl. 13, fig. 5F; reproduced by Ross \& Newman, 1973: fig. 19, top). In his 1937 report on the barnacles in the vicinity of the Seto Marine Biological Laboratory no mention is made of $H$. monticulariae. But, in his 1938 study of the pyrgomatids of Palau he discussed the host specificity of $H$. monticulariae, which was not known there. Therefore, his remarks (Hiro, 1938:
405) likely relate to observations on the Tanabe Bay form, which we consider a new species, Ahoekia tanabensis.

Several specimens of this species were discovered recently in a display case in the Seto Marine Biological Laboratory, Japan, on several corals from the same region as the types (Harada, pers. comm., 1995). Based on Harada's photographs, the corals were identified by Veron (pers. comm., 1995) as $H$. bonsai Veron, 1990. In Japan, $H$. exesa occurs sympatrically with $H$. bonsai (Nishihira \& Veron, 1995), but whether this or another hoekiine occurs on the former is presently equivocal.

Etymology. - The Latin suffix, -ensis, denotes locality, in reference to Tanabe Bay where this species occurs.

Ahoekia chuangi n. sp.

(Fig. 14)

Material. - Three dried specimens from Hydnophora rigida (Dana, 1846) “'Eiland Onrust-oost, Noordelijk deel”, Bay of Batavia, Java Sea, Indonesia, J. Verwey coll., 28 Mar. 1931, approx. $6^{\circ} 08^{\prime} \mathrm{S}, 106^{\circ} 45^{\prime} \mathrm{E}$. Holotype: Nationaal Natuurhistorisch Museum, Leiden, no. C-2542; 2 paratypes, same, no. C-2542 (P1, P2).

Diagnosis. - Shell white, translucent; peritreme small; carinal ridge low, narrow; periphery of marginal fringe compact, apparently poorly perforate, with indistinct gap between outer and inner lamina.

Description. - Shell vitreous, translucent, thick, massive (Fig. 14b); peritreme only slightly elevated, orifice ovate, subapical on rostral slope; ratio of rostro-carinal diameter to orifice approximately 18:1; carinal ridge narrow; growth ridges not visible due to coral overgrowth; distal edge of outer lamina ascendant, high; marginal fringe narrow to wide, decidedly wider at extremities; outer lamina and marginal fringe not separated by distinct gap; sheath about $1 / 2$ height of wall, semi-glossy, with translucent radial lines; inner wall opaque to chalky, roughened, irregular; lacunae irregular, ovate to elongate, irregularly arranged (Fig. 14c).

Etymology. - Named in honor of Prof. S.H. Chuang, National University of Singapore, who kindly 
brought us preserved specimens of $\boldsymbol{H}$. monticulariae on Hydnophora exesa that he collected. These formed the basis for our anatomical work.

\section{Structure of the wall and basis}

The general development of the balanid shell was described by Darwin (1854), Costlow (1956), Newman et al. (1967), Ross \& Newman (1967), Newman \& Ross (1976) and Bourget (1977), and the crystalline microstructure by Newman et al. (1967), Newman \& Ross (1971), and Bourget $(1977,1987)$. Externally, the surface of the shell is covered completely by a thin cuticle, the epicuticle. Where the opercular plates are suspended in the orifice of the shell, the cuticle is uncalcified and coriaceous, and is termed the arthrodial membrane. Internally, the entire shell is lined by the hypodermis which secretes the calcareous layers as well as the cuticle exposed to the exterior, including that of the body and appendages as well as that of the uncalcified portion of the basis.

Ross \& Nefwan (1973: 139) reviewed what was known about the growth pattern of the pyrgomatid shell, from the time of settlement to the early adult stage. The following discussion covers how the Hoekiini depart from it.

The shell shape in Hoekiini is conical in early ontogeny, with the orifice opening apically or on the rostral slope. All of the specimens have a concrescent wall with no indication of the line of juncture between individual wall plates, but the earliest ontogenetic stages were not available.

External ornamentation is limited to granular or beaded growth ridges, and where the ridges are obscure the surface remains granular or beaded. Each bead represents the site of a seta that originates internally (Fig. 15a, b) and traverses the wall (Bocquet-Védrine, 1966: 339; Newman \& Ross, 1971: 146; Bourget, 1977: 293; Clare et al., 1994: 30). The holes through which the setae grow range in diameter from 2.73 to $3.09 \mu \mathrm{m}$, and may be seen under high magnification (Fig. 15c).

The circumference of the wall in most balanomorphs approximates an oval or circle, and this shape is essentially characteristic for each species (Spivey, 1988: 279). There are variations, but in good measure these arise from irregularities in the substratum and crowding by adjoining individuals. In Hoekiini, due to the arrangement of the hydnons of the host, there is no fixed form to the circumference (Figs. 4a, 8a, 13a). Their outline is best described as protean, and this sets them apart from all known balanomorphs. The only constant features of the adult wall are the presence of a raised peritremal area, minute aperture, and the hypertrophied lateral margin.

In some pyrgomatids, and in most sessile barnacles, the conical wall has an apical and basal designation. However, in Hoekiini, as in many pyrgomatids, the basal portion of the wall comes to lie essentially in a horizontal plane (Figs. 11b, 14b). Therefore, the basal margin in such forms is referred to herein as the lateral margin.

In most balanomorphs the wall consists of an inner and outer lamina often separated by tubes and related structures (Darwin, 1854; Costlow, 1956; Newman et al., 1967; Newman \& Ross, 1971, 1976). In Hoekiini, the shell in cross section is reminiscent of the Greek letter Omega (Fig. 1a). The outer (upper) lamina of the wall in Hoekiini does not extend laterally as far as the inner (lower) lamina (Figs. 1a, 4a). The distal edge of the outer lamina is thin and comes to lie in essentially a horizontal plane, or it may turn upward and reflex, or even become ascendant (Fig. 14b), to degrees varying with each group. The lateral margin may be of such height as to exceed the height of the peritreme and/or the orifice.

The inner lamina in plan view, is usually widest at the extremities of the shell (Fig. 6a). In some species it is narrow and turns upward to almost the same height as the outer lamina, but in others it is significantly higher. A unique feature of the inner laminae is the deliquescent periphery. This deli-

Fig. 13. Ahoekia tanabensis n. sp.: a, apical view of holotype, USNM no. 259982, carinal end at right; b, oblique view of same, carinal end at left; c, internal view of paratype, USNM no. 259983, carinal end at bottom; note lateral arrangement of lacunae; d, enlarged view of right extremity of specimen shown in a, showing opening of ancillary connection from periphery of fringe to circumferential channel. 


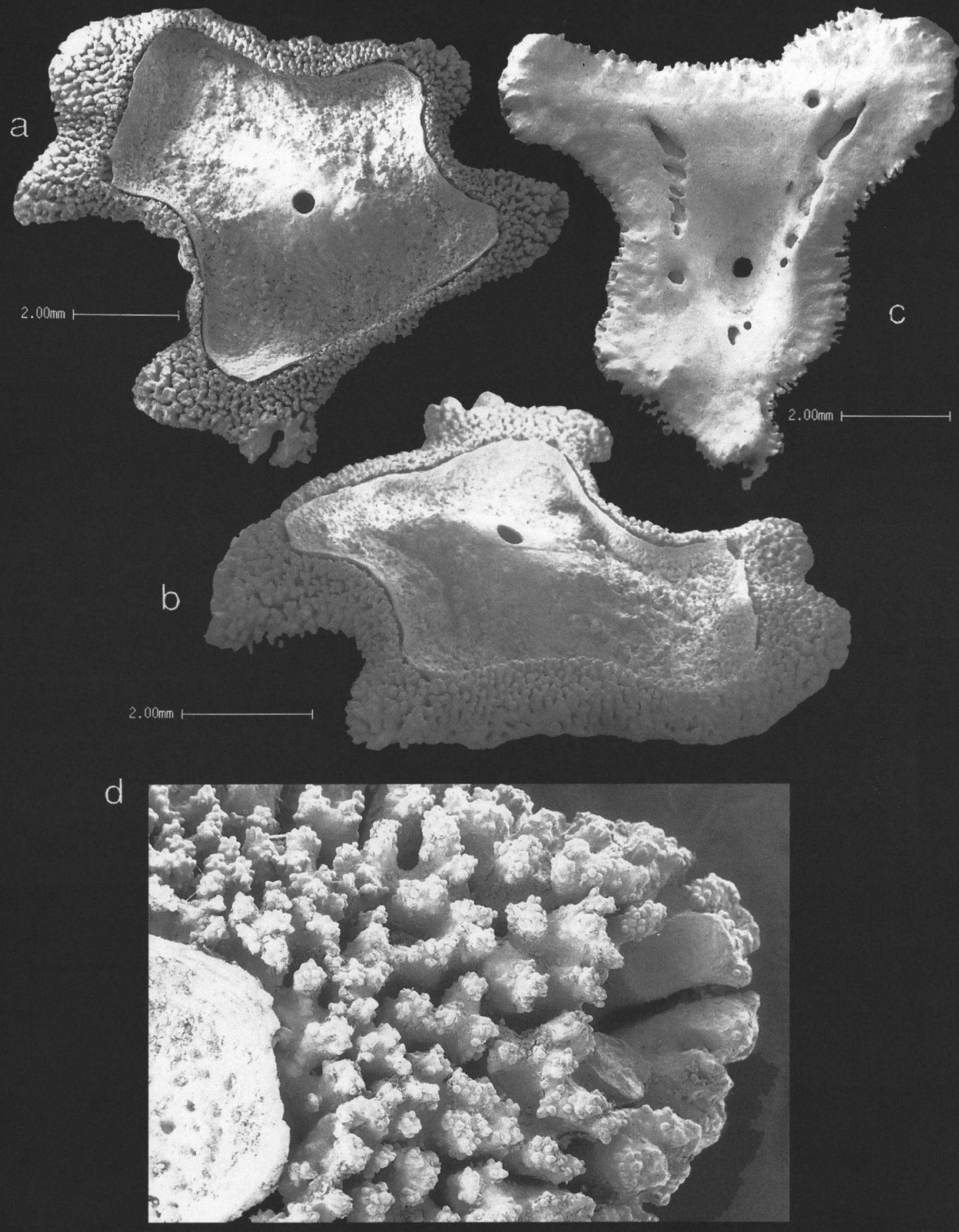

$500 \mu \mathrm{m}$ 
Table II. Measurements of the shell, orifice and opercular plates of the type and figured specimens of Hoekiini. Abbreviations: RCD, rostral-carinal diameter; LD, lateral diameter; RCOL, rostro-carinal diameter of outer lamina; L, length; H, height; ?, unknown or not determined. All measurements in $\mathrm{mm}$.

\begin{tabular}{llll}
\hline Species & $\begin{array}{l}\text { Shell } \\
\text { RCD-LD-RCOL }\end{array}$ & $\begin{array}{l}\text { Orifice } \\
\text { RCD-LD }\end{array}$ & $\begin{array}{l}\text { Opercular plates } \\
\text { L-H }\end{array}$ \\
\hline $\begin{array}{l}\text { Eohoekia } \\
\text { chaos holotype; Fig. 4a }\end{array}$ & & & \\
chaos paratype; Fig. 4b & $6.0-7.0-3.4$ & $0.3-0.3$ & $1.3-0.3$ \\
nyx holotype; Fig. 5 & $5.8-5.0-3.7$ & $0.3-0.25$ & $?$ \\
nyx paratype; Fig. 16 & $6.4-5.1-4.0$ & $0.4-0.3$ & $1.4-0.3$ \\
Parahoekia & 4 ?-3.0 & $0.4-0.3$ & $1.25-0.4$ \\
aster holotype; Fig. 6 & & & \\
aster paratype & $4.5-3.8-3.2$ & $0.35-0.25$ & $1.3-0.3$ \\
Hoekia & $4.4-3.9-3.1$ & $0.35-0.30$ & $1.4-0.4$ \\
fornix holotype; Fig. 8 & & & $?$ \\
monticulariae & $7.3-5.7-5.5$ & $0.4-0.4$ & $1.7-1.2$ \\
monticulariae; Fig. 9 & $7.5-5.3-6.2$ & $0.4-0.3$ & $?$ \\
monticulariae; Fig. 18a & $5.8-3.4-5.1$ & $0.35-0.3$ & $?$ \\
monticulariae; Fig. 19 & $9.1-8.2-?$ & $0.5-0.4$ & $?$ \\
mortenseni holotype; Fig. 11a & $4.8-3.4-?$ & $0.25-0.22$ & $?$ \\
mortenseni paratype & $6.8-4.0-5.7$ & $0.4-0.4$ & $?$ \\
mortenseni paratype & $6.1-6.1-5.7$ & $0.4-0.3$ & $1.0-0.3$ \\
Ahoekia & $5.1-3.5-4.2$ & $0.35-0.2$ & $?$ \\
tanabensis holotype; Fig. 13a & & & $?$ \\
tanabensis paratype; Fig. 13c & $10.1-9.0-7.5$ & $0.4-0.3$ & $?$ \\
chuangi holotype; Fig. 14a & $8.6-7.8-8.1$ & $0.4-0.35$ & $1.3-0.35$ \\
chuangi paratype; Fig. 14c & $8.9-9.0-6.3$ & $0.5-0.4$ & \\
\hline
\end{tabular}

quescence is verrucose to papillose, and in those species where it is translucent it is reminiscent of a thick sheet of icicles.

The minute size of the orifice relative to the size of the shell is unparalleled in other balanomorphs. Rostro-carinal diameters of the orifice range from 0.2 to $0.5 \mathrm{~mm}$ and widths from 0.2 to $0.4 \mathrm{~mm}$ (Table II). This would seemingly pose limitations to normal biological activities owing to the otherwise essentially normal size of the body. In the absence of a functional cirral net, the presence of a minute orifice is due largely to a wholly unique method of feeding unknown in other balanomorphs (see the sections Cirri, and Feeding and nutrition).

Aperture enlargement is not uncommon in intertidal balanomorphs. In balanids it is due largely to diametric growth, whereas in tetraclitids that have fused compartments it is due mainly to abrasion by water-borne particles and corrosion (Darwin, 1854: 324). Obviously, the only way to enlarge the orifice in barnacles that have a concrescent shell, is through abrasion and/or corrosion. In most Hoekiini the aperture is neatly "worn" so that the wall of the orifice is perpendicular to the adjoining shell surface (Fig. 14a). Orifice size evidently increases as needed, but how might this be accomplished? Neither the appendages nor the trophi appear capable of being rotated $180^{\circ}$, and hence they are incapable of abrading the orifice. The likely explanation is chemical corrosion by the opercular membrane (tergo-scutal flaps), but no significant membrane or frill was evident in the preserved materials available.

The basis in balanomorphs is attached to the sub-

Fig. 14. Ahoekia chuangi n. sp.: a, apical view of holotype, NNM no. C-2542, carinal end at upper right, note perpendicular edge of orifice appears uniformly worn; b, oblique view of same, carinal end at left; $c$, internal view of paratype, NNM no. C-2542 (P1), carinal end at left, note incompletely formed lacunal opening and the channel toward the lower right. 


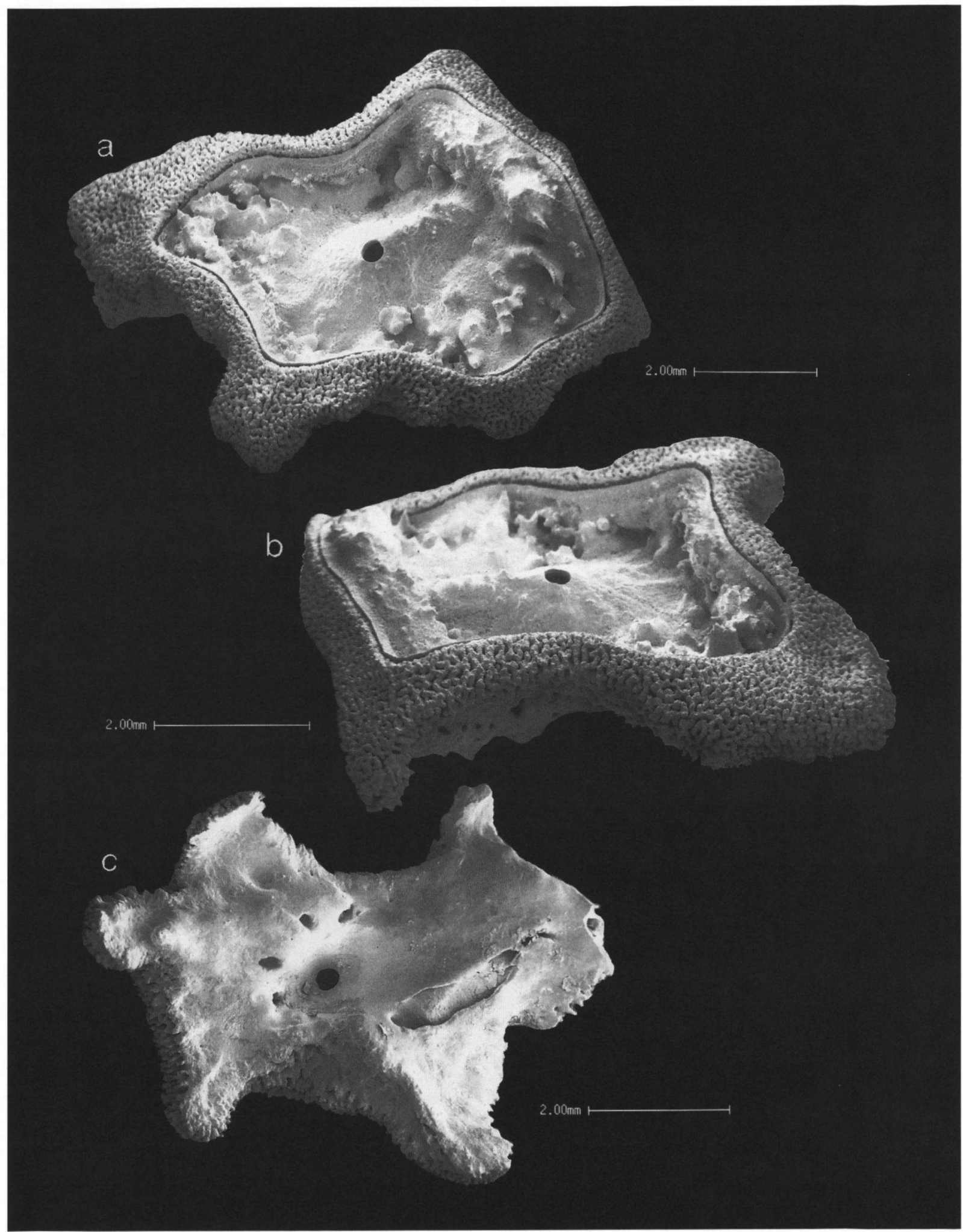




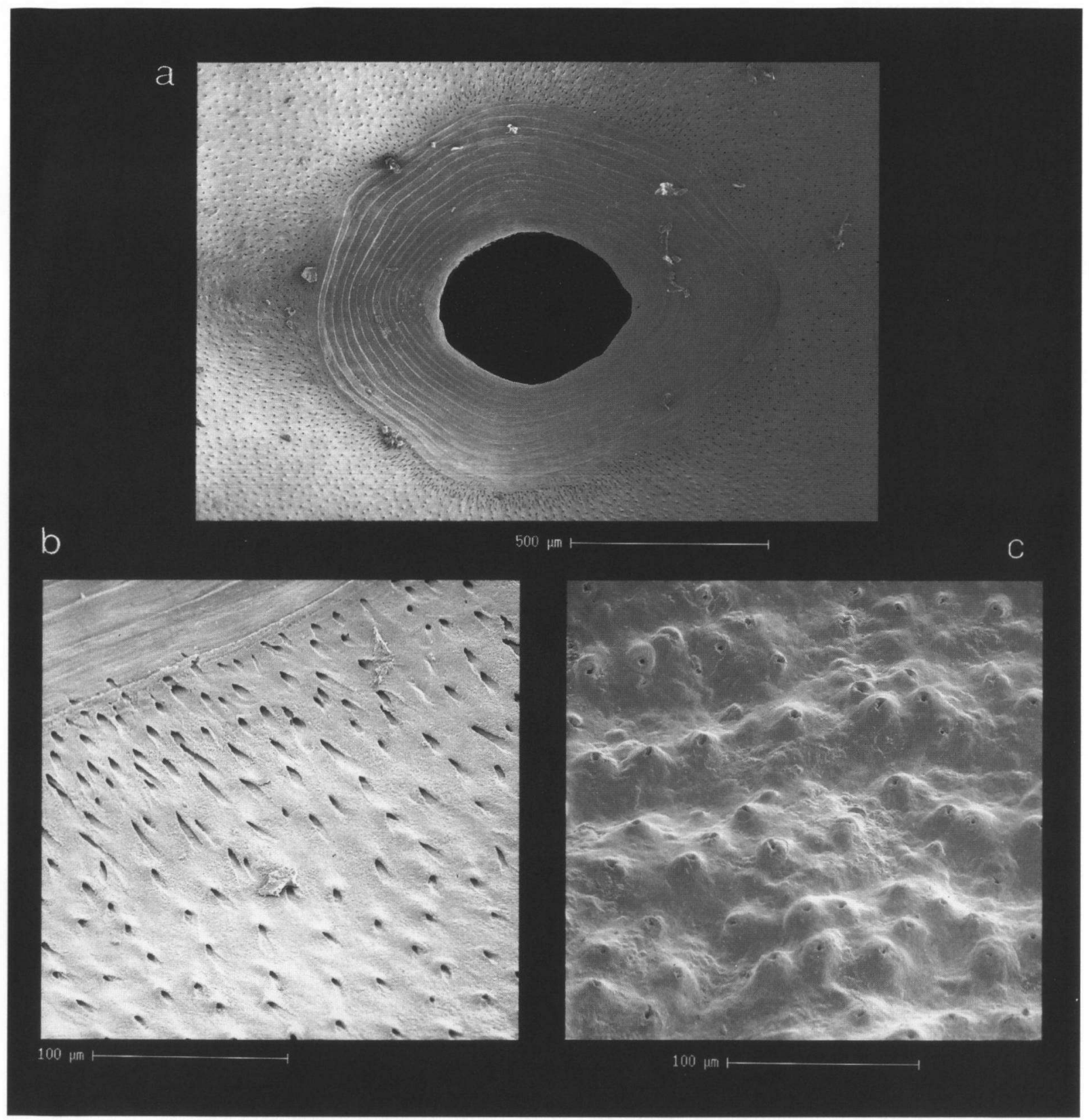

Fig. 15. Hoekia monticulariae (Gray, 1831): a, enlarged view of adpressed sheath surrounded by pores for setae that traverse the wall; b, enlarged view of sheath, upper left corner, and pores; c, enlarged view of outer lamina showing external pores for setae that traverse the wall; pores range from 2.73 to $3.09 \mu \mathrm{m}$ in diameter. Topotype, SIO no. C-8375.

stratum by secretions from the cement glands. Growth occurs in a narrow zone at the edge of the basis and the lower lateral margin of the wall. In those forms in which the wall plates are separate, growth may also occur along the sutures between the plates.

Utinomi (1943: 19) noted that the basis in the earliest stages of pyrgomatids is wholly mem- 
branous and persists until the rostro-carinal diameter of the shell is nearly $1 \mathrm{~mm}$, which is generally the case in balanomorphs having a calcareous basis. Among the pyrgomatines, only Pyrgopsella Zullo, 1967 , in addition to an incompletely calcified wall, retains a wholly membranous basis throughout life evidently as an adaptation to living in calcareous sponges. Following cementation and calcification of the basis to the skeleton of the coral, lateral growth of the shell and basis proceeds rapidly "... so that the shell reaches essentially maximum diameter early in life"' (Ross \& Newman, 1973: 139). This effectively establishes the area that the barnacle will occupy on the coral until overgrown. Subsequent growth, to accommodate the body, ovarian and mantle tissue, is largely accomplished by lengthening the basis. This phenomenon was illustrated by Hiro (1938: 409), and is readily seen in fossils that have been leached from corals (Newman \& Ladd, 1974: pl. 2, fig. H). We subscribe to the observation of Baluk \& Radwanski (1967: 488) that growth of the basis is largely synchronous with that of the host skeleton, but with some exceptions (Newman et al., 1976: 69; Ross \& Newman, 1973: 140). The coral will eventually overgrow the barnacle, and not infrequently with the opercular plates cemented in life position by the coral.

Lateral growth of the basis, and concomitantly the wall in Hoekiini, is determined by the configuration of the coral's hydnons. Most subsequent growth is by additions to the distal margin of the basis, in keeping pace with the growth of the host.

Shell profile in pyrgomatines is conical to essentially flat. When flat, the lateral margin parallels the vertical surface of the basis. Thus, the peripheral outline is a reversed image of the outline of the basis. Although the basis may continue to grow slightly wider after the initial period of rapid lateral expansion, it and lateral growth of the shell wall are essentially determinate. On the other hand, vertical growth of the basis is virtually indeterminate.

The unusual aspect of the basis in Hoekiini is that not only is the circumference irregular in outline, relative to the configuration of the surrounding hydnons, but above the calcareous portion there is a membranous zone. Calcium deposition apparent- ly lags behind growth, and thus a membranous portion of the basis is continuous with that of the lateral and superior margins of the hypertrophied inner lamina. Consequently, this membranous covering of the wall broadly contacts coral tissue rather than the calcareous basis.

The bottom of the basis has a higher opacity, and is more than twice as thick as its vertical walls. There are mammillated deposits at the bottom of the basis that are unknown in other pyrgomatines.

As noted above, the peripheral margin of the wall is filled with tissue covered by a cuticle that is in contact with coral tissue rather than the calcareous basis of the barnacle or the surrounding calcareous skeleton of the coral. By applying light pressure to alcohol-preserved specimens the shell can be "wiggled" both vertically as well as horizontally, as is undoubtably the case for living animals. In effect, the shell wall and surrounding portion of the basis are "floating" in soft coral tissue, and this is unique among the pyrgomatids.

From the foregoing it is apparent that the barnacle is effectively a cyst surrounded by coral skeleton, except for the marginal fringe and the exterior surface of the wall which is surrounded by coral tissue. A plausible explanation of why the top portion of the basis is membranous and the shell does not rigidly interlock with it, as in other pyrgomatines, is that there is metabolic activity between the barnacle and host coral tissues. This activity could be simply that which keeps coral skeleton from overgrowing the barnacle, but considering the extent of the area, and that it is highly vascularized, it could serve as a pathway for the exchange of nutrients.

\section{Shell development}

In Hoekia, as with pyrgomatids in general, the wall is solid, but it is apically thickened by the sheath, a secondarily deposited innermost layer (Ross \& Newman, 1973: 143; Bourget, 1977: 289). In primitive Pyrgomatini, such as Cantellius Ross \& Newman, 1973, the basal margin of the sheath is not attached to the wall, and is said to depend freely (Newman \& Ross, 1976: 27). An extension of the 
sheath forms an inner wall or lamina that develops parallel to, and is fundamentally shorter than, the outer wall or lamina. Although it is called an inner lamina in higher pyrgomatids, it is not homologous with that of higher balanids (Costlow, 1956: 370; Ross \& Newman, 1973: 143). In pyrgomatines having a tubiferous wall, the wall and sheath are separated by vertical partitions (ribs) to form one or more rows of tubes.

In the ontogeny of Hoekiini, the inner lamina begins simply as an adpressed sheath, but quickly develops a dependent lower margin as indicated by the position of the proximal portion of the abandoned carinal sinus (see below). The lower margin of the dependent sheath becomes weakly cemented or fused, by radial ribs or bridges (Fig. 16), to the outer lamina. As growth progresses, the basal margins of both laminae come to lie in essentially a horizontal plane, after which growth of the outer lamina slows relative to the inner. When beyond the outer lamina, the lateral margin of the inner lamina hypertrophies to form the marginal fringe which, in $H$. monticulariae according to Darwin (1854: 373), resembles a "mass of moss".

Between the outer and inner laminae, before development of the marginal fringe, an intervening but minor and temporary lamina develops, the basal edge of which is lobate. At the carinal end, below the basal edge of the outer lamina, one lobe of this minor lamina forms a complex tongue-like extension that keeps pace with the growth of the outer lamina before coalescing with the wall (Fig. 16). In doing so, it becomes the floor for the carinal sinus, an abandoned channel, which may fill with calcareous material to varying degrees.

The space between the inner lamina and the growing edge of the outer lamina forms a peripheral circumferential channel, which we infer provides space for the inferior ( = basal) circumferential vessel found in balanomorphs (Burnett, 1977: 301). The circumferential channel moves laterally with lateral growth of the outer lamina, and in doing so much of the tissue between the laminae withdraws and the vacated channels may become partly or wholly filled.

At an early stage, before the inner lamina begins to extend beyond the outer lamina and, concomi- tantly, beyond the circumferential channel, the margin of the inner lamina begins to digitate. The spaces between the digitations form passages radiating from the inner surface through the inner lamina to the circumferential channel. In morphologically simple forms, such as Eohoekia, the digitations deliquesce as they extend peripherally. In some cases, elements between radiating deliquescences coalesce to form a filigree (Fig. 4b) channelizing the passages to the circumferential channel, and to the outer surface of the marginal fringe as it expands, but the openings in this filigree may fill secondarily.

Parahoekia is similar to Eohoekia in the development of the marginal fringe, but there are several differences. The elements of the fringe are thicker, narrower and not reflexed (cf. Figs. $4 \mathrm{c}$ and $6 \mathrm{c}$ ). At the digitations or extremities, adjacent elements either touch or coalesce to form one or two terminal apico-basal foramina. Internally, at the extremities, there is a shallow sulcus that deepens as it leads to the base of these foramina. The sulcus may be obscure on some extremities, but obvious on others.

In Eohoekia and Parahoekia growth of the outer lamina and marginal fringe of the inner lamina is accomplished by the hypodermis that extends from within the shell up and between the comb-like teeth and foramina of the inner lamina. The irregular upper surface of the inner lamina, broken into ridges and valleys, provides space for thin threads or sheets of tissue contacting those marginal surfaces abutting against coral tissue.

In morphologically more complex forms, such as Hoekia and Ahoekia, the undersides of the radiating deliquescences close off as they grow laterally. In so doing, they leave behind lacunae that lead to radial channels that connect with the circumferential channel and its tributaries from the marginal fringe. The fringe is thick and massive and embodies the lacuno-circumferential channel. We infer that this elaboration of the marginal fringe and the included lacuno-circumferential portion of the circulatory system allows for a substantial increase in the area of contact between tissue of the barnacle and that of the host in which it is suspended (see Figs. 1a-e). 


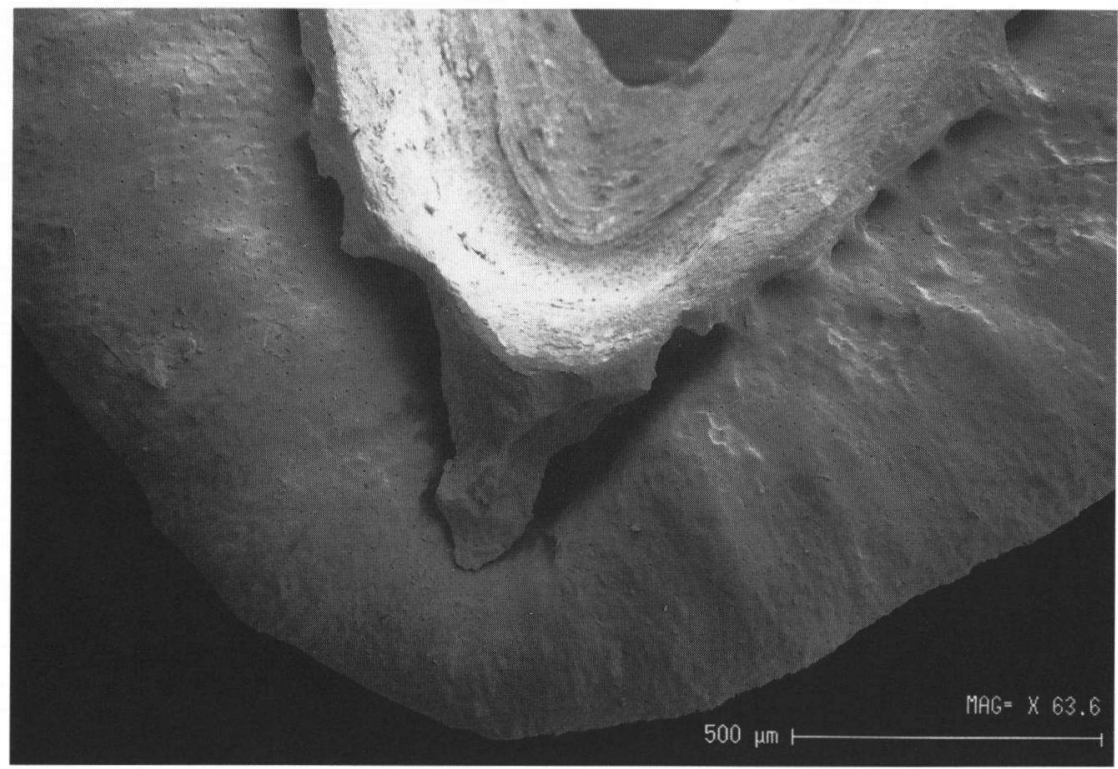

Fig. 16. Eohoekia nyx n. sp.: internal view of paratype, USNM no. 259981, carinal end of shell and basal edge of inner lamina with tongue-like extension that forms the floor of the carinal sinus; to the right bridge-like structures unite the inner and outer lamina; the adpressed sheath is visible at top.

\section{Peripheral shell shapes}

All of the specimens of $E$. chaos available are apparently of the same age class because of comparable size. The outer lamina is primarily ovate in outline, but the marginal fringe varies in shape. The fringe is strongly reflexed further suggesting maturity. Shell shape in early juveniles, of which we have seen only one specimen $(E . n y x)$ approximates that of other pyrgomatids; a conical wall with a circular to ovate outline (Hiro, 1938: 409; Moyse, 1971: 135). The Hoekiini take on protean shapes as they grow, but they retain part of this primitive condition throughout life in the form of the peritreme. Their growth is constrained by the arrangement and growth of coral hydnons. Bourget \& Crisp (1975a: 245) note that in ordinary barnacles there must be some mechanism controlling the rate at which individual parietal plates grow when hindered or unhindered by obstacles, but what the mechanism is has not been determined.

The wall of Parahoekia is much like that of Eo- hoekia in being conical and ovate, but the overall outline is stellate (Fig. 6a). In this case settlement probably occurred between essentially equally spaced hydnons. Subsequent growth of the marginal fringe appears to be uniform in all directions. Based on our limited observations of Hydnophora microconos, we infer that any other species found on this coral will have a stellate outline similar to that of $\boldsymbol{P}$. aster.

Hoekia exhibits the most variable shell pattern, but all three species develop a marginal fringe that parallels and remains close to the outer lamina except at the digitations. In $H$. monticulariae the shell assumes a more digitiform outline than in $H$. mortenseni, which tends to be trapezoidal (Fig. 11c).

The shell in Ahoekia is much like that of Hoekia. However, it is more trapezoidal, and does not assume the protean outline characteristic of the latter. The shape suggests that whereas the two species of Ahoekia may be limited in their ability to grow laterally, they have essentially unlimited vertical growth. 

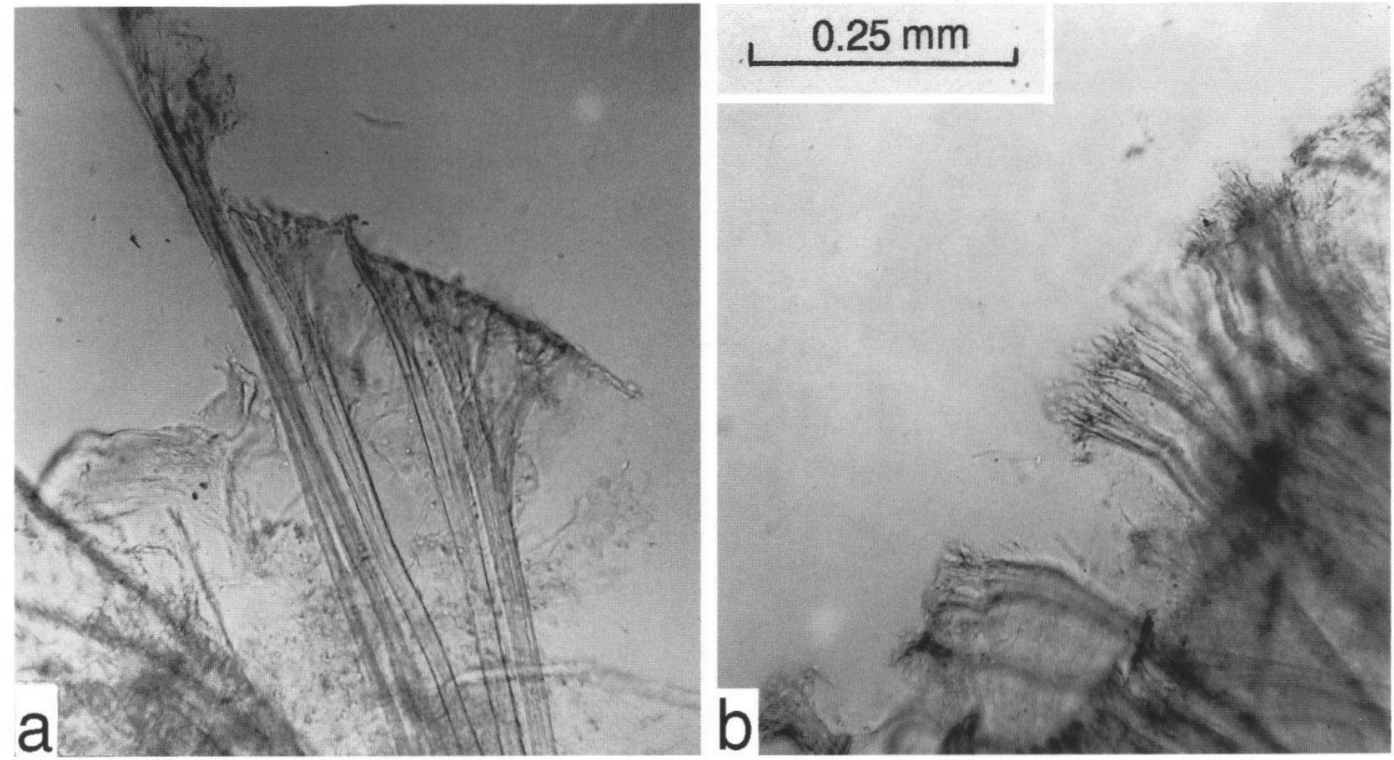

Fig. 17. Hoekia monticulariae (Gray, 1831): a, fixation fibers with anastomoses attached to membrane; b, fixation fibers removed from wall of shell; note disc-like surfaces at termination of fibers that enhance attachment to wall. Topotype, SIO no. C-8375.

\section{Wall-basis interface}

Observations on the interface between the wall and basis are limited because of the paucity of preserved material available. However, by applying light pressure to the shell of an alcohol-preserved specimen, it can be "wiggled", as noted earlier. This is puzzling when one considers that the wall of all other pyrgomatids, except for the Pyrgopsellini, mechanically interlock with the basis. In Hoekiini, the lower portion of the basis is calcareous, whereas the upper is membranous. This membrane is white, flexible, tough, but relatively thin. The distal margin of the membrane passes up and over the marginal fringe to attach around the outer margin of the outer lamina and helps hold the wall in place (Fig. 3). However, the wall is also connected to the calcareous basis by fixation fibers, as described below.

If the wall is pulled free from the coral, the opercular plates and commonly the body remain attached to it, whereas the lining of the membranous basis, the accompanying tissue and sometimes the body remain with the coral. The separation generally occurs along a horizontal plane where the wall is attached to the fixation fibers (Fig. 17) which originate beneath the basal margin of the inner lamina and insert on the calcareous portion of the basis.

Gutmann (1960: 13) first discovered "Fixierungsfasern", or fixation fibers, in Semibalanus balanoides (Linnaeus, 1766), which anchor the wall to the basis, as they also do in Elminius modestus Darwin, 1854 (cf. Bubel, 1975: 288). Bourget \& Crisp (1975b: 457) suggested that the fixation fibers "... allow the parietes limited movement relative to the base". Each fiber consists of a long fine tendon, a short section of striated muscle, and a shorter basal tendon. The fibers, which are remarkedly robust in $\boldsymbol{H}$. monticulariae, lack the short striated muscle section and, therefore, presumably do not contract. At the origins and insertions they anastomose, which provides a broad area of attachment (Fig. 17). When the wall is pulled free, the fibers generally remain attached to the basis rather than to the wall.

\section{Coral overgrowths}

All pyrgomatids, except for the sponge-dwelling Pyrgopsella, live on stony corals and are subject to overgrowth by the host coral. There are two types 
of overgrowth, coenenchymal or calcareous. The cover of coenenchyme keeps the barnacle shell "... clean and free from epizoic growths" (Moyse, 1971: 137), and it also tends to make the barnacle less conspicuous. This blanket of tissue extends to the margin of the orifice, and Anderson (1992: 305) hypothesized that it is kept from overgrowing the orifice by modified tergo-scutal flaps, the "apertural frill", which he stated is unique to pyrgomatids. The frill itself may be the site of inhibitory secretions, although in some species, e.g., Pyrgoma elongatum Hiro, 1931, Wanella milleporum (Darwin, 1854), and Pyrgoma cancellata (Leach, 1818), there are large subopercular glands that may be the secretory source (Anderson, 1992: 337). A frill as such probably does not exist in Hoekia because the orifice and underlining aperture are completely overgrown by coral tissue, and we failed to detect subopercular glands in the specimens of Hoekia and Parahoekia that we examined.

In many pyrgomatids the shell is partly or almost wholly covered by coral skeleton. These overgrowths extend from the coral on to the shell proper. But they are either broken at the wall/basis interface or contiguous growth at this junction is inhibited by the barnacle, as it is around the aperture (Moyse, 1971: 139; Ross \& Newman, 1973: 139; Anderson, 1992: 292). In the sulcus between the peritreme and ascendent margins of the shell, both $A$. tanabensis and $A$. chuangi have crustose overgrowths which extend on to the lower portion of the peritreme. The overgrowth of $A$. tanabensis is white, opaque, and compactly nodular or verrucose. On A. chuangi it is semitranslucent and more crystalline in appearance. These overgrowths are not suggestive of normal coral sclerosepta. On one specimen of $H$. mortenseni the shell is partly covered by a coral hydnon, and the balance of the outer lamina covered completely by drusy calcite.

Hydnophora differs from most scleractinians in that the mouths occur in the "valley" between hydnons, and the tentacles encircle hydnons rather than mouths. The shell morphologies of the Hoekiini and the coral tissue overgrowing them are suggestive of these tuberosities. Although it appears that the barnacle/coral mimics a hydnon because the tentacles encircle the barnacle, the combination approximates a classic text-book scleractinian polyp. This "polyp", or pseudopolyp, includes two layers of tissue separated by radial mesenteries or septa that extend from the periphery of the shell almost to the aperture, and covering the lateral margin of the shell there are one or two whorls of en echelon tentacles (Fig. 3). In the preserved materials available no oral disc, mouth or pharynx, situated over the aperture of the barnacle, were observed. If a mouth were present, it is possible that the coral's food is going directly to the barnacle, as well as the barnacle acquiring food indirectly by eating coral tissue (Ross \& Newman, 1969: 255).

\section{Opercular plates}

Closure of the orifice by paired opercular plates, formed by the articulated scuta and terga, characterizes most balanomorphs. The opercular plates are attached to the sheath by a flexible arthrodial membrane. The sheath may or may not form a distinct structural strengthening element of the wall (Newman \& Ross, 1971: 146; Bourget, 1977: 289; 1987: 275). Commonly, a narrow band of this membrane is exposed to the environment in intertidal forms. Because of the size of the orifice in Hoekiini, only the limbus occludens (see Fig. 2) of each opercular plate occludes the orifice and, therefore, the opercular membrane is completely concealed.

Although we have not seen opercular plates for all Hoekiini, the ones examined differ in relative proportions, flexure, symmetry and other details. They are thin, translucent, and exceedingly fragile. All are compound or concrescent plates that lack a distinct juncture between the scutum and tergum. The plates are wider than high with the scutal longer than the tergal portion. External ornamentation consists of closely spaced simple or slightly beaded growth ridges (Fig. 9a) covered with a hirsute cuticular membrane. The cuticle covering the plates is dense and darkly pigmented in Parahoekia, but not in those species of Hoekia that we examined.

In most balanomorphs growth increments to the opercular plates are added at the basal margins (Darwin, 1854: 54). Each increment increases the 
thickness of the plate as well as its height and width. There is rarely any addition to the occludent margins.

When discussing opercular morphology and growth in some pyrgomatids, Darwin (1854: 54) introduced the term limbus occludens (= occludent ledge or edge; Hiro 1938: 403; Soong \& Chang, 1983: 247) for growth along the apical margin of the plate. He noted that this edge formed an addition along the occludent margins of the scuta and terga (Fig. 9a, b). This is readily seen on the external surface, and represents "unimportant exceptions to the rule" that growth increments are added only at the basal margin. He also noted that this edge reaches its maximum development in $H$. monticulariae, and that the balance of the plate, representing the original tergum and scutum, is "... reduced to a mere basal edge or border" (Darwin, 1854: 356). However, his description of $\boldsymbol{H}$. monticulariae is ambiguous, insofar as orientation and manner of growth are concerned, because he stated "... the scutum itself is curved, with a slip, along the true occludent margin (best seen at the rostral end), lying in a different plane from the rest of the valve ..." (Darwin, 1854: 373; emphasis added). This "slip" is depicted in his figure below the "basal edge or border" (pl. 13, fig. 5f). From this one might be led to believe that there are two occludent margins, but the "true" margin is simply the "original" margin to which growth increments producing the occludent edge have been added.

As Darwin noted, opercular growth in Hoekiini contravenes the general concepts of growth in other balanomorphs in that major growth increments are made along the occludent rather than the basal margins. Furthermore, the modified scutal adductor ridge and tergal muscle crest (see below) wrap around both sides of the basal margin of each plate, and where they contact the exterior surface there is a narrow, shallow sulcus (Fig. 9a). It is along this juncture, effectively the original basal margin of the plate, that the arthrodial membrane attaches the plates to the sheath.

Why have Hoekiini reversed the manner by which growth increments are added to the opercular valves? It has to do with the manner of growth of the wall. Monometric shell growth characterizes the tetraclitines where orifice enlargement is by attrition or corrosion (Darwin, 1854: 324; Ross, 1969: 238). But this has very little effect on growth and form of the opercular plates, which are added to at the basal margins, because growth of the wall remains conical. The "reverse" growth pattern of the valves seen in Hoekiini is necessitated by the change from conical to horizontal growth, and concrescence of the wall plates. With growth of the wall, and enlargement of the orifice, enlargement of the superior portion of the opercular plates for occlusion of the orifice is required if a low profile is to be maintained. This growth forms the occludent edge, and it is anticipated in other pyrgomatines such as Trevathana dentatum (Darwin, 1854) and Savignium crenatum (Sowerby, 1823) where less than one half of the plates show apical growth, as opposed to more than one half in Hoekiini (Soong \& Chang, 1983: 247).

The occludent margins of the scutal plates interlock to varying degrees in nearly all balanomorphs. In primitive barnacles the occlusal surfaces are relatively smooth, as they are in Hoekiini. Interlocking closure of the occlusal surfaces has obvious adaptive value in barnacles exposed to predators. However, for Hoekiini there is apparently no adaptive value in possessing such a mechanism because of the minute orifice which is covered by a cloak of coral tissue.

The unexposed upper margins of the opercular plates in Hoekiini do not occlude completely. Only the medial occludent edges are brought into apposition. On the rostral and carinal ends the edges diverge laterally leaving distinct, somewhat elliptical openings or fenestra, with the rostral larger than the carinal (Fig. 2). A similar situation exists at the carinal end of the operculum in Nobia grandis Sowerby, 1839 (see Ross \& Newman, 1973: fig. 12C). The fenestrae are simply the free spaces adjacent to the hinge points formed by the tergal and scutal extensions of the valves.

In those balanomorphs having scuta with interlocking occludent margins, the plates are slightly bilaterally asymmetrical. This results from interdigitation of basal growth increments along the occludent margin. Although the occludent margins do not interlock in Hoekiini, the plates are asymmetri- 
cal. The apico-medial portion of the plate, the occludent edge, is semicircular in outline, and when the plates are in apposition they form a hemisphere. But, one side is usually more inflated than the other, and the disparity in length between the two plates may arise from asymmetry of the wall.

In $\boldsymbol{H}$. monticulariae the opercular plates average four to five times longer than the rostro-carinal diameter of the orifice. One specimen, with a rostrocarinal orifice diameter of $0.35 \mathrm{~mm}$, has plates that are $1.7 \mathrm{~mm}$ and $1.2 \mathrm{~mm}$ long, respectively (Table II). Thus, a minute orifice has not precluded the need for proportionately large opercular plates. This is because they are required for body and muscle attachment.

The scutal portion of the plate lacks depressions for the adductor and the lateral and rostral depressor muscles. However, in $\boldsymbol{H}$. monticulariae, along the basal margin there is a medially projecting flange (Fig. 9a) that is the attachment site for the lateral depressor. The basal portion of the scutal segment is greatly thickened and constitutes the adductor ridge. It serves as the site of attachment for the scutal adductor muscle as well as the prosoma, and laterally extends well beyond the rostral angle, thus forming a rostral point or tooth. The distal end of the tooth is simple and spatulate in $H$. monticulariae and $E$. chaos, but in $A$. chuangi it is folded and inflexed medially. The termination is the site of attachment for the rostral depressor muscle.

The tergal portion of each plate lacks a spur. The basal margin at the tergal end is produced, but not to the same degree as at the rostral end. The tergal end is a modified crest, or fusion of several crests, for insertion of the tergal depressor muscles (Figs. $2,9 a, b)$. The distal portion of the tergal extension may be simple and spatulate or complex and inflexed medially. However, unlike the rostral depressor muscle, the tergal depressor muscle bundles in $\boldsymbol{H}$. monticulariae and $\boldsymbol{P}$. aster are arrayed along the length of the tergal crest.

Darwin (1854: 373) stated that the "U-shaped" opercular plates of $\boldsymbol{H}$. monticulariae, when viewed in section along the major axis "... form a bow with the two ends curled rather abruptly inwards ...". Because of the length disparity in large $H$. monticulariae the "two ends" may not be proxi- mate. The opposed spatulate distal extremities in $A$. chuangi may serve as pivotal or hinge points for the plates, but how the inequality in length is compensated for is unknown.

\section{Body shape and size}

Shell shape in pyrgomatids dictates whether the body will be housed within the confines of the wall, partly within the wall and basis, or essentially within the basis. In Hoekiini the space available within the confines of the conical portion of the adult wall suggests that only sufficient room exists for part of the oral cone and terminal cirri. The balance of the prosoma and thorax reside in the basis (Fig. 3). According to Anderson (1992: 290) the same relationship exists in Cantellius euspinulosum (Broch, 1931).

In many pyrgomatids the prosoma is larger than the thorax (Anderson, 1992: 299), and in many it is globose or spheroidal (Ross \& Newman, 1969: 253). Thus, there appears to be a reverse correlation: the larger and more globose the prosoma, the smaller and more slender the thorax. According to Anderson, concomitant with diminution of the thorax there is reduction in cirral size and length, and hence perhaps functional dependency on the cirral net as a captorial feeding mechanism.

The prosoma in large specimens of $\boldsymbol{H}$. mortenseni eclipses the thorax in size; there is no clear distinction between these two regions because what is left of the thorax is engulfed by inflation of the prosoma. And, the thoracic appendages are vestigial except for the aberrant cirrus VI (see section Cirri). There is a distinct thorax in $\boldsymbol{H}$. monticulariae, but it too is small relative to the prosoma, and in large specimens it is rotated anterioventrally. In this orientation, the tips of the posterior cirri approach the apex of the oral cone directly beneath the orifice (Fig. 3). The thorax in Parahoekia is also diminutive and positioned anterioventrally with the inflated prosoma extending posteriorly beyond it.

Because of the low profile of the wall and size of the body in Hoekiini, the bulk of the body must be housed in the basis. When raised to the feeding position, the oral cone or alternatively, the intromit- 
tent organ and/or cirrus VI, can be extended out through the orifice.

\section{Opercular musculature}

In balanomorphs there are four groups of opercular muscles and their size, shape and length vary (Anderson, 1992: 334; 1994: 74). Although opercular musculature may serve more than one function (Anderson, 1981: 447), the primary role is in regulating the aperture between the opercular plates. The three peripheral groups include the paired rostral, lateral, and tergal depressor muscles. The fourth is the unpaired scutal adductor. The opercular muscles in balanomorphs may comprise a large portion of the soft parts of the animal. But, they form an exceedingly minute percentage of the tissue mass in Hoekiini.

In order for the opercular plates to close, the scutal adductor, the most conspicuous muscle in Hoekiini, must be more apical than the lateral depressors; that is, above the pivot or hinge points. It pulls the opercular plates medially, thus closing the aperture. Unlike that of other balanomorphs and pyrgomatids, this muscle bundle is broad, flat and thin rather than being essentially ovate in cross section. It is attached to the rostral tooth along the basal margin of the plate, but does not extend all the way to the end of the tooth (Fig. 2).

The depressor muscles open the opercular plates, and can generally draw the entire operculum downward. The lateral depressors in Hoekiini, although moderately slender, are exceedingly long. In specimens of $\boldsymbol{H}$. monticulariae and $\boldsymbol{H}$. mortenseni they are more than three times the length of the opercular plates. The proximal half is striated muscle, whereas the distal half is tendonous. The latter portion anastamoses and inserts on the basis rather than on the shell wall. In Parahoekia this muscle is smooth, not striated, it is shorter and greater in cross section than in Hoekia, and it lacks the tendinous distal portion.

The rostral depressor muscles are more slender than the lateral depressors. Their origin is on the apical surface of the rostral tooth, and they extend somewhat laterally before inserting on the wall.
The tergal depressors originate on the ridge along the basal margin of the tergal portion of the opercular plate, and they also insert on the wall. They are thin and shorter than the lateral scutal depressors, and are divided into three or four distinctly separate bundles in $H$. monticulariae. In $P$. aster they are divided into six or seven distinct bundles, and each appears to have a greater cross-sectional area than that found in $\boldsymbol{H}$. monticulariae. The depressor musculature in Hoekiini follows a similar pattern as that depicted by Anderson (1992: 331) for type 3 pyrgomatids.

Because the shell in Hoekiini is covered by coral tissue, and the aberrant cirri no longer serve a captorial function, the activities normally associated with opercular and cirral movements are largely precluded. However, in concert with the prosomal muscles, the depressor muscles may create the pumping action that ventilates the mantle cavity and aids in expelling larvae in ordinary balanomorphs (H. Barnes, 1955: 114).

\section{Trophic structures}

The oral cone, thus far known only in Parahoekia and Hoekia, holds a prominent position on the prosoma, and its size can overshadow the thorax and its appendages (Fig. 3). It was this difference that originally led us to the fact that Hoekia feeds on host tissue rather than capturing food with cirri extended into the water (Ross \& Newman, 1967: 255).

The labrum in both $H$. mortenseni and $H$. monticulariae is only slightly sulcate rather than deeply notched as it is in $P$. aster (Fig. 7a). In all three species the crest lacks setules and teeth. The mandibular palps, fused laterally to the labrum, are small, clothed with setae of various lengths, and do not extend to the top of the labrum; that is, they tend to close the sides rather than the top of the oral cone (cf. Figs. 7a, 10a, 12a).

The structure of the mandibles suggests that they serve more than one function. The cutting edge of the superior portion is smooth, but parallel to the edge there are exceedingly long, fine ctenae that extend well beyond the cutting edge. The inferior portion of the cutting edge is divisible into two 
functional regions armed with multicuspid spines, the upper of which projects beyond the inferior angle.

Of the three regions of the mandible, the function of the superior portion is equivocable, but in light of the lateral position of the palps, it likely strains or brushes food particles back toward the mouth. The medial portion, acting much like a coarse-toothed saw, shreds coral tissue, maintains access to the "outside", and triturates large food particles. The inferior angle, armed with smaller spines, transfers food to the mouth.

Maxillae I have an unbroken array of equal length spines in $\boldsymbol{H}$. mortenseni and $\boldsymbol{P}$. aster but there are two discontinuities in the array in $H$. monticulariae, suggestive of functional groups (Fig. 10d). The arrangement of spines, suggestive of a comb more than a saw, probably clean the mandibles as well as assist in moving fine food particles to the mouth.

Maxillae II in Parahoekia, densely and darkly pigmented, are reduced to a mere knob-like prominence surmounted by a few short setae (Fig. 7f). They are fused to a large, unpaired, laterally compressed, median languette (hypostome), similar in appearance to that found in the ascothoracidan Synagoga Norman, 1913, and related genera (Norman, 1913: 163; Moyse, 1983: 170; Grygier, 1984: 168). Although Hoekiini and ascothoracidans have an attenuated oral cone and mandibles and maxillae with saw-like edges, those of $S$. mira (Norman, 1913: 161) are terminally accumulate, and therefore better adapted for piercing as well as rasping the host's tissue. Flanked by the maxillules, in Hoekiini the languette forms a seal to the posterior border of the oral cavity. The apical border is higher than the labrum and adjoining appendages, and the periphery is armed with a single row of short, slender, simple setae. In $H$. monticulariae (Fig. $10 \mathrm{f}$ ) and $\boldsymbol{H}$. mortenseni (Fig. 12f) the languette is comparable in size to the adjoining trophi and does not broadly close the back of the mouth field as it does in $P$. aster. The presence of a languette that equals or dwarfs the remaining appendages is apparently a synapomorphy that unites the Hoekiini, because they are the only balanomorphs known to possess such a structure. Why a hypostome is so highly de- veloped in these biting parasitic crustaceans is likely for the same functional reasons as it is in primitive ascothoracidans.

\section{Cirri}

Balanomorphs, except those noted below, are characterized by six pairs of biramous thoracic appendages which fall into two functional groups. In balanoids the anterior three pairs are maxillipeds that clean the posterior three pairs of food and transfer it to the trophi. Furthermore, the cirri respond to mechanical stimuli, such as the direction of water currents. They also serve some role in the reproductive process (Ross, 1969: 248; M. Barnes, 1992: 520) and may function in respiratory exchange (Crisp \& Southward, 1961: 290).

The Hoekiini are unusual in that the cirri are reduced and aberrant. Those of $H$. mortenseni represent the most extreme case: the first three pairs are wholly vestigial; cirrus IV is malformed and tipped with a few short setae; cirrus $V$ is questionably biramous, unsegmented, essentially devoid of setae, and only slightly longer than the coxopodite of cirrus VI, the rami of which are unequal in length and shorter than the protopodite.

The cirri of $\boldsymbol{H}$. monticulariae and $\boldsymbol{P}$. aster (Fig. 7h) are more readily identified, but they are also aberrant. The location of cirri II and III is normal in $\boldsymbol{P}$. aster whereas in $\boldsymbol{H}$. monticulariae they attach medially, just posterior to the mouth field, and they are somewhat reminiscent of the mouth cirri (Fig. $10 \mathrm{~g}, \mathrm{~h}$ ) in acrothoracicans (Tomlinson, 1963: 268). In this position they are flanked and "hidden" by the protopodite of cirrus I, the coxopodite of which, some 20-25 times larger than the basipodite (Fig. 10g), likely retains its "normal" size because of the presence of the oviducal gland and female genital aperture (Walley, 1965: 118). All three of the maxillipeds have discernible protopodites, but the remaining segments are variously fused or indiscernible; they are distinguished only by indentations in the cuticle rather than by true articulations. Cirrus IV in $P$. aster, only slightly separated from the posterior two pairs, is aberrant, has a poorly segmented protopodite, and equal-sized rami that 
are shorter than the protopodite (Fig. 7h). In $\boldsymbol{H}$. monticulariae cirrus $\mathrm{V}$ is essentially fused to cirrus VI (Fig. 10j), and about one-fourth its length, but the rami of cirrus VI are equal to or slightly longer than the protopodite. All of the posterior cirri have setae, but these, as in $H$. mortenseni, occur almost wholly on the greater curvature of the rami.

On the basis of the foregoing it is evident that the maxillipeds no longer function in the transfer of food to the trophi. Similarly, the remaining three pairs cannot function in a captorial manner. Consequently, they must serve other functions. Severe size reduction in all but cirri VI, which flank the intromittent organ, suggests that the latter serve a reproductive function in these species.

\section{Lacuno-circumferential system}

Among the unique and obvious structures in Hoekiini is the external carinal ridge. It is short, commonly does not extend to the edge of the outer lamina, and is a seemingly anomalous protuberance (Figs. $6 \mathrm{~b}, 8 \mathrm{~b}$ ) that bears little resemblance to the ridges or ornamentation of other barnacles.

Under transmitted light, the ridge in Hoekia appears to house a hollow cavity or sinus within the shell, and grinding revealed a cavity. In Eohoekia, a rostral as well as a carinal sinus can be observed when specimens are candled.

A prominent rostral and a carinal ridge occur in Parahoekia, and there are indications of lateral ridges interspersed between them. These ridges appear to be hollow under transmitted light, but the opacity of the shell precludes further study. The broad, low carinal ridge in $A$. tanabensis also houses a sinus, but grinding revealed that it was filled secondarily. These sinuses represent circulatory channels that were abandoned as the circumferential circulatory channel moved peripherally during ontogeny. In those forms with lacunae, there is generally a well-developed carinal lacuna connecting with the carinal sinus (see below).

The development of lacunae is a unique feature in Hoekia and Ahoekia. These occur below or distal to the basal margin of the sheath (Figs. 18a, 19a).
Darwin (1854: 373) described the inner walls of $H$. monticulariae as being smooth, but noted that "... they are perforated by many quite irregular, small orifices, which have the appearance of having been formed by some boring animal ..." His illustration (1854: pl. 13 fig. 5b) shows a highly pockmarked surface, which we have not observed. The lacunae may be circular, ovate or irregular in outline (Fig. 19b, c). Some may be confluent, but more commonly they are discrete, and in Ahoekia they are concentrated along the lateral portions of the shell (Fig. 13c). "More or less irregular" best describes their spatial distribution because there is no fixed pattern from one specimen to another of the same species. Each lacuna leads to a lumen, which in turn opens into a narrow, partially enclosed, circumferential channel that lies between the marginal fringe and the distal margin of the outer lamina. In Ahoekia there are ancillary connections from the circumferential channel to the periphery of the marginal fringe (Fig. 13a, d).

Internally, access to the abandoned carinal sinus is generally through a carinally situated lacuna in these species. The same lacuna also leads distally to the circumferential channel. Eohoekia lacks the enclosed lacunal interconnections, but access to the circumferential channel, and in turn to the sinuses, is via shallow, basal and distal sulci that occur between the digitations of the marginal fringe. The same situation prevails in Parahoekia, but the sulci are deeper and more pronounced, and in one instance a sulcus has been closed by secondary calcification. All of these connections and interconnections are traceable by transmitted light, grinding the shell, and/or by inserting a probe (an eye lash is excellent) into the passage and observing where it emerges around the fringe (Fig. 18a).

On the basis of the foregoing it is evident that the carinal ridge (sinus) and the lacunae are but two aspects of the same system, but which system? We infer that this extensive and elaborate interconnecting system accommodates part of the circulatory system, in connection with pronounced elaboration of the lateral margin of the shell which is in direct contact with host tissue. Both Eohoekia and Parahoekia have only the circumferential and carinal portion of the network, and thus the circumferen- 


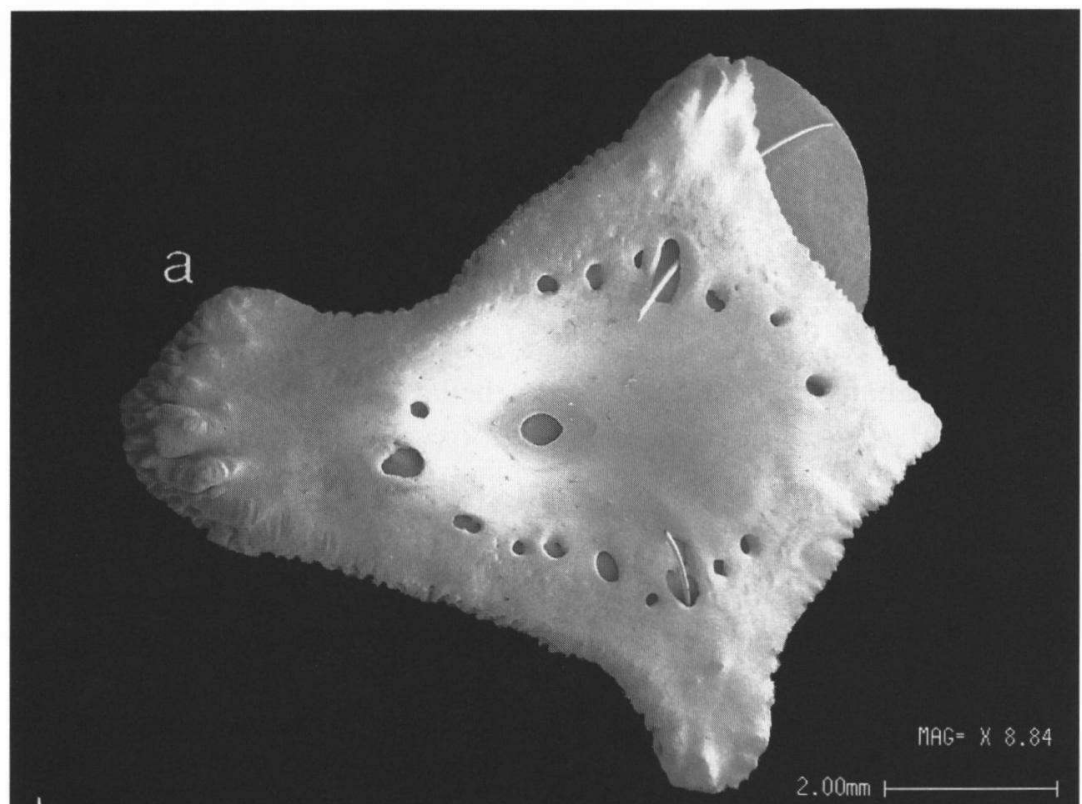

b

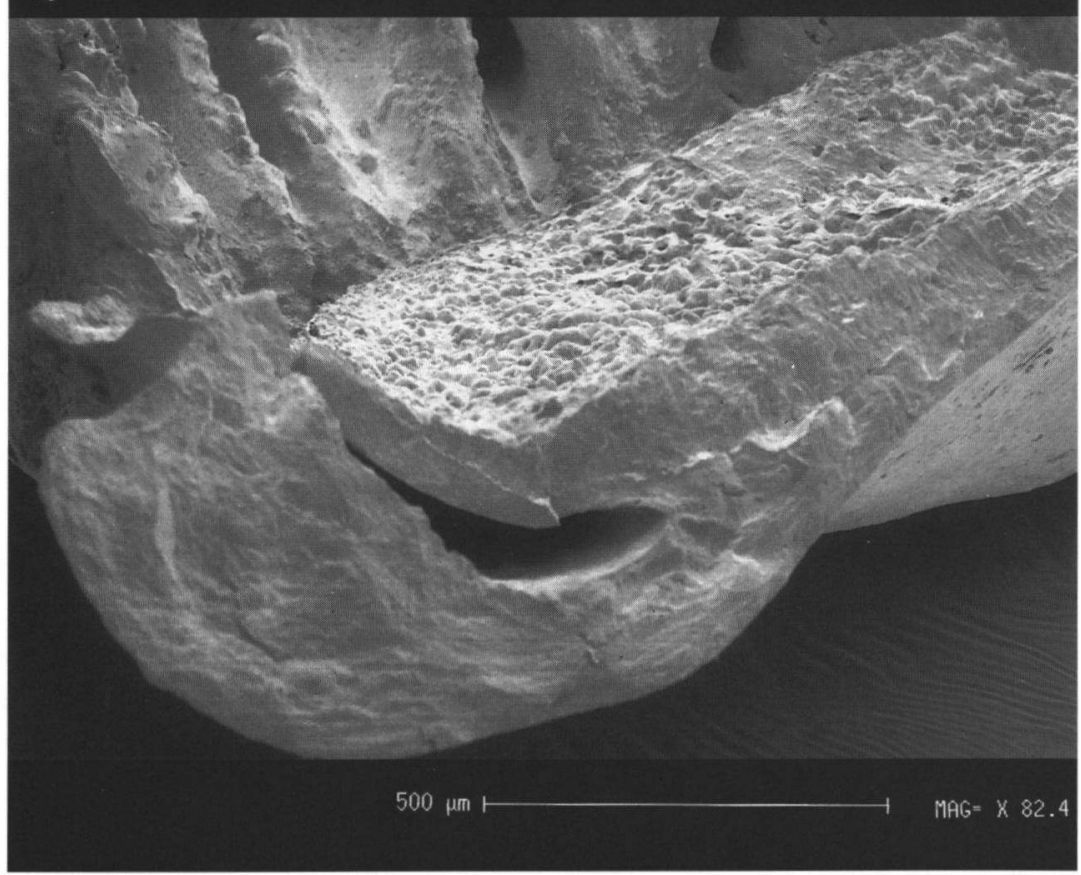

Fig. 18. a, Hoekia monticulariae (Gray, 1831), internal view of shell; note essentially symmetrical arrangement of lacunae, with eyelash traversing shell from inner to outer surface; topotype, SIO no. C-8375.

b, Eohoekia chaos n. sp., fragment of paratype, USNM no. 259979, view of circumferential channel; flat portion is the outer lamina with the reflexed marginal fringe to the left and rear. 
tial channel must be supplied by vessels that pass from beneath the shell through the marginal fringe. The lacunate system shortens this route for the hemolymph, between the body proper to the circumferential channel, but it potentially separates the afferent and efferent circulation which would allow for greater elaboration of the marginal fringe.

The only recent study on the balanomorph hemolymph system (Burnett, 1977) provides a background against which the present situation can be interpreted. Although Burnett's study was on a higher balanid, Megabalanus californicus (Pilsbry, 1916), it is likely that barnacles having a solid and wholly concrescent wall differ only in detail from this general plan. Although we could not trace the vessels themselves, from the preserved material it appeared that branches from the basal (= inferior) circumferential vessels, that may be observed in Megabalanus, formed the lacuno-circumferential channel network in the lacunate Hoekiini. It is also evident that there is a major carinal vessel, previously unrecognized in balanomorphs, that supplies the tergal depressor muscles. Based upon reexamination of Burnett's specimens in the collections of Scripps Institution of Oceanography, this vessel evidently not only supplies these muscles, but also the branchiae.

In general, movements associated with cirral activities affect circulation of body fluids (Crisp \& Southward, 1961: 292). Obviously, the presence of greatly reduced cirri necessitates some other mechanism, rhythmic or otherwise, to assure circulation. In the absence of cirral movements, Blatchford (1970: 914) suggested that “ . . . rhythmic contractions of the body wall in the region between the adductor scutorum muscle and the oral cone may serve to produce regular pressure pulses in the body fluids which may aid circulation of the blood", and this is likely the case here.

Balanomorph respiration takes place by diffusion through the body surfaces, the mantle, and extensions thereof such as the branchiae. Because of the reduced opercular area for vascularization, coupled with limited exposure to the external milieux via the orifice and the absence of branchiae, Hoekiini may depend on the highly vascularized peripher- al system for respiratory exchange. However, it apparently has been elaborated beyond all needs of the barnacle as far as respiration is concerned.

According to Goreau et al. (1970: 169) the zooxanthellae within colonial corals produce more oxygen in daylight than can be consumed by the host, and metabolic waste products are taken up by the zooxanthellae. Although, by virtue of their zooxanthellae, reef corals behave much like plants, the zooxanthellae "function as intracellular lungs and kidneys", thereby reducing the host's work involving "respiratory gas exchange and transport of waste products". Elaboration of a marginal fringe and its proximity to the host coral tissue fosters our hypothesis that it functions as a metabolic pathway to and from the host, and hence, the development and elaboration of a lacuno-circumferential circulatory system to better serve these functions.

\section{Reproduction}

Balanomorphs are fundamentally cross-fertilizing hermaphrodites. Although there is no elaborate courtship behavior, individuals acting as receptive females induce surrounding individuals to act as males at the time of mating (H. Barnes et al., 1977: 197; Crisp \& Southward, 1961: 288). The three species we examined have a well-developed intromittent organ as do presumably all Hoekiini, and therefore it appears that cross-fertilization remains integral to their reproductive biology. The pedicel of the penis arises between cirri VI, extends to an inflated basidorsal point from where the probosciform portion turns abruptly anteriorly and comes to lie along either side of the prosoma. The pedicel is almost the same height as the protopodite of cirrus VI in $\boldsymbol{H}$. monticulariae (Fig. 10k), but it is half the height of the coxal segment in $H$. mortenseni (Fig. $12 \mathrm{~g}$ ). In all of the dissected specimens of $\boldsymbol{H}$. monticulariae the paired seminal vesicles were swollen and readily visible through the body wall. They were whitish, vermiform, large, and traceable to where they unite in the pedicel of the penis.

The length of the penis may vary with the reproductive season, thus the differences noted may not be significant (M. Barnes, 1992: 518). In 


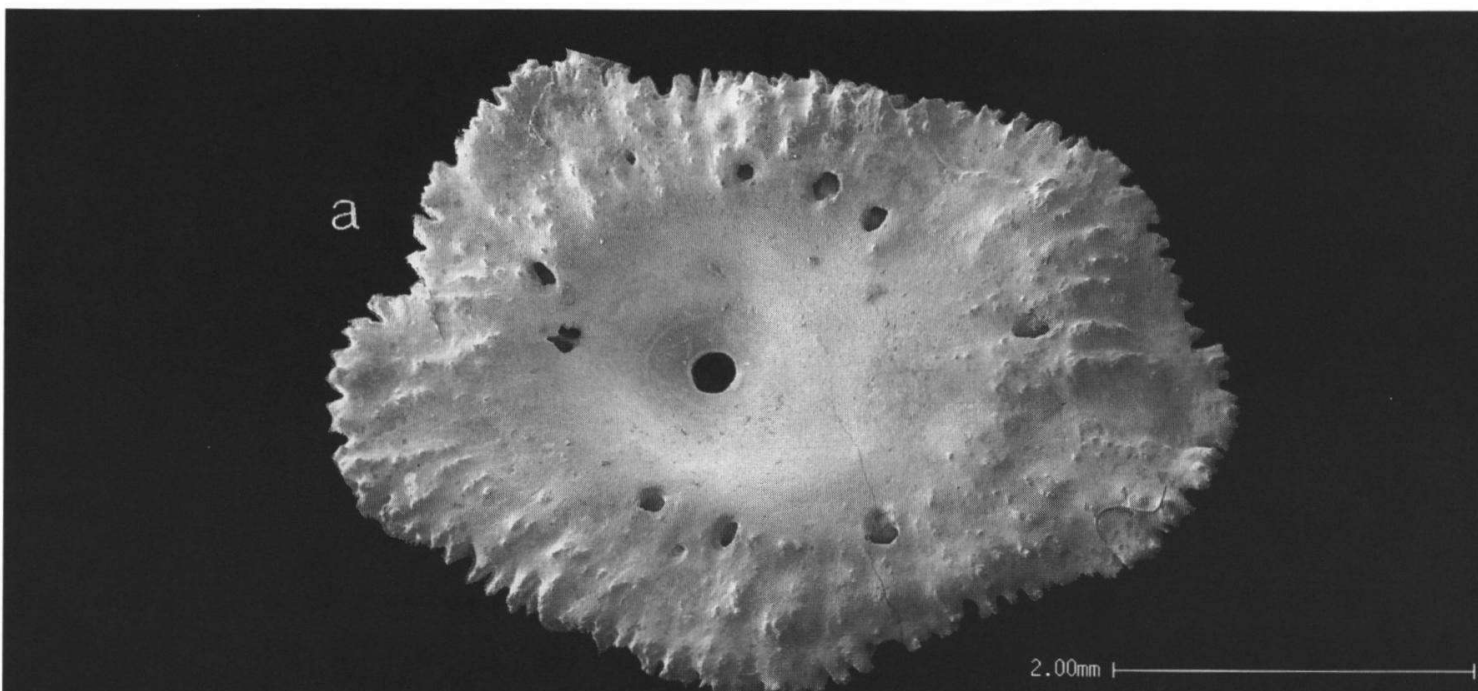

b

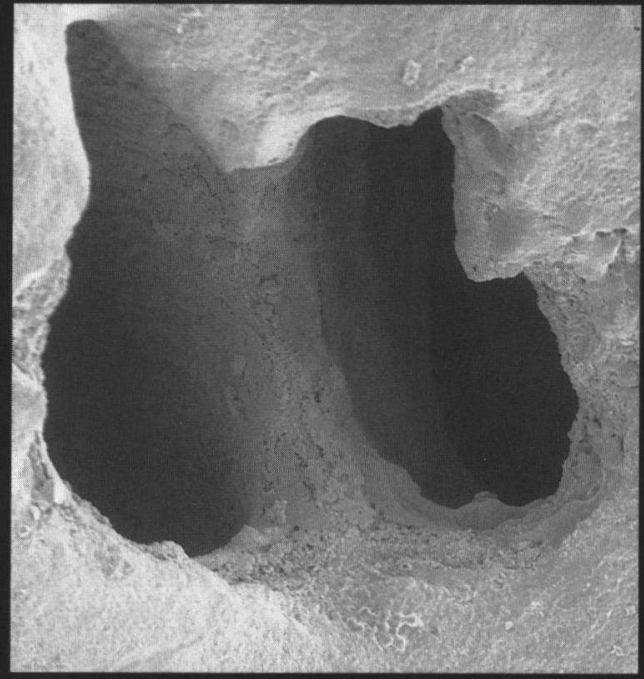

$100 \mu \mathrm{m}$

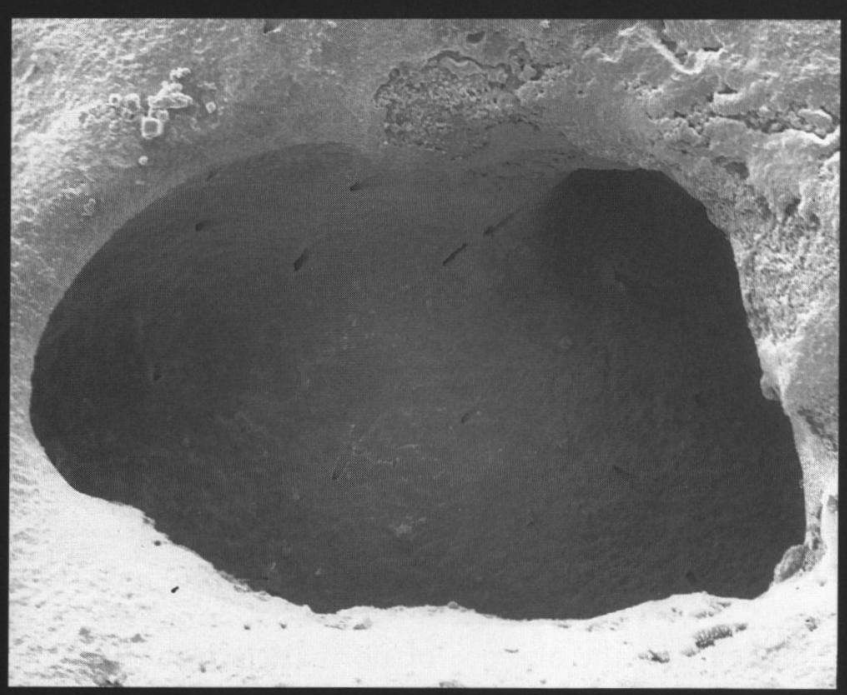

$50.0 \mu \mathrm{m}$

Fig. 19. Hoekia monticulariae (Gray, 1831): a, topotype, SIO no. C-8375, internal view of shell, carinal end at left; b, enlarged view of paired carinal lacunae shown in a, above, at left center; c, enlarged view of single lacuna shown in a, above, top right; note that wall of lacuna is perforated with pores that accommodate setae that exit on outer wall of shell.

$H$. mortenseni it is less than twice the length of cirrus VI, but it is more than twice the length in $H$. monticulariae and $P$. aster. There are simple, minute setae scattered sparsely over the surface, except in $P$. aster there are more setae, and at the distal end there are four equally spaced clusters of four or five short, slender setae in each (Fig. 7i). A chemosensory function has been attributed by
Munn et al. (1974: 96) to the setae that clothe the penis in Semibalanus balanoides (Linnaeus, 1766).

Only cirrus VI appears truly functional in Hoekia and Parahoekia, and then perhaps only during mating (see also section Feeding and nutrition). Distention of the penis in balanids does not take place until the cirri have been fully unfurled, and consequently their presence may be requisite for 
copulation (Crisp \& Southward, 1961: 288).

In tropical or warm-water barnacles breeding is not uniform throughout the year, and it may be asynchronous in a population (Achituv \& Barnes, 1978: 316; M. Barnes, 1989: 143; 1992: 493). Our samples were too few and too small to add to this generalization, but we noted the following. One specimen of $\boldsymbol{H}$. monticulariae collected in December, mid-summer in the southern hemisphere, was brooding eggs. They were somewhat ovate and average $0.3 \mathrm{~mm}$ in diameter. The specimens of $\boldsymbol{H}$. mortenseni taken in October, early spring in the southern hemisphere, were barren.

We recovered from the sole specimen of $P$. aster, collected in May, or late fall in the southern hemisphere, some pre-stage I nauplii that were eyed and filled with yolk and oil droplets. The specimen was received detached from the host coral and therefore we cannot estimate brood size, but it did not appear that reproductive effort was particularly high. If not, this is curious because parasites normally have a high reproductive output.

Our limited observations suggest that population densities in Hoekiini are low. However, considering the difficulty in obtaining preserved material, and the likelihood of their being washed off in the preparation of coral skeletons, they could be relatively common.

\section{Feeding and nutrition}

As noted earlier, the absence of normal cirri, the nature of the trophi, and the presence of nematocysts in the stomach of Hoekia led to our inference that Hoekia feeds on coral tissue (Ross \& Newman, 1969: 255). A somewhat similar scenario is evident in the ascothoracidan Isidascus Moyse, 1983. This minute, piercing and sucking, gall-forming parasite of octocorals feeds on host tissues which are probably "... continually proliferating to replace any used by the parasite"' (Moyse, 1983: 175). However, we now believe that in the Hoekiini ingestion of coral tissue may not be the sole source of nutriment.

In the preserved specimens we have examined, the wall is totally covered by living coral tissue (Fig. 3); in fact it appears to mimic a hydnon. After rasping and consuming the tissue immediately covering the orifice, the oral cone, now in a protruded state, could enter the host's gastrovascular canal system. If it did, it could divert gastrovascular fluids from the coral to itself.

It is instructive to note a somewhat parallel situation involving the mytilid Fungiacava eilatensis Soot-Ryen, 1969 and various monostomatous corals of the family Fungiidae. It resides in a cavity within the skeleton of the host coral, and its enlarged inhalant siphon opens directly into the coelenteron of the host. Its diet consists of phytoplankton, zooxanthellae, and other particles found in the coelenteron (Goreau et al., 1970: 164; Patton, 1976: 11). The foot of this mytilid is involved in the food selection process as well as serving some sensory role. This suggests that retention of cirri VI in Hoekia may also have a sensory role in feeding as well as in reproduction.

In balanomorphs, the anus is situated at the base of the last thoracic segment, immediately above the pedicel of the intromittent organ (Darwin, 1854: 87). There appears to be an "anal depression" in $\boldsymbol{H}$. monticulariae and $H$. mortenseni, but no anal flaps or opening could be detected. The same also applies in $P$. aster, except that we did not detect an anal depression.

Acrothoracicans (Apygophora), which likewise apparently feed on fine particles, lack an anal opening, and Tomlinson (1969: 19) summarized the various aspects of how metabolic wastes are voided in such forms. Therefore, if an anus is lacking in Hoekiini, it is not unprecedented among the barnacles.

\section{Host specificity and exploitation}

The faviinid Hydnophora Fischer, 1807, which was widely distributed in the Cretaceous, is presently limited to the Indo-West Pacific region (Veron, 1993b: 428). This coral is unusual in that corallite centers are arranged around protuberant collines or hydnons, the result of circummural budding. Short tentacles surround the base of each hydnon, with one tentacle between each pair of sclerosepta (Veron, 1993b: 428). Ogawa \& Matsuzaki (1992: 97) reported the apparently facultative occurrence of Creusia indica Annandale, 1924 (= Galkinia in- 
dica) on Hydnophora spp., but usually hoekiines are the only pyrgomatids encountered on this coral. What it is about the unique morphology of this coral that favors hoekiines, but tends to exclude other pyrgomatids, may be the thickness of the coral tissue in the "valleys" between the hydnons in which the wall of the barnacle becomes suspended, and to which its highly vascularized marginal fringe is applied.

Newman et al. (1976: 73) note that there is a good to excellent correlation between being morphologically specialized and exploiting a limited number of genera of host corals, and this is the case here (see section Biogeography). Furthermore, based on our limited data for the Hoekiini, species in a particular area settle on one host species, and wide-ranging hosts are generally exploited by more than one species. But so far it appears that only 3 or possibly 4 of the 22 species of Hydnophora (Veron, 1993a: 77; table I) have been identified as hosts of this barnacle.

Success in becoming established on a host may depend on several factors. Coral-inhabiting and other symbiotic barnacles apparently have patchy distributions and settlement may be due largely to some sort of perturbation, otherwise they would be far more common. For example, cyprids of the acrothoracican Cryptophiallus melampygos Berndt, 1907 preferentially settle on those areas of the host mollusk where the periostracum has been eroded (Batham \& Tomlinson, 1965: 143). Gomez (1973: 163) found that cyprids of Conopea galeatus (Linnaeus, 1767) preferentially settle on those areas of the host gorgonian that have been striped or browsed by an ophistobranch mollusk. In the classic study by Ritchie \& Høeg (1981: 343) on the rhizocephalan Lernaeodiscus porcellanae F. Müller, 1861 , host crabs living among rocks, as compared to those among mussels, had a higher incidence of parasitism presumably because of more frequent damage to their cleaning appendages by shifting rocks. The observation of Duerden (1902: 38) on a West-Indian coral, Siderastrea radians (Pallas, 1766), indicates that, among others, pyrgomatids "... are particularly numerous on specimens obtained from muddy shores as compared with those from the cleaner water of the reefs". Similarly, in Tanabe Bay, Japan, Hiro (1935: 21) found coralinhabiting barnacles to be rather abundant where there was an influx of silt-laden waters. Furthermore, the pyrgomatid Hiroa Ross \& Newman, 1973 was first discovered in the high energy zone of the reef front (Ross \& Newman, 1973: 153) where the corals are subject to heavy surf as compared to the rest of the reef front. Thus it would not be surprising if the larvae of coral-inhabiting barnacles capitalize on localized or micro-disturbances.

According to Veron (1993b: 428) Hydnophora exesa is more common than $H$. rigida, which is sometimes common, and $\boldsymbol{H}$. microconos which is least common on protected reef slopes and especially in lagoons. Because they occur in essentially protected, or low energy environments, hydnophorans may not be readily subject to wave perturbation. But other forms of stress, such as freshwater run off and/or siltation, or perhaps predation, may play some role in Hoekiini becoming established on them.

Pyrgomatid cyprids settle directly on the coenenchyme of the host (Duerden, 1902: 38; Gravier, 1911: 211; Moyse, 1971: 127; Utinomi, 1943: 16), but what cues are involved or what time of day cyprids settle remains unknown. It has been suggested that symbionts achieve some immunity to the defenses of the host by absorption of substances secreted from them, and if so these may aid the settling symbiont (Patton, 1976: 29; Ogawa \& Matsuzaki, 1992: 91).

Hydnophorans, except $H$. exesa, are nocturnal feeders (Veron, 1993b: 428), and it seems likely that Hoekiini cyprids settle when the host is not actively feeding. Unlike most corals, where each polyp occupies a corallite, in hydnophorans there are no distinct corallites. Mouths may occur where several tentacle-encircled hydnons come together, but there may be no visible mouth in a similar array. There are two possible sites for the cyprid to settle on tissue between hydnons, either in a mouth of the host or in the intervening areas. Although the barnacle grows to mimic a hydnon rather than a polyp, it could have settled in the mouth of a preexisting polyp as well as the open space between them. 


\section{Biogeography}

In a study of diversity trends in the Pyrgomatidae (Newman et al., 1976) a number of indices involving 10 genera were identified, quantified, and ranked. The principal ones were: (1) structural diversity (SDI), (2) host exploitation (HEI), (3) geographical diversity (GDI), and (4) generic species richness (GSR). Six rank order comparisons were made and rank-difference coefficients $r_{d}$ calculated (cf. Tate \& Clelland, 1957). The results were summarized in a matrix which is updated and reproduced here (Table III; certain recently proposed generic level taxa have yet to be evaluated, and therefore these have been omitted in the tables and discussion that follows).

It can be seen in Table III that the three original principal rank order comparisons (HEI, GDI, and GSR with SDI) support to a greater or lesser extent three general hypotheses, viz., that the relatively unspecialized genera tend (1) to exploit a greater variety of hosts (HEI), (2) to have broader geographical distributions (GDI), and (3) to be richer in species (GSR), than specialized genera. However, it will be observed that in order to achieve reasonable coefficients and concomitant probabilities, it was necessary to exclude the monotypic genus Hoekia from the second, and the monotypic genus Hiroa from all three of these rank-order comparisons with SDI.

Hoekia was removed because it was the only member of the entire family known to be wholly parasitic (Ross \& Newman, 1969), and therefore might not reflect the same diversity trends seen in its setose-feeding allies. Hiroa, on the other hand, was excluded because it was only known from the type locality (Ross \& Newman, 1973: 153), and one would expect such a moderately generalized form to be relatively wide-ranging. We now know much more about both of these genera and one can ask what bearing this new knowledge has on these hypotheses.

As for Hoekia, the new knowledge concerns its structure, systematics, and distribution, and the first two of these parameters bear on SDI. Hoekia is now not only divisible into four genera comprising the Hoekiini, but the basic wall and opercular valves in this group are now recognized as the most modified of the pyrgomatines. Therefore, the Hoekiini exchange places with Pyrgopsella (Pyrgopsellini, the only pyrgomatine occurring on sponges rather than corals) because they have the most advanced walls and operculae among the Pyrgomatidae (Table IV). Furthermore, several of the new genera appear to have relatively restricted ranges despite the wide geographical range of the tribe. Based on the proximity of some species (Gulfs of Suez and Aqaba; Fig. 20) we predict that newly discovered populations will more likely represent new species than range extensions.

As for Hiroa, a normal setose feeder with a moderately modified shell, it was first discovered entombed in fragments of coral blasted from the reef front on Truk (Chuuk), Caroline Islands, more than 20 years ago. Since then it has been found to be widely distributed: Taiwan (Soong \& Chang,

Table III. Summary of rank difference coefficients $\left(r_{d}\right)$ and $p$ values, from Newman et al. (1976: fig. 2a) with newly calculated $r_{d}$ and $p$ values for rank-order comparisons of HEI, GDI and GSR with SDI, with rather than without, Hiroa and Hoekia, given in parentheses below the original values. For further explanation, see text.

\begin{tabular}{llll}
\hline & HEI & GDI & GSR \\
\hline SDI & World-Hiroa & World-Hiroa + Hoekia & World-Hiroa \\
& $r_{d}=.485, p<.20$ & $r_{d}=.037, p<.00$ & $r_{d}=.443, p<.00$ \\
& $\left(r_{d}=.725, p<.01\right)$ & $\left(r_{d}=.585, p<.05\right)$ & W97, $p<.10)$ \\
HEI & - & Worldwide & Worldwide \\
& & $r_{d}=.77, p<.05$ & $r_{d}=.83, p<.01$ \\
GDI & - & & Worldwide \\
& & & $r_{d}=.60, p<.10$ \\
\hline
\end{tabular}


Table IV. (A) Correlation between structural modifications of walls $(\mathrm{W})$ and valves $(\mathrm{V})$ based on the rankings of Newman et al. (1976) emended to reflect the diversification of the Hoekiini reported herein. The rank difference coefficient $\left(r_{d}\right)$ is now $.896, p<.01$, considerably more significant than that of .732 , $p<.02$ in the previous study. (B) Structural diversity indices, SDI, formed by multiplication of $\mathrm{W} \times \mathrm{V}$ and ranked accordingly. The SDI ranking can then be used to test certain hypotheses taken up in Table V; the $r_{d}$ values are summarized in Table III.

\begin{tabular}{lrrrrrrr}
\hline & \multicolumn{3}{c}{ A } & & & \multicolumn{2}{c}{ B } \\
\cline { 2 - 5 } \cline { 6 - 8 } & W & r & V & r & SDI & r \\
\hline Ceratoconcha & 1 & 2.5 & 1 & 1.0 & 1 & 13.0 \\
Cantellius & 1 & 2.0 & 2 & 2.5 & 2 & 12.0 \\
Hiroa & 1 & 2.5 & 3 & 4.0 & 3 & 11.0 \\
Creusia & 1 & 2.5 & 4 & 6.5 & 4 & 9.5 \\
Megatrema & 2 & 5.0 & 2 & 2.5 & 4 & 9.5 \\
Savignium & 3 & 7.0 & 4 & 6.5 & 12 & 7.5 \\
Nobia & 3 & 7.0 & 4 & 6.5 & 12 & 7.5 \\
Pyrgoma & 3 & 7.0 & 5 & 9.0 & 15 & 6.0 \\
Pyrgopsella & 4 & 9.0 & 4 & 6.5 & 16 & 5.0 \\
Eohoekia & 5 & 10.5 & 6 & 10.5 & 30 & 3.5 \\
Parahoekia & 5 & 10.5 & 6 & 10.5 & 30 & 3.5 \\
Hoekia & 6 & 12.5 & 7 & 12.5 & 42 & 1.5 \\
Ahoekia & 6 & 12.5 & 7 & 12.5 & 42 & 1.5 \\
\hline & & & & & & & \\
\hline
\end{tabular}

1983: 248), Japan (Ogawa \& Matsuzaki, 1990: 75), and other localities in the western Pacific as far west as the Marshall Islands and south as the Gilbert Islands and New Caledonia, and into the Indian Ocean as far as Mauritius (Achituv \& Newman, in prep.). Thus, there is no longer an excuse to exclude it from the comparisons. However, in spite of being wide-ranging, it is considered the same species, Hiroa stubbingsi Ross \& Newman, 1973 (Achituv \& Newman, in prep.).

Except for the record of the astrocoeniid Stylophora cited by Ogawa \& Matsuzaki (1992: 101; Ogawa, pers. comm.), Hiroa is known only on the astrocoeniid Astreopora (reexamination of a fragment of the host skeleton from the type locality indicated that it also belongs to this genus; S. Cairns, pers. comm.). Whether Hiroa turns up on hosts other than Astreopora and Stylophora remains to be seen, but in consideration of its moderately specialized valves this appears unlikely.

Including Hoekia and Hiroa in the rank-order comparisons of HEI, GDI, and GSR with SDI produces a significant result (Table V). In the HEI
Table $V$. Rank order comparisons between structural diversity (SDI), host exploitation (HEI), geographical diversity (GDI), and generic species richness (GSR). The $r_{d}$ and $p<$ values, newly calculated and from Newman et al., 1976 (in parentheses), are discussed in the text.

\begin{tabular}{lcccc}
\hline & SDI & HEI & GDI & GSR \\
\hline Ceratoconcha & 13.0 & 6 & 6 & 9.0 \\
Cantellius & 12.0 & 13 & 11 & 13.0 \\
Hiroa & 11.0 & 7 & 10 & 2.0 \\
Creusia & 9.5 & 10 & 7 & 12.0 \\
Megatrema & 9.5 & 12 & 13 & 7.5 \\
Savignium & 7.5 & 11 & 12 & 10.0 \\
Nobia & 7.5 & 9 & 8 & 11.0 \\
Pyrgoma & 6.0 & 8 & 5 & 2.0 \\
Pyrgopsella & 5.0 & 3 & 4 & 5.0 \\
Eohoekia & 3.5 & 3 & 3 & 5.0 \\
Parahoekia & 3.5 & 3 & 3 & 2.0 \\
Hoekia & 1.5 & 3 & 9 & 7.5 \\
Ahoekia & 1.5 & 3 & 3 & 2.0 \\
& $r_{d} \& p<=.725, .01$ & $.585, .05$ & $.497, .10$ \\
& $\left(r_{d} \& p<=.485, .20\right.$ & $.037, .00$ & $.443, .00)$ \\
\hline
\end{tabular}

and GSR rank-order comparisons with SDI this appears largely due to adjustments made to the SDI stemming from the discovery of the complexity of the hoekiine shell and its division into four genera. On the other hand, considering the robustness of rank-difference correlations, it is reassuring to see that despite the mismatch due to Hiroa being monotypic, including it as well as Hoekia in the analyses, produces $r_{d}$ and $p$ values that support the hypotheses that (1) generalized genera inhabit a greater variety of hosts, (2) have greater geographic ranges, and (3) include more species than specialized genera (Table $\mathrm{V} ; \boldsymbol{r}_{d}{ }^{2}$ provides an approximate percentage of the variation of either variable explained by its correlate, $52 \%, 34 \%$, and $25 \%$, respectively).

\section{Affinities and relationships}

One of the unique characters that unites the genera comprising the Hoekiini, and separates them from other Pyrgomatinae, is the development of a marginal fringe and concomitantly elaboration of the circumferential part of the circulatory system. Each genus within the Hoekiini has developed this in a 


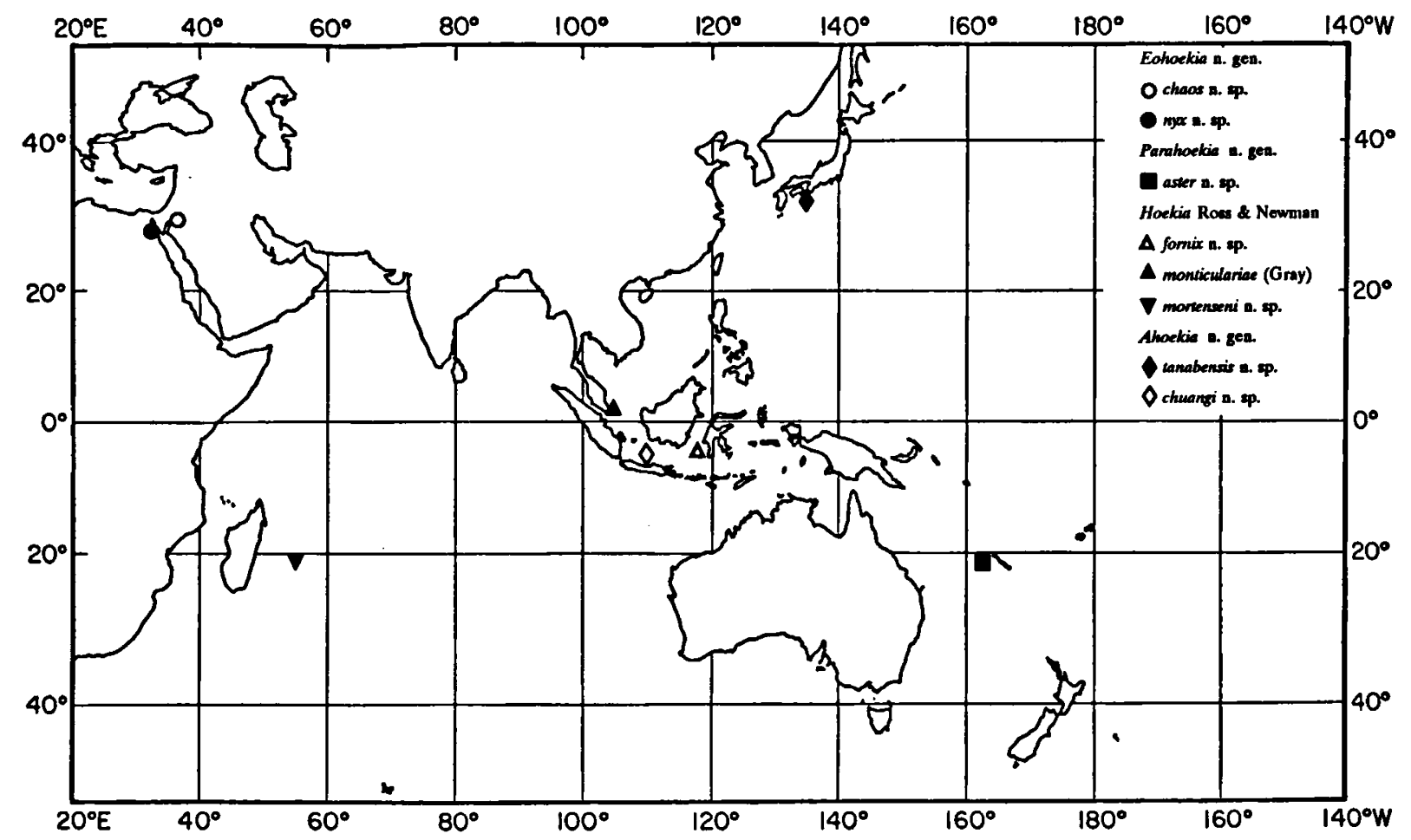

Fig. 20. Distribution of the species of Hoekiini. All of the species appear to be limited in their distribution, i.e., only a single species occurs at each location, even though the host, Hydnophora, ranges throughout the Indo-West Pacific.

different manner (Fig. 1b-e), and there is a clear evolutionary trend. In the more generalized taxa, Eohoekia and Parahoekia, foramina, distal to the outer lamina, appear to develop haphazardly in various positions and are ephemeral, and access to the circumferential system must come around from beneath the shell. In the advanced taxa, Hoekia and Ahoekia, haphazardly to more or less uniformly spaced permanent lacunae and passages in the wall not only provide direct access to the circumferential system from the interior, but make it possible to separate afferent and efferent vessels.

Eohoekia chaos possesses the greatest number of plesiomorphic characters. It has an essentially conical shell coupled with an ovate outer lamina, the retention of which reflects the condition seen in more primitive Pyrgomatini such as Cantellius. The same morphology prevails in the somewhat more specialized $E$. $n y x$, where ontogenetically, an ovate and conical shell persists until the rostro-carinal diameter is some $4.0 \mathrm{~mm}$. Although $E$. chaos and $E$. nyx undoubtedly share a common ancestry, the thicker, slightly narrower but more complex marginal fringe places $E$. nyx at a higher level of organization. Deep incisions in the fringe of $E$. nyx seemingly coalesce, but the borders are not fused. In one fragment of a marginal fringe, where foramina are apparent only on the inner surface, coalescence of adjoining fringe elements occurred, but there are no visible or traceable interconnections to the external surface or circumferential channel. Why these foramina have been abandoned is not clear, but it is obvious that they have been partially sealed or filled secondarily.

Parahoekia shares a conical peritreme and ovate shell with Eohoekia, but the shell of the former is set apart by a prominent rostral as well as carinal and subsidiary ridges in addition to a flat, marginal fringe. Under transmitted light Eohoekia has both a rostral and a carinal sinus within the shell, presumably heralding the development of the rostral and carinal ridges in Parahoekia. Another difference between these genera concerns how the ridges relate to the circumferential system. In both, 
Table VI. Character states for analysis of relationships in the Hoekiini and outgroups.

1. Shell configuration: conic - 4 plates (0); modified conic - concrescent (1); flat - concrescent (2).

2. Shell to basis interface: interlocking (0); not interlocking (1).

3. Length of shell to orifice ratio: $<1: 10(0) ;>1: 15(1)$.

4. Carinal ridge: absent (0); present (1).

5. Carinal ridge development: absent (0); obscure (1); prominent (2).

6. Outer lamina outline: subcircular (0); elongate-oval (1); irregularly ovate (2); lobate (3).

7. Outer lamina configuration: flat (0); reflexed or ascendant (1).

8. Outer lamina elevation to orifice: same (0); lower (1); higher (2).

9. Marginal fringe: absent (0); present (1).

10. Marginal fringe type: absent (0); filigreed (1); lacunate (2).

11. Marginal fringe elevation: absent (0); flat (1); reflexed (2); ascendant (3).

12. Marginal fringe width: absent (0); broad (1); narrow (2).

13. Lacuno-circumferential system: absent (0); diffuse (1); concentrated (2).

14. Opercular plate configuration: separate, tergum with spur (0); concrescent, tergum with spur (1); concrescent, tergum without spur (2).

15. Limbus occludens: absent (0); poorly developed (1); well developed (2).

16. Feeding method: setose (0); parasitic (1).

17. Labral crest: deeply incised with teeth (0); deeply notched without teeth (1); shallow-sulcate without teeth (2).

the sinuses were evidently functional channels during early ontogenetic development, with access to the circumferential system and marginal fringe from beneath the shell, but for some reason the rostral and carinal ridges have taken on an unusual importance in Parahoekia.

Although somewhat comparable in size to Eohoekia, the shell of Parahoekia has a lobate outline and a well-developed, narrow, marginal fringe that is lower than the orifice. Coalescence of proximal elements in the marginal fringe of $\boldsymbol{P}$. aster results in foramina, but their final outcome is unknown.

The lacunate genera are more highly evolved and the lacuno-circumferential system in Ahoekia represents a significant advance over Hoekia. In Hoekia this system is more uniformly arranged than in Ahoekia where the lacunae are commonly confluent and concentrated along the lateral margins of the shell, and the marginal fringe is higher and more compact or dense. In both, the peritreme remains essentially conical, but in Hoekia the carinal ridge sinus apparently is not subsequently filled or sealed as it is in Ahoekia. Moreover, in Ahoekia lateral expansion of the marginal fringe is arrested when it begins to ascend vertically, which provides a greater surface area directed toward and in contact with the adjacent coral tissue. This represents a significant departure from Hoekia. Furthermore, development of the peritreme in Ahoekia appears to be arrested at an earlier stage, which suggests that ontogenetic development of the marginal fringe begins earlier than in Hoekia.

It is from a relatively narrow and essentially flat, but thick marginal fringe, such as that of Parahoek$i a$, that the ascendant, or vertically elaborated and complex fringe of Hoekia was derived. Within Hoekia there appears to be a general trend towards a low or reduced peritreme: in $H$. fornix a high peritreme and narrow marginal fringe occur in parallel and the progression through $\boldsymbol{H}$. monticulariae to $H$. mortenseni ultimately results in a low peritreme and narrow fringe. Although the soft parts are unknown in $\boldsymbol{H}$. fornix, those of $\boldsymbol{H}$. mortenseni suggest a greater degree of cirral vestigiality in comparison with $\boldsymbol{H}$. monticulariae. Trophic structures in these latter two species are obviously similar, but this may relate to comparable diets rather than innate similarities.

Cladistics. - There is a consensus, first promulgated by Ross \& Newman (1973: 147), that Cantellius has the greatest number of plesiomorphies (four wall plates and generalized opercular plates; see Table VI and Fig. 21). Therefore it is from the level of organization found in Cantellius that all of the genera within the Pyrgomatinae have been derived, 


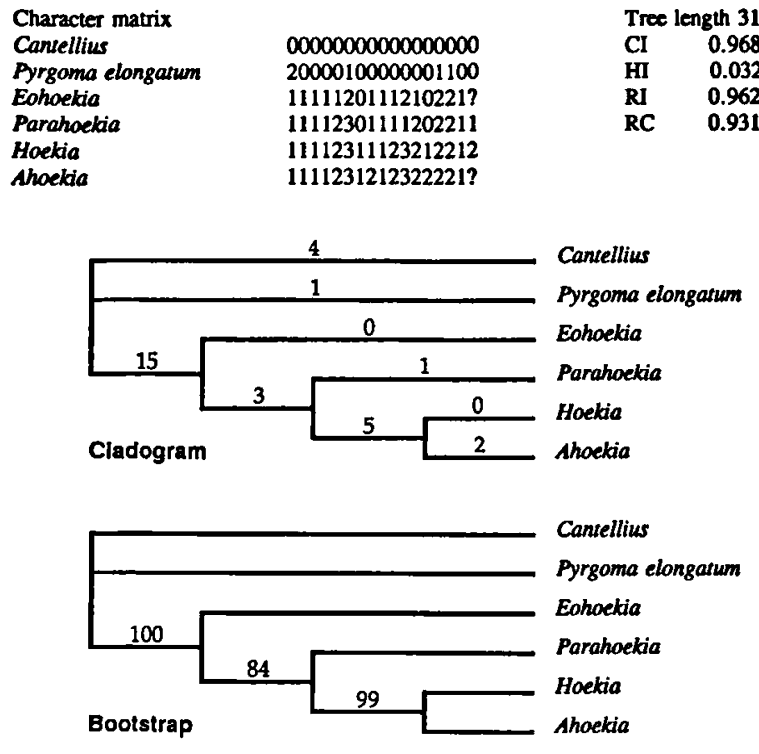

Fig. 21. Character matrix, cladogram, consensus tree and indices (CI, consistency index; HI, homoplasy index; RI, retention index; RC, rescaled consistency index) for the Hoekiini. See Table VI for the summary of characters and character states used in developing the above.

and therefore we selected this taxon as our first outgroup. Selection of a second outgroup, intermediate between Cantellius and the Hoekiini, posed problems that stem from recent taxonomic changes that are beyond the scope of this study. Consequently, we refer to the second outgroup as Pyrgoma elongatum Hiro, 1931 (: 154), which also has a concrescent shell and opercular plates.

This preliminary cladistic analysis is based on relatively few characters only because of inadequacies in the materials available. Moreover, it is based almost wholly on shell characters, because it is the shell that is most commonly encountered (Table VI). All of the characters were unweighted because they contain sufficient information to resolve relationships among the taxa without biasing the data set.

In three instances (characters 14,15 , and 17) we have coded a character as present in all members of a taxon when we have observed its presence in only one or two of its members. Also, on the basis of shell and opercular morphologies we have concluded a priori that none of the Hoekiini are setose feeders (character 16). We have not seen the labrum in five of the species and therefore, for two genera we have scored this character with a (?), but when a member of a genus has that character state we conclude a priori that all of the species have it.

Among the 17 characters selected, there are numerous multistate characters. To obviate problems inherent with continuous variables we established character polarity using outgroup comparisons based on studies by Ross \& Newman (1969, 1973), Newman \& Ross (1976), Soong \& Chang (1983), and Anderson (1992).

Our character matrix, cladogram, consensus tree, consistency index (CI), homoplasy index (HI), retention index (RI), and rescaled consistency index (RC) are presented in Fig. 21, and the characters and character states are summarized in Table VI. It will be observed that the results corroborate the conclusions regarding affinities reached above.

\section{Parallels with other parasitic thecostracans}

Hoekiini have adapted to living within tissue of the host coral, and thus they are internal parasites. Growth of coral tissue directly over the barnacle conveniently places it where it can be eaten. The barnacle feeds by extending the oral cone and associated mouthparts up through the aperture, so that they can rasp and cut the basal tissue of the coral and carry it to the mouth. Moreover, not only is the oral cone in a position to feed directly on coral tissue, it is likewise in a position to penetrate into the gastrovascular canal of the coral. Therefore, Hoekiini may also be able to feed directly on food being collected by the host.

This remarkable group of barnacles also appears to be in a position to draw upon the host's resources in an additional way. This is accomplished by elaboration of the distal margin of the inner lamina and its loss of contact with the calcareous basis, apparently to accommodate increased vascularization and contact with the tissue of the host coral. We have no direct evidence that there is metabolic exchange across the membrane separating the tissues of the coral from those of the barnacle, but the pronounced modifications of the shell makes the likelihood worth exploring. 
The lateral margin of the shell or carapace is unusual not only in being hypertrophied and highly vascularized, but in suspending the wall of the barnacle in the host tissue rather than locking it into a calcareous basis, as in other pyrgomatids. In fact, development of the calcareous basis in the region of potential contact has been completely curtailed. Thus an extensive and vascularized surface is strategically located where it can absorb nutrients from tissues of the host.

The Hoekiini are in some ways paralleling the evolutionary histories of the Ascothoracida and perhaps the Rhizocephala. These histories apparently involved biting parasites becoming absorptive ones, but there are some differences. One is that while setose feeding has clearly given way to a biting parasitism in Hoekiini, the piercing and biting ascothoracids have a non-setose feeding ancestry (Newman et al., 1969: R253). The ascothoracids and Hoekiini apparently parallel one another not only in the similarity between their mouthparts but in the elaboration of the carapace as an absorptive organ (see Norman, 1913: 161, covering mouthparts of Synagoga, and Bresciani \& Jespersen, 1985: 148, concerning the carapace of the ascothoracidan Ulophysema Brattström, 1936).

It has long been considered that the rhizocephalans evolved from an epizoic, setose-feeding barnacle that developed roots at the base of the peduncle that penetrate the host (Newman et al., 1969: R259). However, a study of the metamorphosis of the rhizocephalan cyprid that infects its host crab through the gill membranes (Høeg, 1985) suggests an alternative hypothesis involving a free-living, non-setose feeding, biting ancestor (Newman, 1982: 201; 1987: 37). Recent studies, involving molecular as well as morphological evidence (Abele et al., 1992: 377; Høeg, 1992: 325; Jensen et al., 1994: 141; Spears et al., 1994), tend to favor the original setose-feeding hypothesis. If indeed this is the case, then the evolution of the Hoekiini, in giving up setose-feeding and becoming a biting and apparently absorptive parasite, parallels the evolution of the rhizocephalans, albeit on a scleractinian rather than a crustacean host.

\section{Acknowledgements}

For providing us with specimens, access to specimens in their charge or other courtesies, we thank Torben Wolff, Universitets Zoologiske Museum, Copenhagen; the late Huzio Utinomi, Seto Marine Biological Laboratory, Japan; S.H. Chuang, Department of Zoology, National University of Singapore; William K. Emerson, American Museum of Natural History, New York; Lev Fishelson and Yosi Loya, Tel Aviv University, Israel; D.T. Anderson, University of Sydney, Australia; L.B. Holthuis, Nationaal Natuurhistorisch Museum, Leiden; J.E.N. Veron, Australian Institute of Marine Science, Townsville; Toshiyuki Yamaguchi and Kiyotaka Asami, Chiba University, Japan; Bertrand Richer de Forges and Georges Barbigant, Noumea, New Caledonia; Alain Crosnier, Muséum National d'Histoire Naturelle, Paris; Mark J. Grygier, Fisheries Laboratory, Hiroshima University, Japan; Kazunari Ogawa, Z. Nakai Laboratory, Tokyo; Robert J. Van Syoc, California Academy of Sciences, San Francisco; George Wilson, Australian Museum, Sydney; Diana S. Jones, Western Australian Museum, Perth; and Charles Graham, SEM Laboratory, Scripps Institution of Oceanography. We have enjoyed and benefitted from many discussions with Yair Achituv, Bar-Ilan University, Israel, while on sabbatical leave in California. We especially thank him for allowing us to examine specimens from the Nationaal Natuurhistorisch Museum, Leiden in his care, and for forwarding other specimens pertinent to this study. Financial support for his visit to Leiden was through a scientific exchange agreement between Israel and the Netherlands, and we have benefitted from the support for biological research by these nations. We especially thank Vicki Ross, who typed innumerable drafts of this "note", and ask her forgiveness when attention to detail became exceedingly tedious.

\section{Literature cited}

Abele, L.G., T. Spears, W. Kim \& M. Applegate, 1992. Phylogeny of selected maxillopodan and other crustacean taxa based on 18S ribosomal nucleotide sequences: A preliminary analysis. Acta Zool. (Stockholm), 73(5): 373-382.

Achituv, Y.\& H. Barnes, 1978. Some observations in Tetraclita squamosa rufotincta Pilsbry. J. exp. mar. Biol. Ecol., 31: 315-324.

Anderson, D.T., 1978. Cirral activity and feeding in the coralinhabiting barnacle Boscia anglicum (Cirripedia). J. mar. biol. Ass. U.K., 58: 607-626.

Anderson, D.T., 1981. Cirral activity and feeding in the barnacle Balanus perforatus Bruguière (Balanidae), with comments on the evolution of feeding mechanisms in thoracican cirripedes. Phil. Trans. R. Soc. London, 291(1053): 411-449.

Anderson, D.T., 1992. Structure, function and phylogeny of 
coral-inhabiting barnacles (Cirripedia, Balanoidea). Zool. J. Linn. Soc., 106: 277-339.

Anderson, D.T., 1994. Barnacles: structure, function, development and evolution: 1-357 (Chapman and Hall, London).

Anderson, D.T. \& A.J. Southward, 1987. Cirral activity of barnacles. In: A.J. Southward (ed.), Crustacean Issues, 5. Barnacle biology: 135-174 (A.A. Balkema, Rotterdam).

Annandale, N., 1924. Cirripedes associated with Indian corals of the families Astraeidae and Fungiidae. Mem. ind. Mus., 8: 61-68.

Baluk, W. \& A. Radwanski, 1967. Miocene cirripeds domiciled in corals. Acta paleont. pol., 12(4): 457-521.

Barnes, H., 1955. The hatching process in some barnacles. Oikos, 6(2): 114-123.

Barnes, H., M. Barnes \& W. Klepal, 1977. Studies on the reproduction of cirripedes, 1 . Introduction: copulation, release of oocytes, and formation of the egg lamellae. J. exp. mar. Biol. Ecol., 27: 195-218.

Barnes, M., 1989. Egg production in cirripedes. Oceanogr. mar. Biol. ann. Rev., 27: 91-166.

Barnes, M., 1992. The reproductive periods and condition of the penis in several species of common cirripedes. Oceanogr. mar. Biol. ann. Rev., 30: 483-525.

Batham, E.J. \& J.T. Tomlinson, 1965. On Cryptophialus melampygos Berndt, a small boring barnacle of the order Acrothoracica abundant in some New Zealand molluscs. Trans. R. Soc. New Zealand, 7(9): 141-154.

Blatchford, J.G., 1970. Possible circulatory mechanism in an operculate cirripede. Comp. Biochem. Physiol., 34: 911-915.

Bocquet-Védrine, J., 1966. Les soies et les expansions épineuses du test calcaire chez le Cirripède operculé Acasta spongites (Poli). Archs. Zool. exp. gén., 107(2): 337-348.

Bourget, E., 1977. Shell structure in sessile barnacles. Naturaliste Canadien, 104(4): 281-323.

Bourget, E., 1987. Barnacle shells: composition, structure and growth. In: A.J. Southward (ed)., Crustacean Issues, 5. Barnacle biology: 267-285 (A.A. Balkema, Rotterdam).

Bourget, E. \& D.J. Crisp, 1975a. Factors affecting deposition of the shell in Balanus balanoides (L.). J. mar. biol. Ass. U.K., 55: 231-249.

Bourget, E. \& D.J. Crisp, 1975b. An analysis of the growth bands and ridges of barnacle shell plates. J. mar. biol. Ass. U.K., 55: 439-461.

Bresciani, J. \& A. Jespersen, 1985. The ultrastructure of the integument of Ulophysema oeresundense Brattström, 1936 (Crustacea, Ascothoracica). J. crust. Biol., 5(1): 146-159.

Bubel, A., 1975. An ultrastructural study of the mantle of the barnacle, Elminius modestus Darwin in relation to shell formation. J. exp. mar. Biol. Ecol., 20: 287-324.

Burnett, B., 1977. Blood circulation in the balanomorph barnacle, Megabalanus californicus (Pilsbry). J. Morph., 153(2): 299-306.

Clare, A.S., S.C. Ward, D. Rittschof \& K.M. Wilbur, 1994. Growth increments of the barnacle Balanus amphitrite amphitrite Darwin (Cirripedia). J. crust. Biol., 14(1): 27-35.

Cook, P.A., B.A. Stewart \& Y. Achituv, 1991. The symbiotic relationship between the hydrocoral Millepora dichotoma and the barnacle Savignium milleporum. Hydrobiologia, 216: 285-290.

Costlow, J.D., 1956. Shell development in Balanus improvisus Darwin. J. Morphol., 99(2): 359-415.

Crisp, D.J. \& A.J. Southward, 1961. Different types of cirral activity of barnacles. Phil. Trans. R. Soc. London, (B) 243 (705): 271-308.

Darwin, C.R., 1854. A monograph on the sub-class Cirripedia, with figures of all the species. The Balanidae, the Verrucidae, etc.: 1-684 (Ray Society, London).

Duerden, J.E., 1902. The coral Siderastrea radians and its postlarval development. Carnegie Inst. Publ., 20: 1-130.

Galkin, S.V., 1986. The system of coral-inhabiting barnacles (Cirripedia, Balanomorpha). Zool. Zh., 65(9): 1285-1295.

Gomez, E.D., 1973. Observations on feeding and prey specificity of Tritonia festiva (Stearns) with comments on other tritoniids (Mollusca: Opisthobranchia). Veliger, 16(2): 163165.

Goreau, T.F., N.I. Goreau, C.M. Yonge \& Y. Neumann, 1970. On feeding and nutrition in Fungiacava eilatensis (Bivalvia, Mytilidae), a commensal living in fungiid corals. J. Zool., London, 160: 159-172.

Gravier, C., 1911. Sur quelques animaux parasites ou commensaux des Madreporaires du genre Galaxea (Oken). C.r. hebd. Séanc. Acad. Sci., Paris, 152(4): 210-212.

Gray, J.E., 1831. Description of two new species of Serpula, and an undescribed coral barnacle, discovered by Samuel Pearce Pratt, Esq. In: The zoological miscellany. To be continued occasionally: 1-86 (Treuttel, Wurtz \& Co., London).

Grygier, M.J., 1984. Ascothoracida (Crustacea: Maxillopoda) parasitic on Chrysogorgia (Gorgonacea) in the Pacific and western Atlantic. Bull. mar. Sci., 34(1): 141-169.

Gutmann, W.F., 1960. Funktionelle Morphologie von Balanus balanoides. Abh. senckenb. naturforsch. Ges., 500: 1-43.

Hiro, F., 1931. Note on some new Cirripedia from Japan. Mem. College Sci., Kyoto Imp. Univ., (B) 7(3): 143-158.

Hiro, F., 1935. A study of cirripeds associated with corals occurring in Tanabe Bay. Rec. oceanogr. Works Japan, 7(1): 1-28.

Hiro, F., 1938. Studies on the animals inhabiting reef corals, II. Cirripeds of the genera Creusia and Pyrgoma. Palao trop. biol. Stat. Stud., 3: 391-416.

Høeg, J.T., 1985. Cypris settlement, kentrogon formation and host invasion in the parasitic barnacle Lernaeodiscus porcellanae (Müller) (Crustacea: Cirripedia: Rhizocephala). Acta zool. (Stockholm), 66(1): 1-45.

Høeg, J.T., 1992. The phylogenetic position of the Rhizocephala: Are they truly barnacles? Acta zool. (Stockholm), 73(5): 323-326.

Jensen, P.G., J. Moyse, J.T. Høeg \& H. Al-Yahya, 1994. Comparative SEM studies of lattice organs: putative sensory structures on the carapace of larvae from Ascothoracida and Cirripedia (Crustacea Maxillopoda Thecostraca). Acta zool. (Stockholm), 75(2): 125-142.

Kolosvàry, G., 1947. A study of cirripedes associated with corals in the collection of the Hungarian National Museum, Budapest. Proc. zool. Soc. London, 117(2-3): 425-428.

Moyse, J., 1971. Settlement and growth pattern of the parasitic 
barnacle Pyrgoma anglicum. In: D.J. Crisp (ed.), Fourth European Marine Biology Symposium: 125-141 (Cambridge Univ. Press, London).

Moyse, J., 1983. Isidascus bassindalei gen. nov., sp. nov. (Ascothoracida: Crustacea) from north-east Atlantic with a note on the origin of barnacles. J. mar. Biol. Ass. U.K., 63: 161-180.

Munn, E.A., W. Klepal \& H. Barnes, 1974. The fine structure and possible function of the sensory setae of the penis of Balanus balanoides (L.). J. exp. mar. Biol. Ecol., 14: 89-98.

Newman, W.A., 1981. Huzio Utinomi. Crustaceana, 40(1): 100-108.

Newman, W.A., 1982. Cirripedia. In: L.G. Abele (ed.), The biology of Crustacea, 1: 197-221 (Academic Press, New York).

Newman, W.A., 1987. Evolution of cirripedes and their major groups. In: A.J. Southward (ed.). Crustacean Issues, 5. Barnacle biology: 3-42 (A.A. Balkema, Rotterdam).

Newman, W.A. \& H.S. Ladd, 1974. Origin of coral-inhabiting balanids (Cirripedia, Thoracica). Verhandl. naturf. Ges. Basel, 84(1): 381-396.

Newman, W.A. \& A. Ross, 1971. Antarctic Cirripedia. Monographic account based on specimens collected chiefly under the United States Antarctic Research Program, 1962-1965. Antarctic Res. Ser., 14: 1-257 (American Geophysical Union, Washington).

Newman, W.A. \& A. Ross, 1976. Revision of the balanomorph barnacles; including a catalog of the species. Mem. San Diego Soc. nat. Hist., 9: 1-108.

Newman, W.A., P.A. Jumars \& A. Ross, 1976. Diversity trends in coral-inhabiting barnacles (Cirripedia, Pyrgomatinae). Micronesica, 12(1): 69-82.

Newman, W.A., V.A. Zullo \& W.A. Wainwright, 1967. A critique on recent concepts of growth in Balanomorpha (Cirripedia, Thoracica). Crustaceana, 12(2): 167-178.

Newman, W.A., V.A. Zullo \& T.H. Withers, 1969. In: R.C. Moore (ed.)., Treatise on invertebrate paleontology, part $\mathbf{R}$. Arthropoda, 4(1): R206-R296 (Geol. Soc. Amer., Univ. Kansas, Lawrence).

Nishihira, M. \& J.E.N. Veron, 1995. Hermatypic corals of Japan: 311-312 (Kaiyusha Pubs. Co. Ltd., Tokyo).

Norman, A.M., 1913. Synagoga mira, a crustacean of the order Ascothoracica. Trans. Linn. Soc. London, (2) 11: 161-166.

Ogawa, K. \& K. Matsuzaki, 1990. Revision of the coralinhabiting barnacles in Japan - preliminary note. Nankiseibutu: Nanki Biol. Soc., 32(2): 73-79.

Ogawa, K. \& K. Matsuzaki, 1992. An essay on host specificity, systematic taxonomy, and evolution of the coral-barnacles. Bull. biogeogr. Soc. Japan, 47(10): 87-101.

Patton, W.K., 1976. Animal associates of living reef corals. In: O.A. Jones \& R. Endean (eds.), Biology and geology of coral reefs, 3(2): 1-36 (Academic Press, New York).

Pieters, F.F.J.M. \& D. Winthagen, 1990. Discovery of scientific correspondence of P.P.C. Hoek (1851-1914), including three unpublished letters by Charles Darwin. Bijdr. Dierk., 60(3/4): 239-247.

Ritchie, L.E. \& J.T. Høeg, 1981. The life history of Lernaeodiscus porcellanae (Cirripedia: Rhizocephala) and co-evolution with its porcellanid host. J. crust. Biol., 1(3): 334-347.

Rosell, N.C., 1975. On two noteworthy balanids (Cirripedia Thoracica) from the Sulu Archipelago, Philippines. Crustaceana, 29(2): 206-214.

Ross, A., 1969. Studies on the Tetraclitidae (Cirripedia: Thoracica): Revision of Tetraclita. Trans. San Diego Soc. nat. Hist., 15(15): 237-251.

Ross, A. \& W.A. Newman, 1967. Eocene Balanidae of Florida, including a new genus and species with a unique plan of "turtle-barnacle" organization. Amer. Mus. Novitates, 2288: 1-21.

Ross, A. \& W.A. Newman, 1969. A coral-eating barnacle. Pacific Sci., 23(2): 252-256.

Ross, A. \& W.A. Newman, 1973. Revision of the coralinhabiting barnacles (Cirripedia: Balanidae). Trans. San Diego Soc. nat. Hist., 17(12): 137-174.

Soong, K.Y. \& K.H. Chang, 1983. The coral-inhabiting barnacles (Crustacea: Thoracica: Pyrgomatidae) from southernmost coast of Taiwan. Bull. Inst. Zool., Acad. Sinica, 22(2): 243- 253.

Spears, T., L.G. Abele \& M.A. Applegate, 1994. A phylogenetic study of cirripeds and selected relatives (Crustacea: Thecostraca) based on 18s rRNA sequence analysis. J. crust. Biol., 14(4): 641-656.

Spivey, H.R., 1988. Shell morphometry in barnacles: quantification of shape and shape changes in Balanus. J. Zool., London, 216: 265-294.

Tate, M.W. \& R.C. Clelland, 1957. Nonparametric and shortcut statistics: 1-171 (Interstate Printers and Publishers, Illinois).

Tomlinson, J.T., 1963. Two new acrothoracican cirripeds from Japan. Publs. Seto mar. biol. Lab., 11(2): 263-280.

Tomlinson, J.T., 1969. The burrowing barnacles (Cirripedia: Order Acrothoracica). Bull. U.S. natn. Mus., 296: 1-162.

Utinomi, H., 1943. The larval stages of Creusia, the barnacle inhabiting reef corals. Annotnes. zool. jap., 22(1): 15-22.

Veron, J.E.N., 1993a. A biogeographic database of hermatypic corals; species of the central Indo-Pacific and genera of the world. Australian Inst. mar. Sci., Monogr. Ser., 10: 1-433.

Veron, J.E.N., 1993b. Corals of Australia and the Indo-Pacific: 1-644 (Univ. Hawaii Press, Honolulu).

Walker, G., 1983. A study of the ovigerous fraena of barnacles. Proc. R. Soc. London, (B) 218: 425-442.

Walley, L.J., 1965. The development and function of the oviducal gland in Balanus balanoides. J. mar. biol. Ass. U.K., 45: 115-128.

Received: 16 January 1995 